\title{
Investigation of migraine-related molecules in the activated trigeminovascular system
}

\section{Tamás Körtési}

\author{
Ph.D. Thesis
}

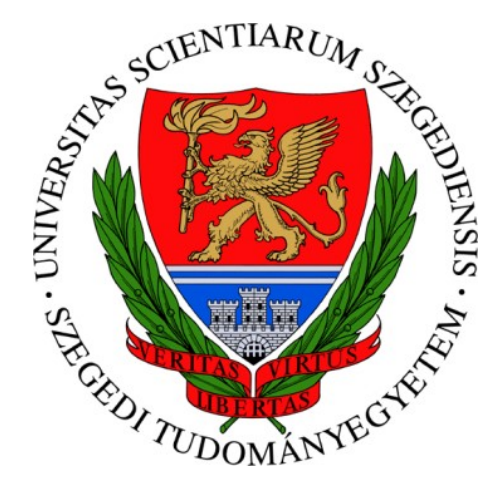

Department of Neurology

Faculty of Medicine

Albert Szent-Györgyi Clinical Center

Doctoral School of Clinical Medicine

University of Szeged

Supervisor: János Tajti M.D., Ph.D. D.Sc.

\section{Szeged}




\section{CONTENTS}

Original publications directly related to the $\mathrm{Ph.D.}$ thesis .................................................... 4

Publications not directly related to the Ph.D. thesis........................................................... 5

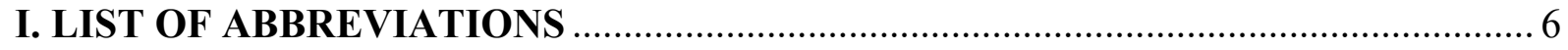

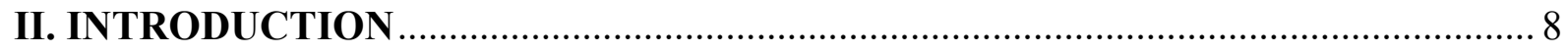

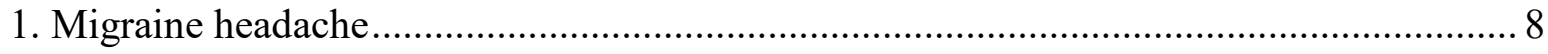

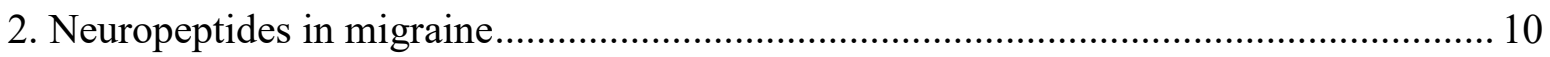

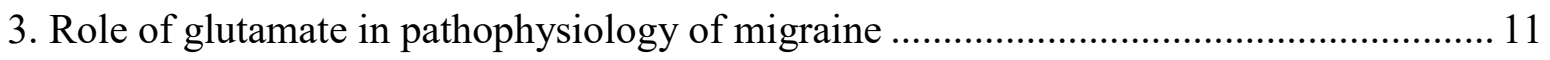

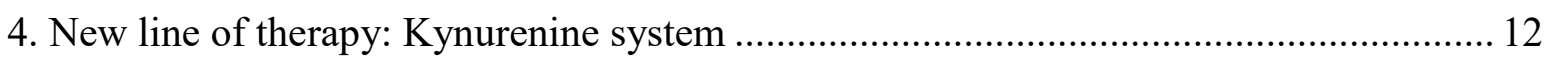

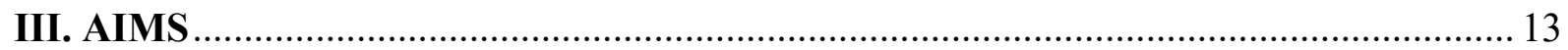

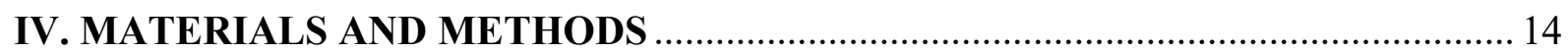

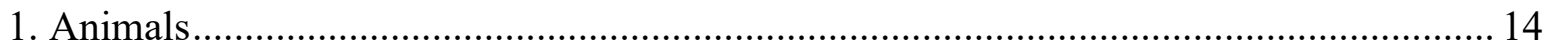

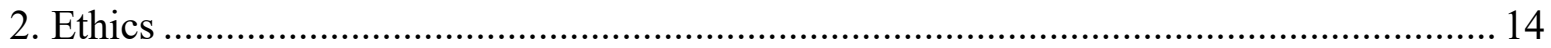

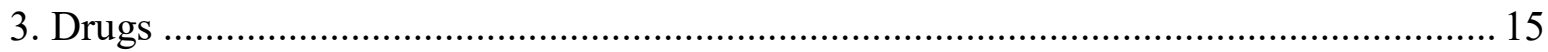

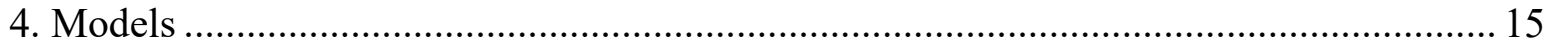

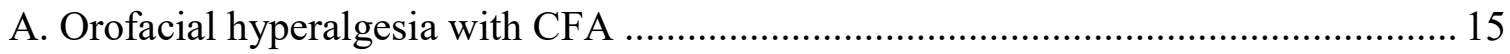

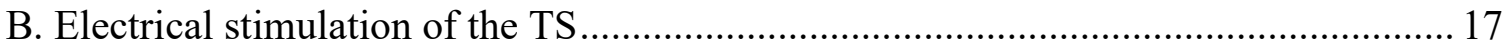

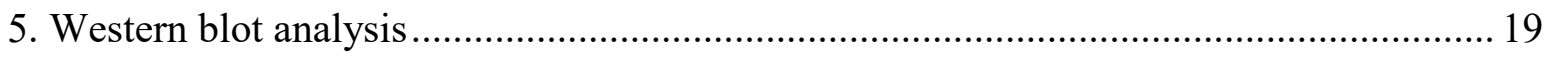

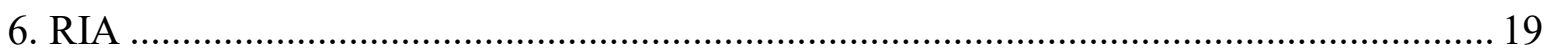

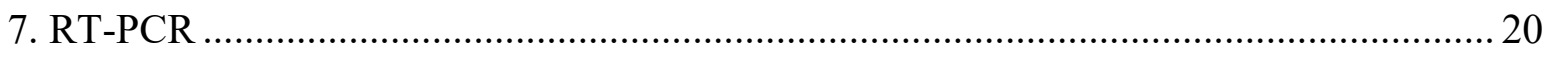

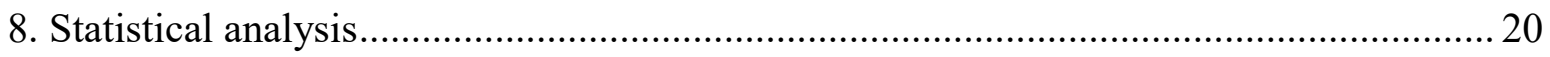

V. RESULTS

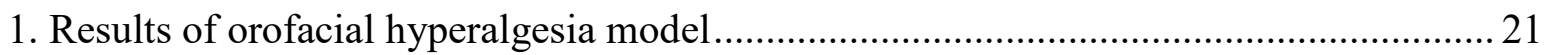

A. Orofacial CFA treatment resulted in significant preproPACAP increase in the TNC. 21

B. Orofacial CFA treatment significantly elevated CGRP relative optical density in the

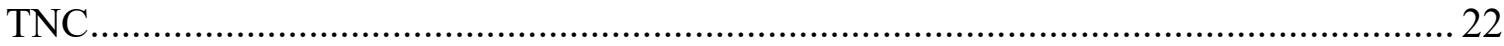

C. Orofacial CFA injection decreased the mechanonociceptive threshold......................23 
D. Correlation between neuropeptides expression and mechanical hyperalgesia 24

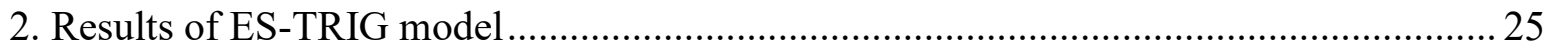

A. Electrical TRIG-stimulation-induced PACAP ${ }_{1-38}-\mathrm{LI}$ increase in the TNC is prevented by SZR72 pretreatment 25

B. Electrical TRIG-stimulation-induced preproPACAP increase in the TNC is prevented by SZR72, KYNA and MK-801 pretreatment .26

C. Electrical TRIG-stimulation-induced increased PACAP ${ }_{1-38} \mathrm{mRNA}$ expression in the TNC is prevented by SZR72, KYNA and MK-801 pretreatment 27

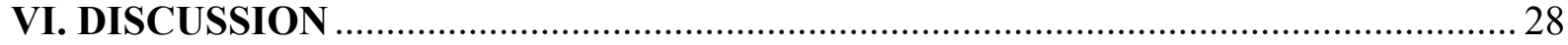

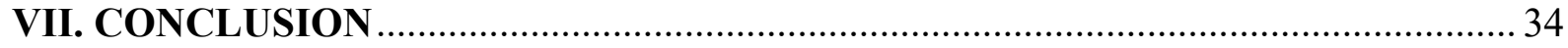

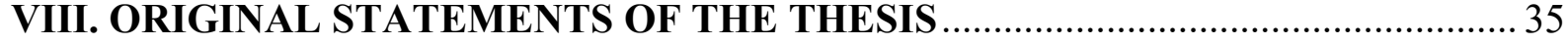

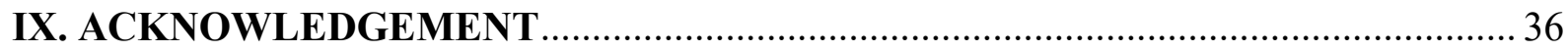

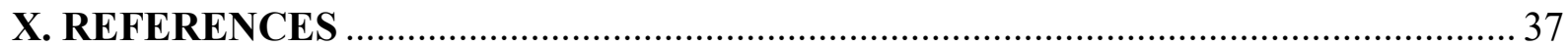




\section{Original publications directly related to the Ph.D. thesis:}

I. Körtési Tamás, Tuka Bernadett, Tajti János, Bagoly Teréz, Fülöp Ferenc, Helyes Zsuzsanna, Vécsei László. Kynurenic Acid Inhibits the Electrical Stimulation Induced Elevated Pituitary Adenylate Cyclase-Activating Polypeptide Expression in the TNC. Frontiers in Neurology. 2018 Jan 16;8:745. Impact Factor: 2.635, Citation:6

II. Körtési Tamás, Tuka Bernadett, Nyári Alíz, Vécsei László. Tajti János. The effect of orofacial complete Freund's adjuvant treatment on the expression of migraine-related molecules. Journal of Headache and Pain. 2019 Apr 29;20(1):43. Impact Factor: 3.918, Citation: 0

Cumulative impact factor of the publications directly to the thesis: $\mathbf{6 . 5 5 3}$ 


\section{Publications not directly related to the Ph.D. thesis:}

I. Tuka Bernadett, Szabó Nikolett, Tóth Eszter, Kincses Zsigmond Tamás, Párdutz Árpád, Szok Délia, Körtési Tamás, Bagoly Teréz, Helyes Zsuzsanna, Edvinsson Lars, Vécsei László, Tajti János. Release of PACAP-38 in episodic cluster headache patients - an exploratory study. Journal of Headache and Pain. 2016 Dec;17(1):69. Impact factor: 3.580 Citation: 35

II. Cseh Edina Katalin,Veres Gábor, Körtési Tamás, Polyák Helga, Nánási Nikolett, Tajti János, Párdutz Árpád, Klivényi Péter, Vécsei László, Zádori Dénes. Neurotransmitter and tryptophan metabolite concentration changes in the CFA model of orofacial pain. Journal of Headache and Pain. Publishing under process. Impact factor: 3.580 Citation: 0

Cumulative impact factor of publications not directly related to the thesis: $\mathbf{7 . 1 6 0}$

Total impact factor: $\mathbf{1 3 . 7 1 3}$ 


\section{LIST OF ABBREVIATIONS}

$\mathrm{AC}$ - adenylate cylase

AHR - aryl hydrocarbon

ALD1910 - monoclonal antibody of PACAP $1-38$

AMG 301 - monoclonal antibody of PAC1 receptor

AMPA - $\alpha$-amino-3-hydroxyl-5-methyl-4-isoxazole-propionate

ATP - adenosine monophosphate

BSA - bovine serum albumin

CALCRL - calcitonin receptor-like receptor

CaM - calmodulin

cAMP - cyclic adenosine monophosphate

CFA - complete Freund's adjuvant

CGRP - calcitonin gene-related peptide

$\mathrm{CN}$ - calcineurin

CREB - cAMP response element binding protein

CRTC1 - CN/Cre binding protein

CSD - cortical spreading depression

EDTA - ethylenediaminetetraacetic acid

ERK1/2 - extracellular signal-regulated kinase 1/2

ES-TRIG - electrical stimulation of the TRIG

GAPDH - glyceraldehyde 3-phosphate dehydrogenase

Glu - glutamate

GPCR - G protein-coupled receptor

Gs - stimulatory G protein

i.p. - intraperitoneal

i.v. - intravenous

IR - immunoreactivity

KAT II - kynurenine aminotransferase II

KYNA - kynurenic acid

LC - locus coeruleus

MAPK - mitogen-activated protein kinase

MCA - middle cerebral artery

MMA - middle meningeal artery 
NMDA - N-methyl-D-aspartate

NMDAR - NMDA receptor

nNOS - neuronal nitrogen-monoxide synthase

NRM - nucleus raphe magnus

NTG - nitroglycerin

PACAP - pituitary adenylate cyclase-activating polypeptide

PACAP $_{1-27}-27$ amino acid form of PACAP

PACAP $_{1-38}-38$ amino acid form of PACAP

PAG - periaqueductal grey matter

PBS - phosphate-buffered saline

PKC - protein kinase $\mathrm{C}$

preproPACAP - precursor molecule of $\mathrm{PACAP}_{1-38}$ and $\mathrm{PACAP}_{1-27}$

RAMP1 - receptor activity-modifying protein

RIA - radioimmunoassay

RT-PCR - real-time polymerase chain reaction

SD - standard deviation

SDS - sodium dodecyl sulfate

SP - substance P

SZR72 - kynurenic acid synthetic analogue

TBST - Tris-buffered saline containing Tween 20

TCC - trigeminocervical complex

TMJ - temporomandibular joint

TNC - trigeminal nucleus caudalis

TRIG - trigeminal ganglion

TS - trigeminovascular system

TSH - thyroid-stimulating hormone

VIP - vasoactive intestinal polypeptide 


\section{INTRODUCTION}

\section{$\underline{\text { 1. Migraine headache }}$}

Migraine is a neurovascular primary headache disorder that affects around $14.4 \%$ of the adult population thereby it causes significant socioeconomic problems worldwide (1). The female:male ratio of migraine is around 1:1 during childhood, with even a small preponderance in boys. This trend is completely reversed after puberty and the female:male incidence ratio in adults reaches $2: 1$ to $4: 1(2-4)$. The one-year prevalence of disease has been reported to be 10$12 \%$ (5). It is ranked among the top 10 causes of disability worldwide $(4,6,7)$. This pain syndrome is typically characterized by recurrent attacks of unilateral, throbbing headache of moderate or severe intensity (8). Most frequent migraine-associated phenomena include nausea and/or vomiting, phonophobia and allodynia. Two main subtypes of this neurological disease have separated/divided: migraine with aura and migraine without aura. The aura usually precedes the headache, this phase is mainly accompanied by visual disturbances, but it can also be sensory, motor or verbal confusion (IHS, 2013). There is currently no causative cure for disease, although a number of treatments are available to help ease the symptoms. Medications used to combat migraines fall into two broad categories: acute (non-steroidal anti-inflammatory drugs, triptans, ergot alkaloids) and prophylactic treatments ( $\beta$-adrenergic receptor blockers, tricyclic antidepressants, anticonvulsant drugs, such as valproate and topiramate). The newest preventive medicines are the monoclonal antibodies targeting migraine-related neuropeptides specifically developed for the treatment of migraine. The main cause of limited therapeutic potential, that the pathophysiology of disease is still not fully understood, but several hypotheses have been proposed to explain the processes of migraine. The aura phase of the migraine attack is currently explained by the phenomenon of the cortical spreading depression (CSD). This is a slowly propagating $(2-6 \mathrm{~mm} / \mathrm{min}$ ) wave of neuronal and glial cell membrane depolarisation, followed by a long-lasting suppression of neuronal activity $(9,10)$. Several population studies have proved that migraine has genetic background $(11,12)$. Monozygotic twins show a significantly higher concordance rate for the disease in comparison with dizygotic twins (13). Additionally, large number of single nuclear polymorphisms, and related genes, are significantly associated with migraine and its clinical variants (14). In a study assocation between five polymorphisms of the insulin receptor gene and migraine headache was described, supporting clinical evidence suggesting a close relationship between impaired cerebral glucose metabolism and disease $(15,16)$. Based on some publications the circadian clock may also participate in the pathomechanism. Migraine is considered a chronobiological disorder, which 
has characteristic periodicity. Often, migraine attacks evolve in the morning, although acute headache episodes may occur all day long. Moreover, a late-night peak is present, particularly with advancing age. Therefore, hypothalamic peptides involved in the regulation of the circadian clock may have a role in the pathogenesis of disease $(17,18)$. Futhermore certain environmental factors (alcohol, certain foods, stress, weather, hormonal changes, etc.) can influence development of migraine. In 1979, Moskowitz and colleagues introduced the trigeminovascular hypothesis of migraine, calling attention to a potential role for the trigeminal nerve and its vasoactive neuropeptide-containing axonal projections to the meninges and its blood vessels. Over the past 30 years a growing number of translational and clinical data proved that the activation of trigeminovascular system (TS) is crucial in pathogenesis of disease, but the primary cause of this activation is enigmatic $(8,19,20)$. The TS provides an important pain-transmission link between the vessels and neurons, because this is the main afferent pain pathway between the dural vasculature and the trigeminocervical complex (TCC). The TS consists of pseudounipolar neurons within the trigeminal ganglion (TRIG). The peripheral branches of these neurons innervate the cranial vessels and meningeal tissues, while their central afferents project to the nociceptive second-order neurons in the trigeminal nucleus caudalis (TNC) located in the brainstem and more caudally in the upper region of the spinal cord. The sensory trigeminal unit is regulated by the descending pathways from the dorsal raphe nucleus, the periaqueductal gray matter and the locus coeruleus $(8,21)$. The

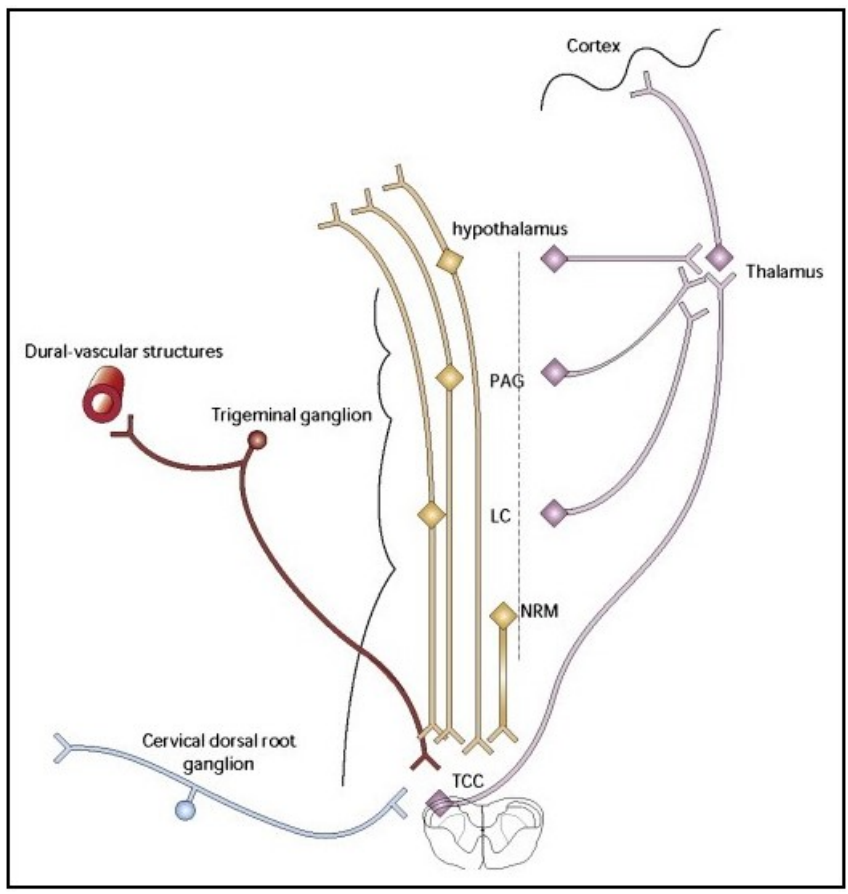

Figure 1. The scheme of TS. TCC: trigeminocervical complex; PAG: periaqueductal grey matter; LC: locus coeruleus; NRM: nucleus raphe magnus Goadsby PJ. Neurol Clin. 2009;27:335-60. structure of TS is presented in Figure 1. 


\section{Neuropeptides in migraine}

Recently, two peptides of key molecules have been highlighted in the pathomechanism of primary headache disorders: calcitonin gene-related peptide (CGRP), as an "old warrior" and pituitary adenylate cyclase-activating polypeptide (PACAP), which is a newer, potential target for headache therapies. These peptides are very similar in their features and functions: e.g. they are potent vasodilators, present in both the peripheral and central nervous system and can function in the transmission of nociception and neurogenic inflammation.

\section{CGRP}

CGRP is a 37 amino acid neuropeptide and it is member of the calcitonin peptide family along with the calcitonin, adrenomedullin and amylin. CGRP was discovered in 1982 by molecular cloning of calcitonin gene. It has two major forms: $\alpha$ - and $\beta$-CGRP, otherwise known as CGRP I and II (22,23). $\alpha$-CGRP is widely distributed in the central- and peripheral nervous systems, whereas $\beta$-CGRP is found mainly in the enteric nervous system. CGRP mediates its effects through a heteromeric receptor composed of a $\mathrm{G}$ protein-coupled receptor called calcitonin receptor-like receptor (CALCRL) and a receptor activity-modifying protein (RAMP1).

\section{PACAP}

PACAP is a pleiotropic neuropeptide that belongs to the secretin/glucagon/vasoactive intestinal peptide (VIP) superfamily. PACAP was discovered on the basis of its ability to increase the activity of adenylate cyclase in rat pituitary cells and it was first isolated from the ovine hypothalamus in 1989 by research group of Professor Arimura (24). This peptide occurs in two biologically active amidated forms, containing 38 and 27 amino acids: PACAP $_{1-38}$ and PACAP ${ }_{1-}$ 27 (25,26). Both PACAPs are derived from a 176 amino acid precursor molecule (preproPACAP). PACAP ${ }_{1-38}$ is the predominant form, accounting for $90 \%$ of the total PACAP content in most mammalian tissues. Since the PACAP shows particularly high homology with the amino acid sequences of VIP $(\sim 68 \%)$, therefore these peptides share three G-proteincoupled receptors: VPAC1, VPAC2 and PAC1. PAC1 receptor has 1000-fold higher specific affinity for both forms of PACAP than for VIP $(27,28)$.

Relationship between CGRP, PACAP and migraine

Several lines of evidence reflect that CGRP and PACAP play crucial role in primary headache disorders. Immunochemistry examinations revealed, that CGRP and PACAP show colocalization in the TS. The total cells of TRIG contain $40 \%$ CGRP- and $20 \%$ PACAPpositive cells (29). The first clinical study which investigated the release of CGRP in activated TS was published in 1988. Stimulation of the trigeminal pathway caused release of both 
substance P (SP) and CGRP (30). In migraineurs, the level of CGRP in the peripheral blood is increased during a migraine attack compared to the interictal period (30). Recently a similar observation has been made for PACAP suggesting its potential biomarker function in migraine (31). In addition, correspondingly to CGRP (32), the intravenous (i.v.) administration of $\mathrm{PACAP}_{1-38}$ provoked extracerebral vasodilation and headache both in healthy participants and migraine sufferers, whereas it generated delayed, but prolonged migraine-like attacks only in migraineurs $(28,33,34)$.

In experimental conditions, intraperitoneal (i.p.) injection of $\mathrm{PACAP}_{1-38}$ evoked marked photophobia, meningeal vasodilation and increased the number of c-fos-positive activated neurons in the TNC in wild-type, but not in PACAP $_{1-38}$-deficient mice (35). Moreover, increased concentrations of PACAP P-38 $_{1-3}$ were detected both in the peripheral blood plasma and the TNC after the activation of TS in different animal models (21). In orofacial pain model the complete Freund's adjuvant (CFA) increased the mRNA expression of CGRP in TRIG and TNC (36). Repetitive electrical stimulation of dura mater elevated the expressions of CGRP, PACAP and PAC1 receptor in both TRIG and TNC (37).

\section{$\underline{\text { 3. Role of glutamate in pathophysiology of migraine }}$}

Given its excitatory action on nociceptive neurons along the TS, glutamate (Glu) has long been discussed as a essential neurotransmitter in the pathomechanism of migraine and migrainerelated central sensitization $(38-41)$. Glu-induced excitability is mediated via the ionotropic (NMDA: N-methyl-D-aspartate, AMPA: $\alpha$-amino-3-hydroxyl-5-methyl-4-isoxazolepropionate, kainate) and the metabotropic Glu receptor families. Beside to the TNC and TRIG, glutamate receptors are found on other pain-modulating structures including the thalamus and hypothalamus as well as the periaqueductal gray matter $(42,43)$. Synaptic transmission between first- and second-order trigeminal sensory neurons is mediated in part by glutamatergic mechanisms (44). Numerous study prove, that altered glutamate homeostasis is involved in the pathogenesis of migraine. In plasma and platelets of migraineurs elevated basal glutamete levels have been measured, which are further increased in the ictal period $(45,46)$. Moreover, elevated Glu concentration was detected in the cerebrospinal fluid of migraine patients during attacks, which support the hypothesis of neuronal hyperexcitability in nociception (47).

To date, only a few studies have provided evidence for an association between PACAP and the NMDA glutamate receptor. In experimental model of acute ischemic stroke PACAP 1-38 $_{\text {and }}$ PACAP $_{1-27}$ modulated protein expression levels of NMDA receptor subunits, affording neuroprotection (48). PACAP has been demonstrated to enhance the functional coupling of 
neuronal nitrogen-monoxide synthase and the NMDA receptor in models of both inflammatory and neuropathic pain (49). The main regulator of PACAP gene expression are the NMDA receptor-mediated $\mathrm{Ca}^{2+}$ signals. Perturbation of balance between intracellular cyclic adenosine monophosphate (cAMP) and $\mathrm{Ca}^{2+}$ levels may result in psychiatric disorders, such as schizophrenia (50). These observations attract attention that modulation of glutamatergic mechanisms may have therapeutic effect on migraine headache.

\section{$\underline{4 .}$ New line of therapy: Kynurenine system}

Interesting and promising endogenous regulators of glutamatergic neurotransmission include certain metabolites of the kynurenine pathway formed during the catabolism of tryptophan. Some of these metabolites are neuroactive and play essential role in the modulation of NMDA Glu receptor function. Since Glu-induced overexcitation plays a significant role in a number of neuronal diseases (e.g. Alzheimer's disease, Huntington's disease, Parkinson's disease, Amyotrophic lateral sclerosis), the kynurenine system has recently become the subject of intense neurobiological research (51). Kynurenic acid (KYNA), an endogenous NMDA receptor antagonist, is one of the most important end products of this pathway. It can dosedependently inhibit the activation and sensitization of TS (52). However, the penetration of KYNA across the blood-brain barrier is very limited, necessitating the development of synthetic analogues with potentially better pharmacokinetic properties to exploit its therapeutic potential. In a chemically induced animal model of migraine, a derivative of KYNA was able to inhibit the nitroglycerin (NTG)-induced increase of c-fos (53) and CGRP (54) expression in rat TNC. Furthermore, the same KYNA analogue promoted an anti-inflammatory response in the TRIG in the CFA-induced model of dural neuroinflammation (55). 


\section{AIMS}

The goals of our study were to examine:

1.) whether there are any changes in the concentration of migraine-related neuropeptides in the TNC after TS activation and there are any correlations between these neuropeptides and the development of allodynia.

2.) the potential relationship between kynurenine and PACAP systems, with particular regard to NMDA receptor activation

3.) the possible novel therapeutic function of the stable KYNA analogue in terms of its ability to influence the migraine-related elevation of PACAP levels

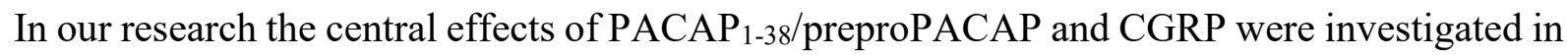
two types of rat experiments, which are models of peripheral and central sensitization by different pathways:

a.) Orofacial hyperalgesia model with CFA

- preproPACAP and CGRP protein expressions were measured in the TNC with western blot analysis following the development of this model in time dependent manner

b.) ES-TRIG model

- $\quad$ in order to evaluate the effects of KYNA and its analogue (SZR72) on the gene and protein expression of $\mathrm{PACAP}_{1-38}$ /preproPACAP the following methods were used after the TS activation: 1.) PACAP ${ }_{1-38}$ immunreactivity by radioimmunoassay (RIA), 2.) preproPACAP protein expression by western blot analysis 3.) PACAP 138 relative mRNA expression by real time polymerase chain reaction (RT-PCR)

Hypotheses of our research were that:

1.) the CFA-induced sensitization may evoke elevated preproPACAP and CGRP expression levels in the TS, which can be manifested in the alteration of mechanical hyperalgesia

2.) the KYNA and SZR72 may decrease the concentration of $\mathrm{PACAP}_{1-38}$ /preproPACAP

3.) the different treatments may influence the expression of preproPACAP/PACAP ${ }_{1-38}$ depending on the receptor specificity of drugs 


\section{MATERIALS AND METHODS}

\section{$\underline{1 . \text { Animals }}$}

106 young adult (10-12 weeks old) male Sprague-Dawley rats were used for the experiments: 30 in orofacial model, 76 in electrical stimulation of the TRIG (ES-TRIG) model (Table 1./AB). The animals were bred and maintained under standard laboratory conditions with a 12-12 $\mathrm{h}$ light/dark cycle at $24 \pm 1{ }^{\circ} \mathrm{C}$ and approx. 50\% relative humidity in the Laboratory Animal House of the Department of Neurology. The rats had free access to standard rat chow and water.

\begin{tabular}{|c|c|c|c|c|c|}
\hline \multicolumn{7}{|c|}{ Orofacial hyperalgesia model } \\
\hline Group & Control & $24 \mathrm{~h} \mathrm{CFA}$ & $48 \mathrm{~h} \mathrm{CFA}$ & $72 \mathrm{~h} \mathrm{CFA}$ & $120 \mathrm{~h} \mathrm{CFA}$ \\
\hline $\mathbf{n}$ & 6 & 6 & 6 & 6 & 6 \\
\hline $\begin{array}{c}\text { Orofacial } \\
\text { injection }\end{array}$ & saline & $\mathrm{CFA}$ & $\mathrm{CFA}$ & $\mathrm{CFA}$ & $\mathrm{CFA}$ \\
\hline $\begin{array}{c}\text { Perfusion and } \\
\text { dissection }\end{array}$ & $\begin{array}{c}24 \text { hour after } \\
\text { treatment }\end{array}$ & $\begin{array}{c}24 \text { hour after } \\
\text { treatment }\end{array}$ & $\begin{array}{c}48 \text { hour after } \\
\text { treatment }\end{array}$ & $\begin{array}{c}72 \text { hour after } \\
\text { treatment }\end{array}$ & $\begin{array}{c}120 \text { hour after } \\
\text { treatment }\end{array}$ \\
\hline
\end{tabular}

Table 1./A Experimental setup of Orofacial hyperalgesia model.

\begin{tabular}{|c|c|c|c|c|c|}
\hline \multicolumn{7}{|c|}{ ES-TRIG model } \\
\hline Group & Control & $\begin{array}{c}\text { vehicle non } \\
\text { stimulated }\end{array}$ & $\begin{array}{c}\text { KYNA ES- } \\
\text { TRIG }\end{array}$ & $\begin{array}{c}\text { SZR72 ES- } \\
\text { TRIG }\end{array}$ & $\begin{array}{c}\text { MK-801 ES- } \\
\text { TRIG }\end{array}$ \\
\hline n & 18 & 18 & 11 & 18 & 11 \\
\hline ES-TRIG & - & + & + & + & + \\
\hline Treatment & - & saline & KYNA & SZR72 & MK-801 \\
\hline
\end{tabular}

Table 1./B Experimental setup of ES-TRIG model.

\section{Ethics}

All experimental procedures performed in this study complied fully with the guidelines of Act 1998/XXVIII of the Hungarian Parliament on Animal Experiments (243/1988) and with the recommendations of the International Association for the Study of Pain and European Communities Council (86/609/ECC). The studies were in harmony with the Ethical Codex of Animal Experiments and were approved by the Ethics Committee of the Faculty of Medicine, University of Szeged (XXIV./352/2012; XI./1102/2018). 


\section{Drugs}

CFA (killed mycobacteria suspended in paraffin oil; $1 \mathrm{mg} / \mathrm{ml}$ ), MK-801 and KYNA were obtained from Sigma-Aldrich Corporation (St. Louis, MO, USA). SZR72 was synthesized by Professor Fülöp and his research team in the Department of Pharmaceutical Chemistry, University of Szeged. The structural formulae of KYNA, SZR72 and MK-801 are presented in Figure 2. Exceptions of CFA, all drugs were dissolved in $1.5 \mathrm{ml}$ physiological saline. After optimization of $\mathrm{pH}$, the solution was supplemented with physiological saline to a total volume of $2 \mathrm{ml}$. Following doses were applied during the investigations:

- CFA: $50 \mu 1$ was administered per animal in order to develop the model.

- KYNA at $189.17 \mathrm{mg} / \mathrm{kg}$ body weight (bw)

- SZR72 at $295.76 \mathrm{mg} / \mathrm{kg}$ bw

- MK-801 at $4 \mathrm{mg} / \mathrm{kg}$ bw

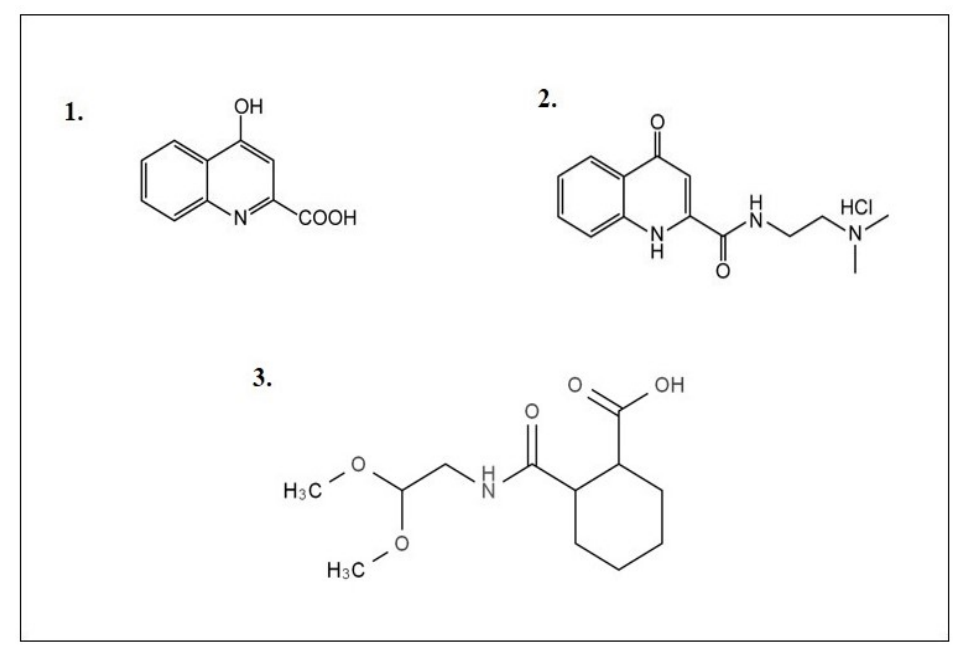

Figure 2. Structural formulae of KYNA (1.), SZR72 (2.) and MK-801 (3.).

\section{Models}

\section{A. Orofacial hyperalgesia with CFA}

CFA has been used for animal modelling of autoimmune and inflammatory illnesses for nearly 50 years and it is an accepted model of orofacial inflammatory hyperalgaesia (36,56-60). The exact mode of action of CFA is not known, but it primarily triggers an inflammatory reaction through the activation of the cellular immune response (56). The CFA-induced chemical stimulation of the orofacial area can activate the extra- and intracranial trigeminal primary 
afferents, which provide the sensory innervation of the face and oral cavity, as well as the vasculature-associated meningeal nociceptive afferents. The cell bodies of these peripheral fibres are located in the TRIG, while the central projections of these neurons terminate in the TNC. Sensitisation of the peripheral fibres and the second order nociceptive neurons in the TNC can contribute to the phenomenon of facial allodynia developing in primary headache disorders (61). Perception of pain can be connected to the thalamic third order neurons $(9,62-65)$. This commonly used peripheral inflammation model can integrate those mechanisms which are involved in migraine, because several primary headache diseases associated with inflammation of extracranial structures (e.g. the temporomandibular joint (TMJ) or the sinuses), can be evoked by similar mechanisms to those mentioned above $(59,66,67)$. Comorbidity was also observed between migraine and TMJ disorders (68). Therefore orofacial inflammation induced by CFA might be suitable to generate hyperalgaesia/allodynia on the face by the activation/sensitization of the TS, namely to mimic the features of migraine (36).

\section{Experiments}

In our experiments five animal groups were created: 1 control group and 4 groups with CFA treatment. First, the rats were anaesthetized with i.p. $4 \%$ chloral hydrate solution $(10 \mathrm{ml} / \mathrm{kg}$ bw dose) and the

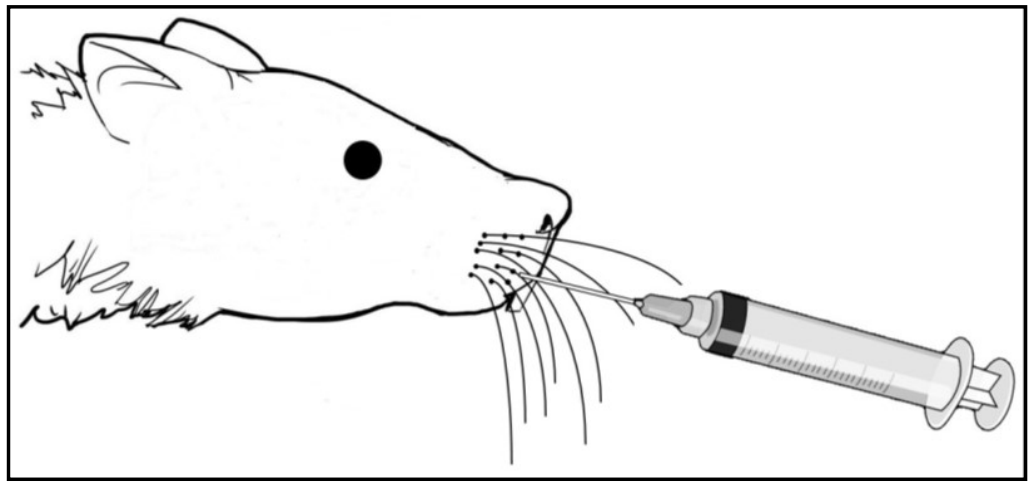

Figure 3. Scheme of the orofacial CFA treatment. throughout the experiment.

Next, $50 \mu 1$ of CFA was injected into the right whisker pad (Figure 3.). Control rats were injected with an equal volume of saline. The von Frey allodynia test was performed before and after treatment. Transcardial perfusion of the animals with $200 \mathrm{ml}$ phosphate-buffered saline (PBS) was initiated 24, 48, 72 and 120 hours after injection, followed by the dissection of the TNC (Figure 4.). After preparation, the samples were stored at $-80^{\circ} \mathrm{C}$ until further use. The relative optical density of CGRP and preproPACAP was analyzed by western blot. 
Orofacial pain sensitivity tested with von Frey filaments

In these experiments the mechanical pain thresholds of the orofacial region were determined with von Frey filaments. Tests were performed before (0) and at 24, 48, 72, 120 hours after $\mathrm{CFA} /$ saline injection. Animals were lightly restrained using a soft cotton glove in order to allow an easier habituation, then a set of calibrated nylon monofilaments (SENSElab AESTHESIOMETER, SOMEDIC Sales AB, Box 194, 24231 Hörby) was used with increasing strengths $(0.39-8.3 \mathrm{~g})$ to measure facial mechanosensitivity. Filaments were applied in ascending order, starting from the $3.3 \mathrm{~g}$ filament during control measurements and the $0.39 \mathrm{~g}$ filament after CFA treatment. The mechanonociceptive threshold was defined as the lowest force evoking at least two withdrawal responses (face stroking with the forepaw or head shaking) out of five stimulations (36).

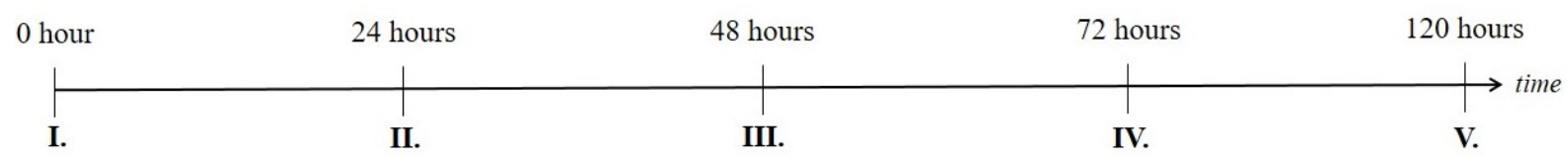

Figure 4. Experimental protocol of orofacial CFA model. I. control allodynia measurement, anesthesia and orofacial treatments: $0.9 \% \mathrm{NaCl}$ / CFA II. all groups allodynia test, control-, and 24 hours CFA groups transcardial perfusion and sampling III. 48-, 72-, and 120 hours CFA groups allodynia test, 48 hours CFA group transcardial perfusion and sampling IV. 72-, and 120 hours CFA groups allodynia test, 72 hours CFA group transcardial perfusion and sampling V. 120 hours CFA group allodynia test, transcardial perfusion and sampling

\section{B. Electrical stimulation of the TS}

Another alternative of the TS activation is the ES-TRIG, which is a well-described, widely used and generally certified method (64,69-74). Similar effect can be evoked by the stimulation of meningeal nerve terminals innervating the superior sagittal sinus (75), the transverse sinus (76) or the middle meningeal arteries (MMA). Direct stimulation of the peripheral trigeminal afferents can cause mast cell degranulation in the dura mater, accordingly neurogenic inflammation (vasodilation and plasma protein extravasation) develops on the brain surface. These responses can be explained by the release of inflammatory neuroactive mediators, e.g. CGRP, PACAP, which 1.) can trigger general neuronal activity in the area of the trigeminal complex or 2.) cause changes in blood flow $(77,78)$ and 3.) even induce structural alterations in the nerve terminals $(30,64,79)$. 


\section{Experiments}

Five animal groups were created: 1 non-stimulated control group and 4 ES-TRIG groups with different pretreatments. The group pretreated with vehicle (physiological saline, i.v.) was used as negative-, where as that pretreated with MK-801 served as positive ES-TRIG control (as a known selective NMDA receptor antagonist). Two additional groups were pretreated with KYNA and SZR72, respectively. First, the rats were anaesthetized with i.p. $4 \%$ chloral

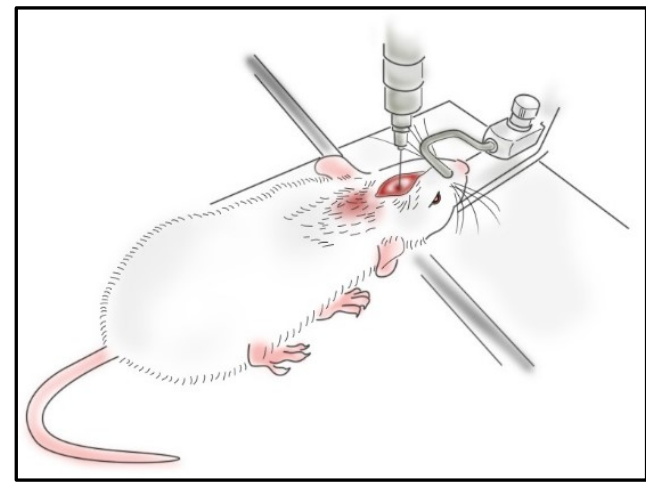

Figure 5. Scheme of the ES-TRIG. hydrate solution $(10 \mathrm{ml} / \mathrm{kg}$ bw dose) and the anaesthesia was maintained throughout the experiment. After i.v. administration of the pretreatments, the animals were placed in a stereotaxic setup. The head was fixed and the right TRIG was localized according to the Paxinos-Watson "The Rat Brain in Stereotaxic Coordinates $7^{\text {th }}$ Edition" atlas (2013, ISBN: 9780124157521). The stimulating electrode (FHC concentric bipolar electrode, OP: $200 \mu \mathrm{m}$ SS; IP: $50 \mu \mathrm{m} \mathrm{Pt/lr)} \mathrm{was} \mathrm{introduced} \mathrm{into} \mathrm{the} \mathrm{TRIG} \mathrm{and} \mathrm{its} \mathrm{ES-TRIG} \mathrm{was} \mathrm{performed} \mathrm{according}$ to the following parameters: duration: $30 \mathrm{~min}$; stimulation rate: $10 \mathrm{~Hz}$; current: $1 \mathrm{~mA}$; stimulation mode: continuous (Figure 5.). From our former studies, we know that the concentration of PACAP $\mathrm{P}_{1-38}$ is the highest 3 hour after ES-TRIG in central nervous system (21); therefore, transcardial perfusion of the animals was initiated $180 \mathrm{~min}$ after the stimulation with $200 \mathrm{ml}$ PBS-, followed by the dissection of the TNC (Figure 6.). In the non-stimulated group the perfusion and dissection was carried out following the anaesthesia. After preparation, the samples were stored at $-80^{\circ} \mathrm{C}$ until further use. The concentration of PACAP $1-38$ was measured by RIA, the relative optical density of preproPACAP was analyzed by western blot, and the relative gene expression of $\mathrm{PACAP}_{1-38}$ was determined RT-PCR.

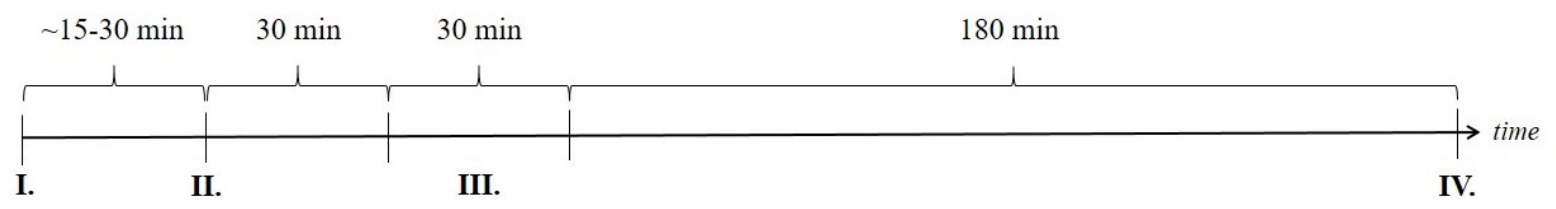

Figure 6. Experimental protocol of ES-TRIG model. I. anesthesia II. treatments (i.v.): $0.9 \% \mathrm{NaCl} / \mathrm{KYNA}(1$ mmol) / SZR72 (1 mmol) / MK-801 (1 mmol) III. ESTRIG IV. transcardial perfusion and sampling 


\section{$\underline{\text { 5. Western blot analysis }}$}

The samples were sonicated in ice-cold buffer containing $50 \mathrm{mM}$ Tris- $\mathrm{HCl}, 150 \mathrm{mM} \mathrm{NaCl}$, $0.1 \%$ Igepal. $0.1 \%$ cholic acid, $2 \mathrm{mg} / \mathrm{ml}$ leupeptin, $2 \mathrm{mM}$ phenylmethylsulphonyl fluoride, 1 $\mathrm{mg} / \mathrm{ml}$ pepstatin, $2 \mathrm{mM}$ ethylenediaminetetraacetic acid (EDTA), and $0.1 \%$ sodium dodecyl sulfate (SDS). After homogenization, the samples were centrifuged at $12.000 \mathrm{rpm}$ for $10 \mathrm{~min}$ at $4^{\circ} \mathrm{C}$, and supernatants were aliquoted and stored at $20^{\circ} \mathrm{C}$ until use. The protein concentration was determined by the BCA Protein Assay Kit using bovine serum albumin (BSA) as the standard. Prior to protein separation, each sample was mixed with the sample buffer, and denatured by boiling for $5 \mathrm{~min}$. Equal amounts of protein samples ( $20 \mathrm{mg} / \mathrm{lane})$ were separated by standard SDS polyacrylamide gel electrophoresis on $10 \%$ Tris-Glycine gel and electrotransferred onto an AmershamHybond-ECL nitrocellulose membrane (0.45-mm pore size). We used the Page Ruler Prestained Protein Ladder (10-170 kDa) to define approximate molecular weights. Following blotting, the membranes were blocked for 1 hour at room temperature in Tris-buffered saline containing Tween 20 (TBST) and 5\% nonfat dry milk powder. Subsequently, the membranes were incubated in TBST containing 1\% nonfat dry milk and anti-PACAP antibody (against the $\mathrm{C}$ terminal; ab174982, dilution: 1:500, incubation parameters: overnight, $4^{\circ} \mathrm{C}$ ) or anti-CGRP antibody (Sigma-Aldrich-c8198, dilution: 1:2000, incubation parameters: overnight, room temperature), anti-glyceraldehyde 3-phosphate dehydrogenase (GAPDH) antibody (D16H11, dilution: 1:1000, incubation parameters: overnight, room temperature). The following day, the membranes were incubated in TBST containing 1\% nonfat dry milk powder and horseradish peroxidase-conjugated goat anti-rabbit secondary antibody (sc-2030, Santa Cruz Biotechnology) for 2 hours at room temperature. The protein bands were revealed with Syngene PXi 6 Access Touch Gel Documentation System.

\section{$\underline{6 . \text { RIA }}$}

The frozen samples were weighed and homogenized in $1 \mathrm{ml}$ ice-cold double-distilled water with a manual Potter homogenizer. The homogenates were centrifuged at $10.000 \mathrm{rpm}$ for $10 \mathrm{~min}$ and then at $12.000 \mathrm{rpm}$ for an additional $10 \mathrm{~min}$, and $25 \mu 1$ samples of the supernatants were used for RIA measurements. The tracer was mono- ${ }^{125}$ I-labeled PACAP $_{1-38}$ prepared in the Department of Pharmacology and Pharmacotherapy, Faculty of Medicine, University of Pécs. The synthetic peptide was used as the RIA standard in concentrations ranging from 0 to $2000 \mathrm{fmol} / \mathrm{ml}$. The assay buffer was composed of $0.05 \mathrm{M}$ (pH 7.4) phosphate buffer containing $0.1 \mathrm{M}$ sodium chloride, $0.25 \%(\mathrm{w} / \mathrm{v}) \mathrm{BSA}$, and $0.05 \%(\mathrm{w} / \mathrm{v})$ sodium azide. The anti-PACAP ${ }_{1-}$ 38 (Abcam, ab35342; Lot. No.: GR48676-4; $100 \mu 1,1: 10,000$ dilution), the RIA tracer $(100 \mu 1$, 
$3000 \mathrm{cpm} /$ tube), and the standards or samples of unknown concentration $(100 \mu \mathrm{l})$ were injected into polypropylene tubes containing $700 \mu \mathrm{l}$ assay buffer ( $1 \mathrm{ml}$ total volume). After incubation for $48-72 \mathrm{~h}$ at $4^{\circ} \mathrm{C}$, the antibody-bound peptide was separated from the free peptide by the addition of $100 \mu \mathrm{l}$ separating solution ( $10 \mathrm{~g}$ charcoal, $1 \mathrm{~g}$ dextran, and $0.5 \mathrm{~g}$ commercial nonfat milk powder dissolved in $100 \mathrm{ml}$ distilled water). Following centrifugation at $3000 \mathrm{rpm}$ at $4^{\circ} \mathrm{C}$ for $20 \mathrm{~min}$, the contents of the tubes were gently decanted and the radioactivity of the precipitates was measured in a gamma counter (Gamma, type: NZ310). PACAP 1-38 immunoreactivities (IR) of the samples were calculated from the calibration curve and expressed as fmol/mg wet tissue.

\section{RT-PCR}

For RT-PCR analysis, total RNA was isolated from the TNC with Trizol, according to the manufacturer's protocol. RNA concentrations were determined using a MaestroNano spectrophotometer and the verification of RNA integrity was performed by gel electrophoresis, using $1 \%$ agarose gel. cDNA was synthesized from $1 \mu \mathrm{g}$ total RNA with random hexamer primers by RevertAid First Strand cDNA Synthesis Kit (Thermo Scientific, USA). The produced cDNA was stored at $-20^{\circ} \mathrm{C}$ until further use. The RT-PCR was performed on a CFX 96 real time System (Bio-Rad, USA) to detect changes in mRNA expression, using forward (5'CCTACCGCAAAGTCTTGGAC 3') and reverse (5'TTGACAGCCATTTGTTTTCG 3') primers designed for $\mathrm{PACAP}_{1-38}$. Thermal cycling conditions were $95^{\circ} \mathrm{C}$ for $2 \mathrm{~min}$ followed by 40 cycles of $95^{\circ} \mathrm{C}$ for $10 \mathrm{sec}$ and $60^{\circ} \mathrm{C} 30 \mathrm{sec}$. The relative mRNA level was calculated by the $2^{-\Delta \Delta \mathrm{Ct}}$ method. A pre-optimized primer and probe assay for $18 \mathrm{~S}$ rRNA was used as an endogenous control (Applied Biosystems, USA).

\section{$\underline{\text { 8. Statistical analysis }}$}

Before the experiments power analysis was performed to sample size estimation. The ShapiroWilk test was used to determine the distribution of data. Based on normality test we used Oneway ANOVA -, and Kruskal-Wallis test with Tukey's post hoc test to analyse the results. A probability level of $\mathrm{p}<0.05$ was considered significant. Mean \pm SD are represented in the diagrams. Regression analyses were performed between the levels of neuropeptides and the value of hyperalgaesia with SPSS 20.0 Software. 


\section{RESULTS}

\section{$\underline{1 .}$ Results of orofacial hyperalgesia model}

A.) Orofacial CFA treatment resulted significant preproPACAP increase in the TNC

A significant $(\mathrm{p}<0.01$ and $\mathrm{p}<0.001)$ increase in the relative optical density of preproPACAP was observed 24 (0.58), 48 (0.69), 72 (1.01) and 120 hours (0.85) after the CFA treatment compared to the control group (0.49). The highest preproPACAP concentration was measured 72 hours after the CFA treatment. The difference between the 72-, and 120 hours groups was significant; therefore it has not been necessary to involve other groups this investigation.

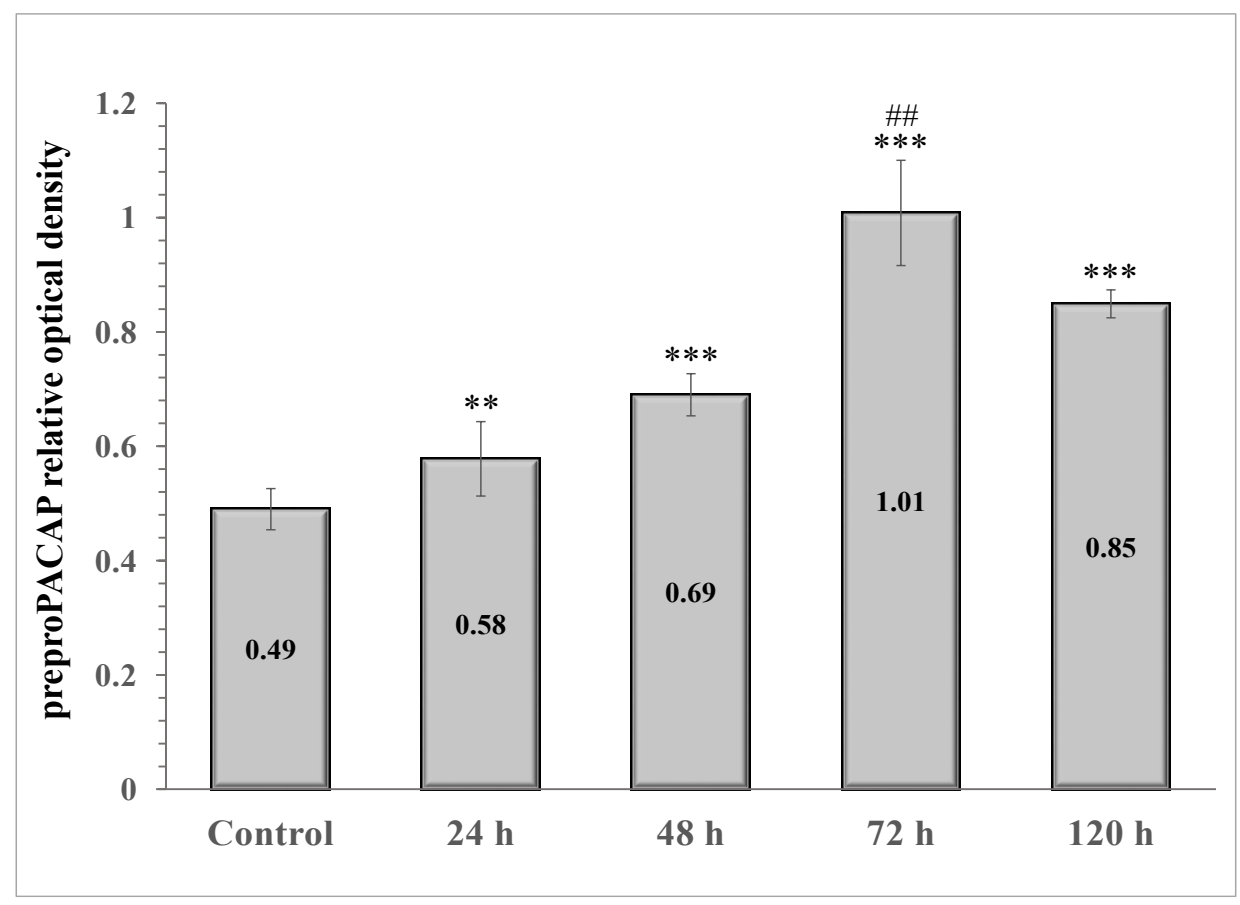

Figure 7. Relative optical density of the preproPACAP protein in the TNC following orofacial CFA treatment. $* * * p<0.001$ vs. control group, ${ }^{* *} \mathrm{p}<0.01$ vs. control group, $\# \# \mathrm{p}<0.01$ vs. 120 h group. Mean $\pm \mathrm{SD}, \mathrm{n}=6$.

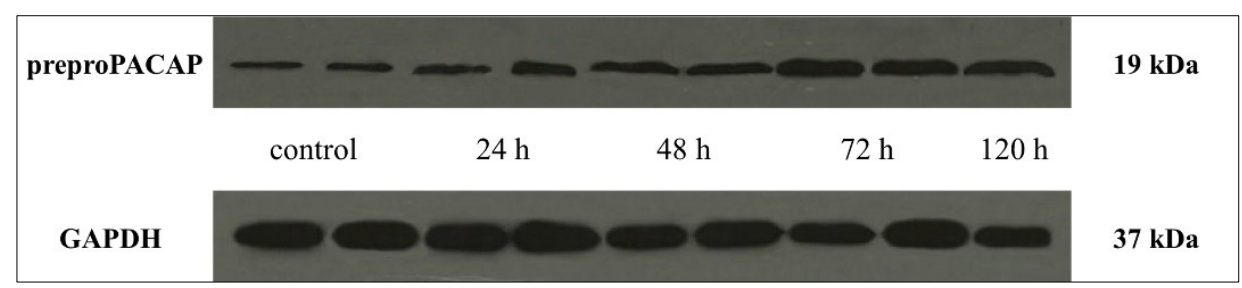

Figure 8. Western blot of preproPACAP and GAPDH expression in the TNC. 
B.) Orofacial CFA treatment significantly elevated CGRP relative optical density in the TNC

The CGRP expression significantly $(\mathrm{p}<0.01$ and $\mathrm{p}<0.001)$ elevated in the TNC $24(0.99), 48$ (1.26), 72 (2.36) and 120 hours (2.1) after CFA injection compared to the control group (0.73). The highest CGRP concentration was detected 72 hours after CFA treatment. The difference was significant $(p<0.05)$ between the $72-$, and 120 hours groups; therefore it has not been necessary the involvement of other groups to this investigation.

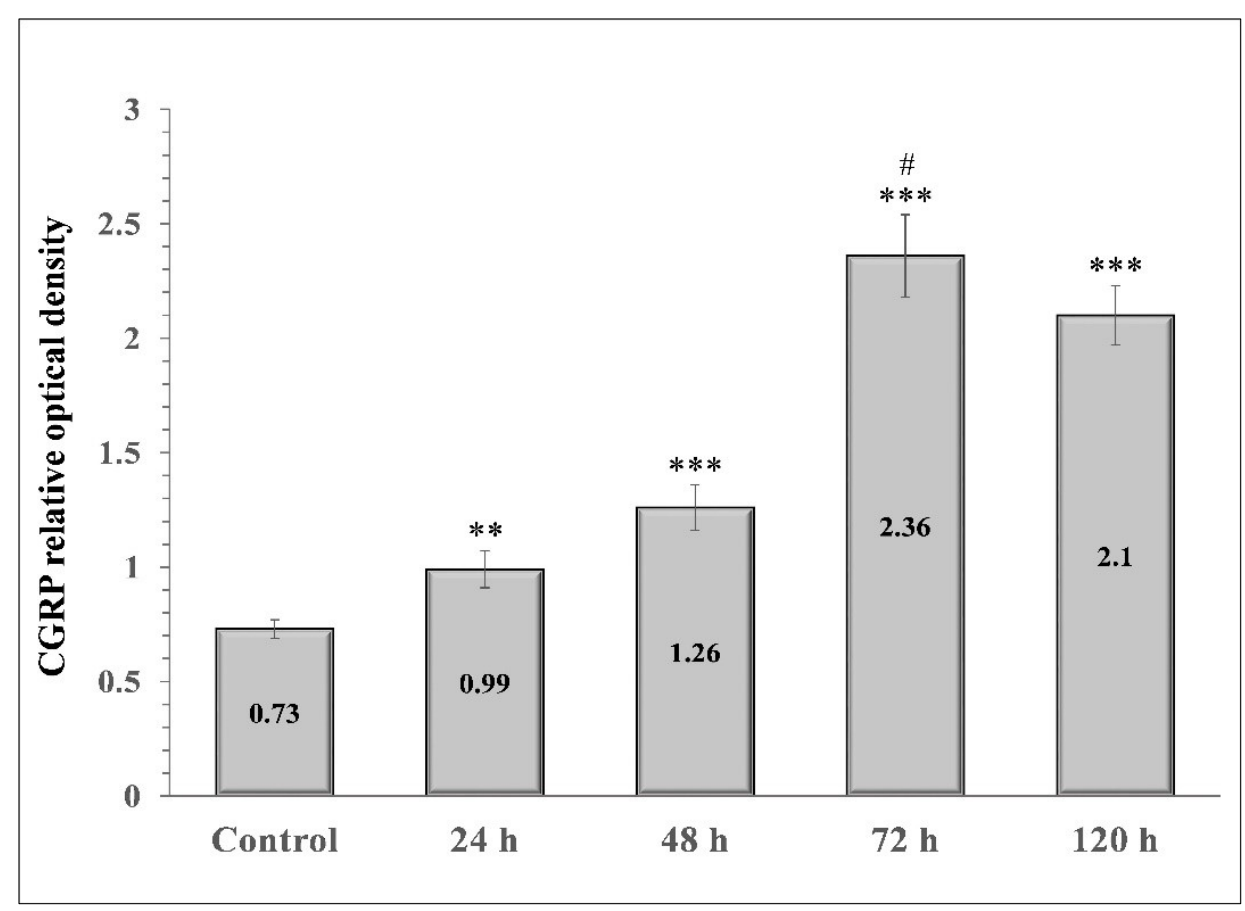

Figure 9. Relative optical density of the CGRP protein in the TNC following orofacial CFA treatment. $* * * \mathrm{p}<0.001$ vs. control group, $* * \mathrm{p}<0.01$ vs. control group, $\# \mathrm{p}<0.05$ vs. 120 h group. Mean $\pm \mathrm{SD}$, $\mathrm{n}=6$.

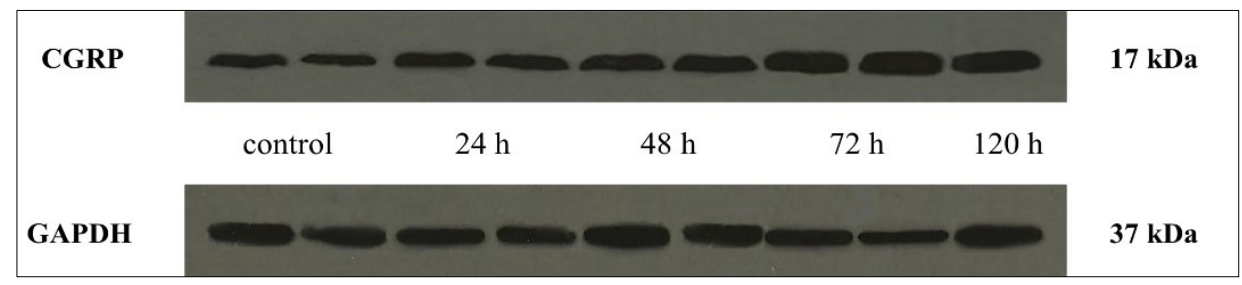

Figure 10. Western blot of CGRP and GAPDH expression in the TNC. 


\section{C.) Orofacial CFA injection decreased the mechanonociceptive threshold}

The facial mechanonociceptive threshold significantly $(\mathrm{p}<0.001)$ decreased compared to the contralateral side 48, 72 and 120 hours after CFA treatment. Compared to the control measurement (7.77), the threshold was reduced significantly $(\mathrm{p}<0.01$ and $\mathrm{p}<0.001) 24$ (6.64), 48 (4.1), 72 (2.1) and 120 hours (2.77) after CFA treatment. The decreased mechanonociceptive threshold manifested in the presence and increase of allodynia, wich reached its maximum at 72 hours, as the threshold change was lower by 120 hours. We did not find any significant differences in the threshold of the contralateral whisker pad area.

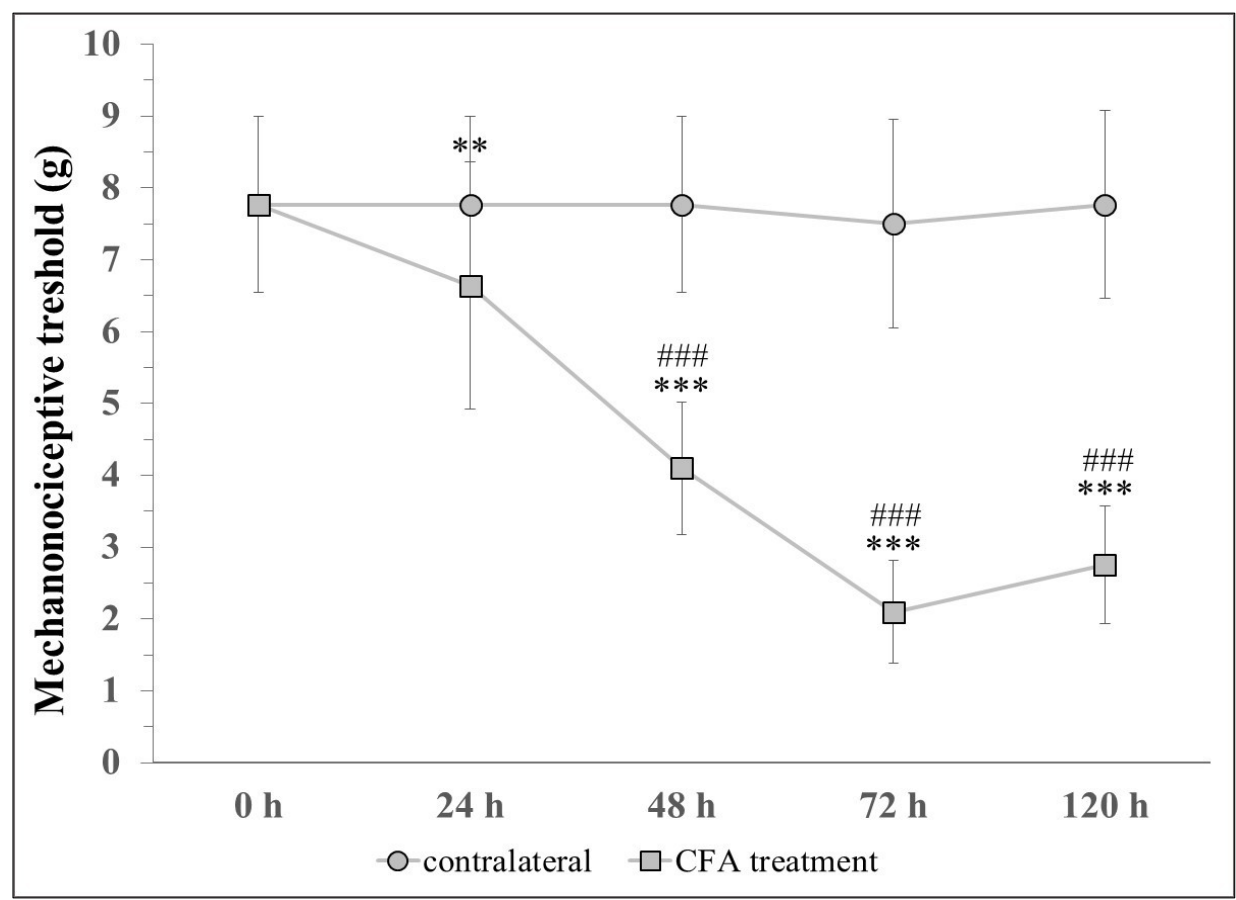

Figure 11. Changes in mechanical theshold before (0) and 24, 48, 72, 120 hours after CFA treatment. $* * * p<0.001$ vs. control measurement $(0 \mathrm{~h})$ in CFA treatment group, ${ }^{* *} \mathrm{p}<0.01$ vs. control measurement $(0$ h) in CFA treatment group, \#\#\# $\mathrm{p}<0.001$ vs. contralateral side. Mean $\pm \mathrm{SD}, \mathrm{n}=6-24$. 
D.) Correlation between neuropeptides expression and mechanical hyperalgesia

Reverse relationship was observed between the concentrations of neuropeptides and the value of the evoked mechanical threshold (CFA treated whisker pad) depending on the time. Data of the saline treated control group and the CFA treated groups were involved in the statistical probe. Regression analyses have revealed that negative, linear correlation is found between the expression levels of preproPACAP or CGRP and the levels of hyperalgaesia. Then data were mixed with bootstrap analyses (1000x), which resulted in the following values: $n=30$, $p_{\text {CGRP }}<0.001, R_{\text {CGRP }}=-0.846 ; n=30, p_{\text {PACAP }}<0.001, R_{\text {PACAP }}=-0.792$

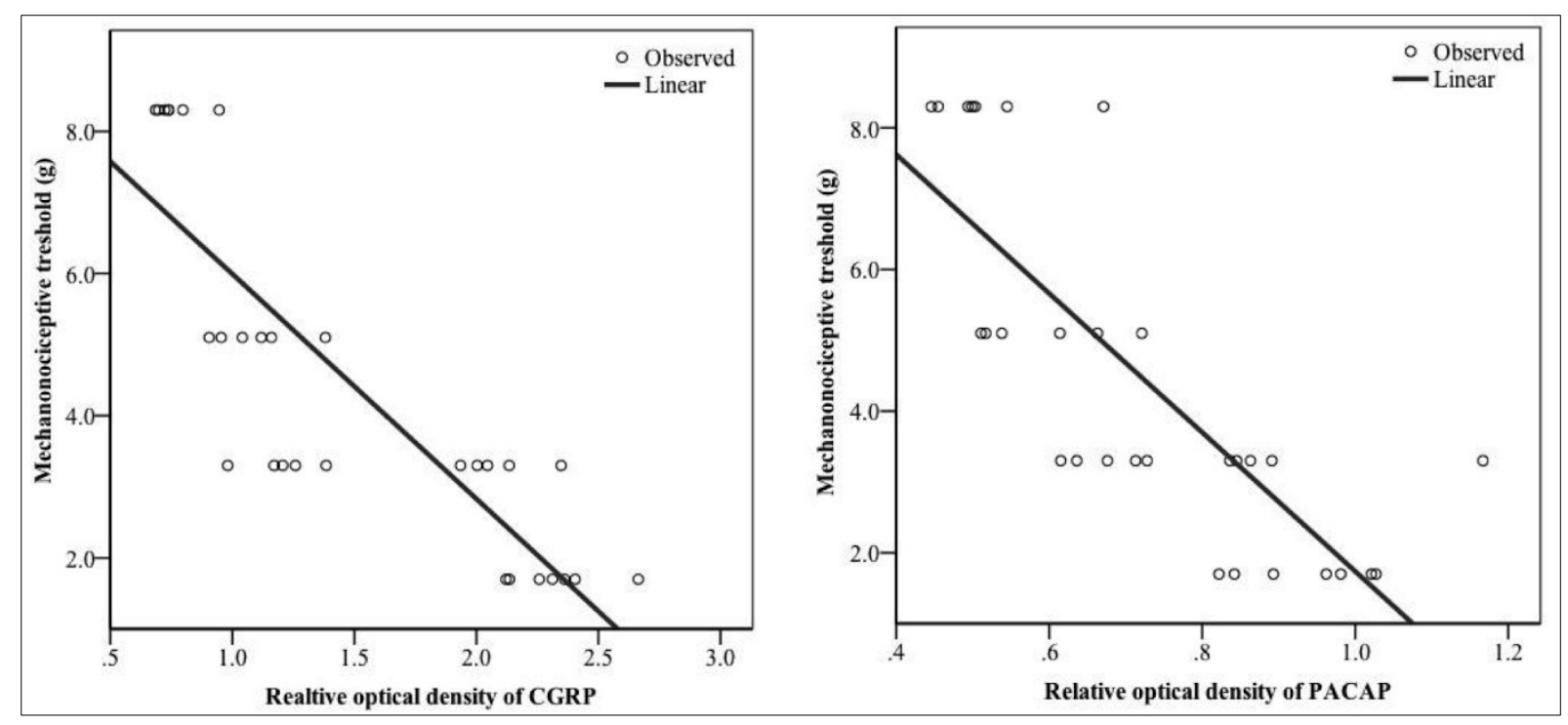

Figure 12. Negative, linear correlation between expression levels of neuropeptides and mechanonociceptive threshold. 


\section{Results of ES-TRIG model}

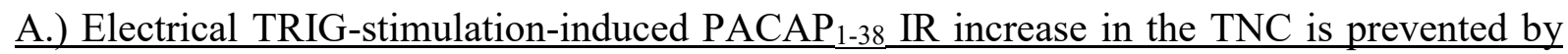

\section{$\underline{\text { SZR72 pretreatment }}$}

Electrical stimulation of the TRIG resulted significant $(\mathrm{p}<0.05)$ increase of PACAP $1-38$ IR in the TNC of the vehicle-treated group $(27.49 \mathrm{fmol} / \mathrm{mg})$ compared to the intact non-stimulated control group $(19.31 \mathrm{fmol} / \mathrm{mg})$. SZR72 pretreatment reduced significantly $(p<0.01)$ this ESTRIG-evoked elevation $(14.68 \mathrm{fmol} / \mathrm{mg})$ when compared to the stimulated, vehicle-treated animals.

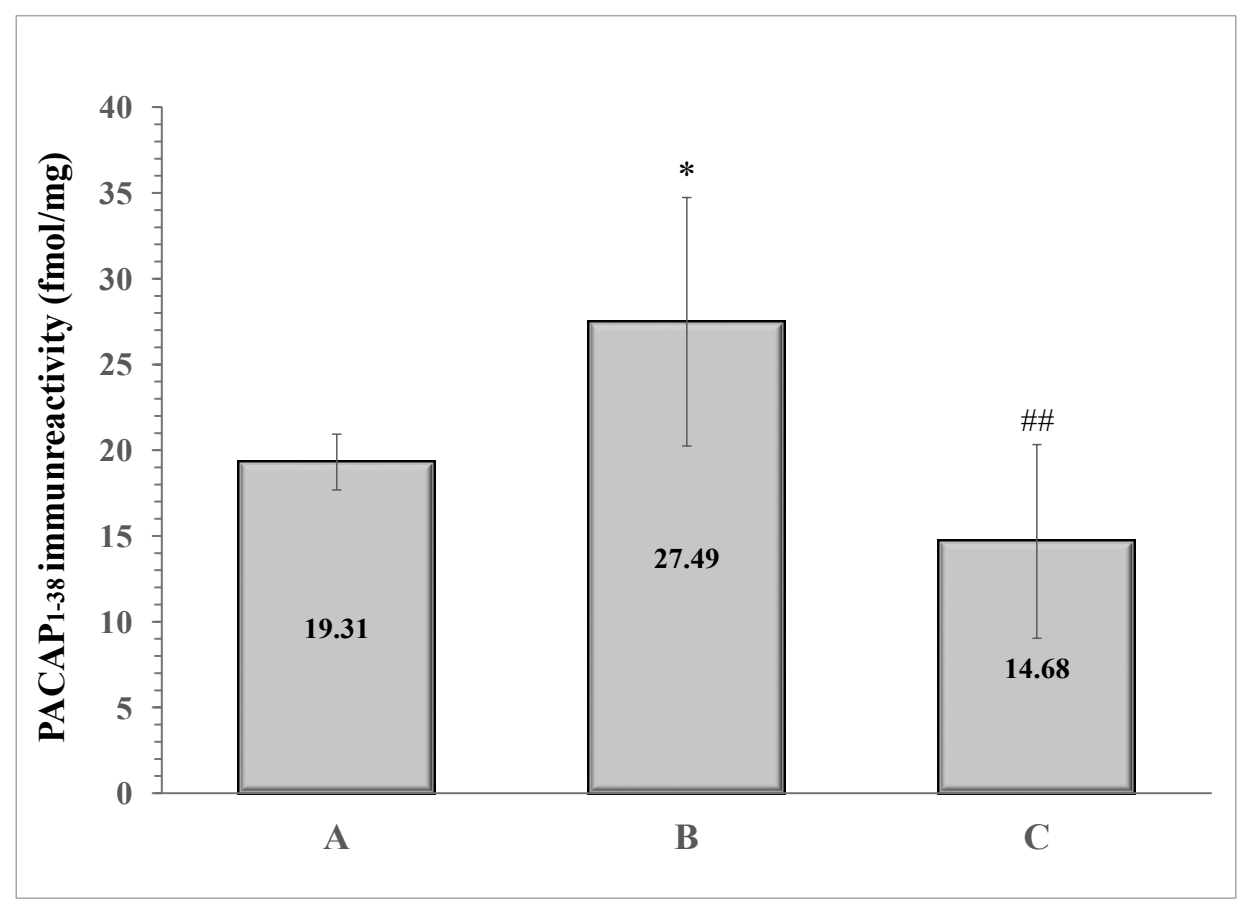

Figure 13. IR of PACAP ${ }_{1-38}$ in the TNC following ES-TRIG. A: control group B: vehicle-treated ES-TRIG group C: SZR72-treated ES-TRIG group. ${ }^{*} \mathrm{p}<0.05$ vs. control group, ${ }^{\# \#} \mathrm{p}<0.005$ vs. vehicletreated ES-TRIG group. Mean $\pm \mathrm{SD}, \mathrm{n}=6$. 
B.) Electrical TRIG-stimulation-induced preproPACAP increase in the TNC is prevented by $\underline{\text { SZR72, KYNA and MK-801 pretreatment }}$

A significant $(\mathrm{p}<0.001)$ increase in the relative optical density of preproPACAP protein was observed in the vehicle-treated ES-TRIG group (1.78) as compared to the non-stimulated control group (0.81). The relative optical density values of preproPACAP in the ES-TRIG groups pretreated with KYNA (0.74), SZR72 (0.51) or MK-801 (1.04) were significantly $(p<0.001)$ reduced compared to the vehicle-treated ES-TRIG group $(p<0.001)$. The difference of relative optical density between the MK-801-, and the SZR72-treated groups was significant $(\mathrm{p}<0.01)$. No significant differences were observed between the KYNA-, and SZR72-treated groups. No differences were found with either the KYNA or MK-801 treated groups.

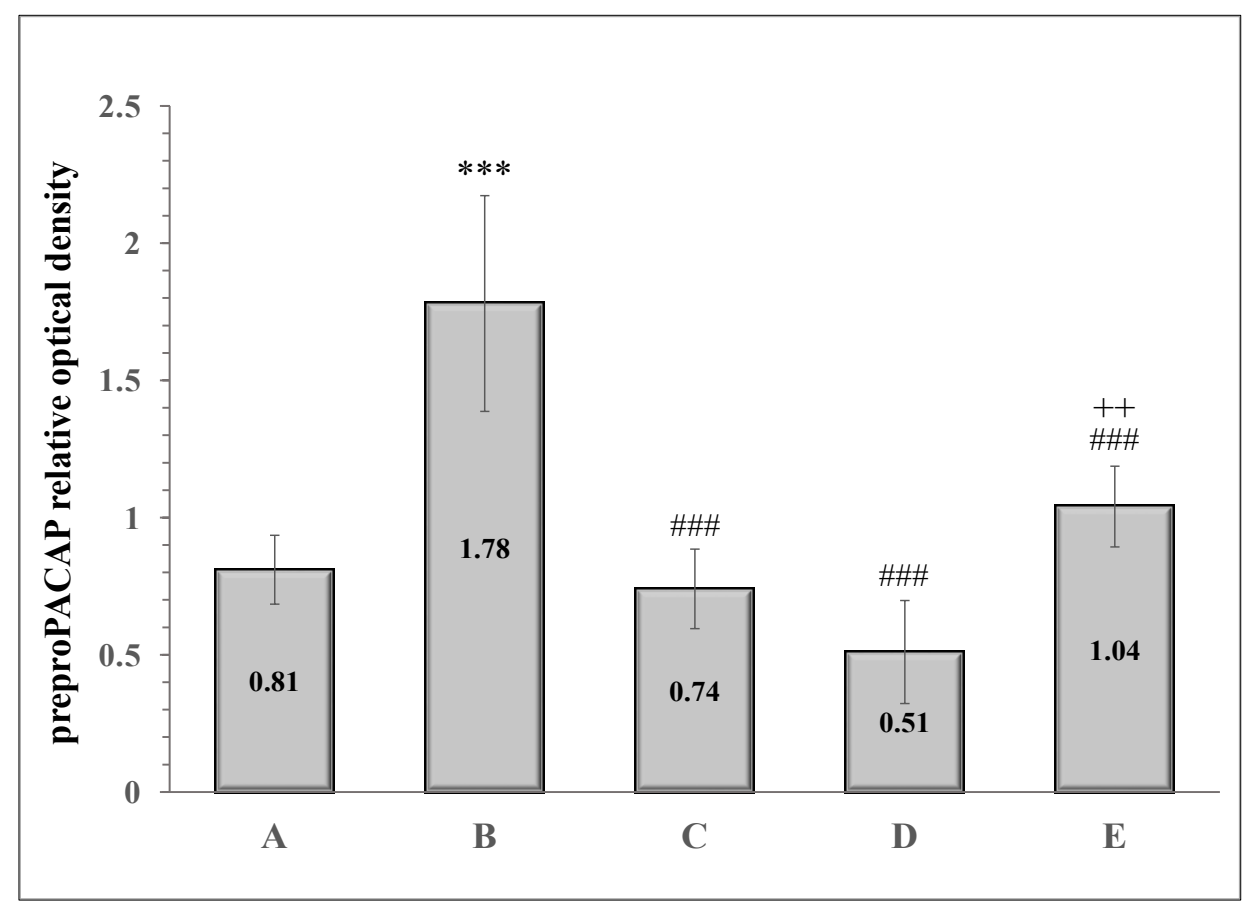

Figure 14. Relative optical density of the preproPACAP protein in the TNC following ES-TRIG. A: control group B: vehicle-treated ESTRIG group C: KYNA-treated ES-TRIG group D: SZR72-treated ESTRIG group E: MK-801-treated ES-TRIG group. ${ }^{* * *}$ p $<0.001$ vs. control group. ${ }^{\# \#} \mathrm{p}<0.001$ vs. vehicle-treated ES-TRIG group. ${ }^{++} \mathrm{p}<$ 0.01 vs. SZR72-treated ES-TRIG group. Mean $\pm \mathrm{SD}, \mathrm{n}=6$. 
C.) Electrical TRIG-stimulation-induced increased PACAP ${ }_{1-38}$ mRNA expression in the TNC is prevented by SZR72, KYNA and MK-801 pretreatment

A significant $(\mathrm{p}<0.05)$ increase in the relative mRNA expression of PACAP ${ }_{1-38}$ was observed in the vehicle-treated ES-TRIG group (1.16), when compared to the non-stimulated control group (0.99). The relative mRNA expressions of PACAP $\mathrm{P}_{1-38}$ in the ES-TRIG groups pretreated with KYNA (0.8), SZR72 $(0.66 ; \mathrm{p}<0.01)$ or MK-801 $(0.72)$ were significantly $(\mathrm{p}<0.001)$ reduced compared to the vehicle-treated ES-TRIG group. Comparison of the different pharmacology treated groups did not reveal any significant difference.

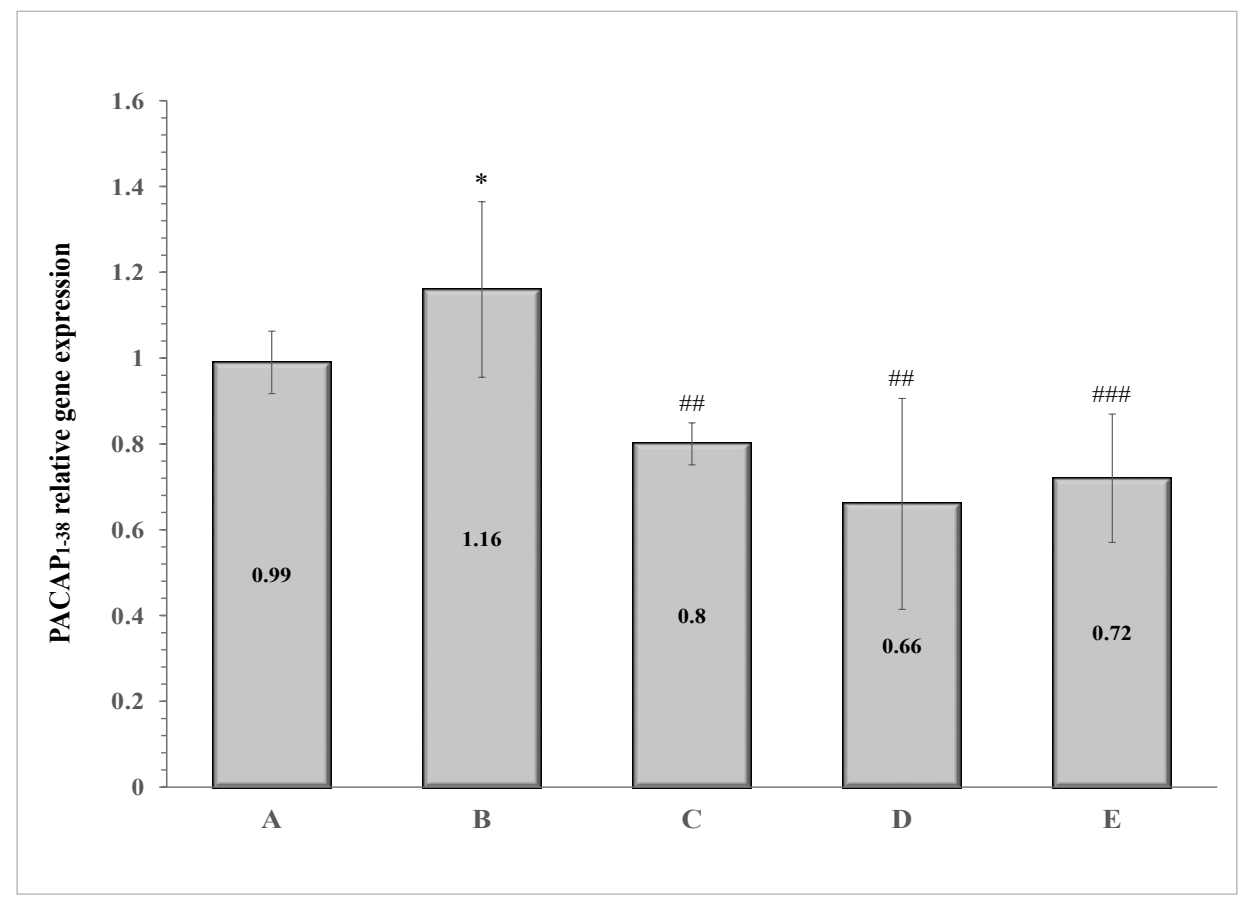

Figure 15. Relative mRNA expression of PACAP ${ }_{1-38}$ in the TNC following electrical stimulation of the TRIG. A: control group B: vehicle-treated ES-TRIG group C: KYNA-treated ES-TRIG group D: SZR72-treated ES-TRIG group E: MK-801-treated ES-TRIG group *p $<0.05$ vs. control group. ${ }^{\#} \mathrm{p}<0.01$ vs. vehicle-treated ES-TRIG group. ${ }^{\# \#} \mathrm{p}<0.001$ vs. vehicle-treated ES-TRIG. Mean $\pm \mathrm{SD}, \mathrm{n}=5$. 


\section{DISCUSSION}

Migraine research in recent years has focused on neuropeptides as potential pathogenic factors and possible therapeutic alternatives. Our experiments proved that the activation of TS cause CGRP and PACAP release in the TNC, which was associated with change of mechanical allodynia. Inhibition of NMDA receptors can prevent the overexpression of PACAP; therefore support the idea that therapies aimed at the modulation of glutamatergic neurotransmission may be a new perspective for the research.

\section{$\underline{\text { Preclinical evidences supporting our results }}$}

A classical study confirmed that the concentration of CGRP and SP were increased during ESTRIG of the external jugular vein of cats (30). A former study suggests that ES-TRIG resulted in significantly elevated PACAP ${ }_{1-38}$ IR of the plasma 180 minutes after ES-TRIG, as well as increased PACAP ${ }_{1-38}$ and PACAP ${ }_{1-27}$ IR in the TNC. Besides ES-TRIG, the i.p. administration of NTG also induced an increase in PACAP $_{1-38}$ and PACAP ${ }_{1-27}$ expression 3 hours after the treatment in the TNC (21). A study showed that PACAP $_{1-38}$ administration can result in increased CGRP expression in the TNC, which points to a potential connection between release

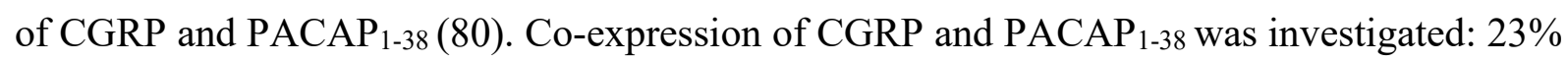
of the neurons expressed both CGRP and PACAP ${ }_{1-38}$ in rat TRIG, and CGRP (49\%) was expressed in more neuronal somas compared to PACAP $_{1-38}(29 \%)(81)$. In a preclinical model of migraine, the simultaneous release of CGRP and PACAP was detected: a chronic NTG treatment caused increased concentrations of these peptides in the plasma of rats, furthermore the intervention evoked mechanical and thermal hyperalgesia (82). Nevertheless the activation of TS could be formed by different CFA treatments, which results in pain associated pathological states, including migraine, neuralgias and TMJ disorders (68). In a previous study the effect of CFA was investigated on the expression of mitogen-activated protein kinases (MAPK), which play essential roles in pain processing. Administration of CFA in the TMJ caused significant extracellular signal-regulated kinase 1/2 (ERK1/2) and p38 MAPK increase in the TRIG (83). Dural administration of CFA resulted elevated ERK1/2, interleukin-1 $\beta$ and CGRP expression in the TRIG (56), as well as increased c-fos and glutamate IR in the TNC and cervical neurons (55). Moreover, gene expression alterations (CGRP, Iba1, GFAP, etc.) were detected following orofacial CFA treatment in the TRIG and TNC (36), which suggest that the

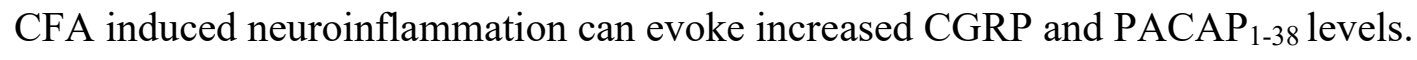

In our experiments was proved, that orofacial CFA injection evokes significant CGRP and preproPACAP increase in the TNC 24 hours after treatment. The neuropeptide levels reach a 
maximum at 72 hours after CFA injection, corresponding to the peak of facial allodynia. These results support our hypothesis according to CFA treatment may increase neuropeptide levels and extent of mechanical allodynia. Our opinion is that the CFA-induced inflammation can evoke continuous and long-term neuropeptide release in the TNC, which is accompanied by manifestation of mechanical hyperalgesia. It is assumed that the CFA can maintain this effect until 72 hours, then both the preproPACAP and CGRP levels start to decrease in the absence of stimulus, which causes the relief of allodynia. Our presumption is supported by a recent study, where the repetitive electrical stimulation of dura mater induced elevation in the expression level of CGRP and PACAP in the TRIG and TNC in rat depending on the stimulation periods (1, 3 and 7 days). It suggests that the number of stimulations can influence the release and effects of neuropeptides (37). Our results are consistent with a previous study, where the orofacial CFA injection provoked increased CGRP expression in the TNC, which elevation reached its maximum 3 days after CFA treatment (36). In another study, activated microglial cells were detected in the ipsilateral TNC and in the cervical dorsal horn 72 hours after orofacial CFA treatment of rats (84). In this context, the activated microglial cells might also be involved to the mechanism of central sensitization and nociception (85-87). It is proved that an antagonist of P2X4 microglia receptor blocked the NTG-induced c-Fos and CGRP release in the TNC, subsequently the hyperalgesia (88). Results of our functional test showed that orofacial CFA injection can already cause a significant increase in mechanical allodynia 24 hours after treatment. Allodynia reached its maximum on day 3 , as the threshold change was lower by day 5 . These results are consistent with observations from animal investigations, where the CFA induced chronic pain-like behaviour 3 days after the treatment $(36,58,89)$. Additionally, it was also demonstrated that chronic stimulation of dura mater can elicit facial cutaneous allodynia during the migraine chronification, via CGRP and PACAP elevation. One of the potential mechanisms, which can mediate the effect of PACAP is that its autoreceptor (PAC1) can influence the G-protein-coupled downstream effects via regulating the pre- and postsynaptic events (37). Nevertheless, the moderating functional alterations might also be explained by the desensitization of receptors, but further investigations are needed to answer this hypothesis.

Another important result of present study is the observed correlation between the alterations of CGRP and preproPACAP expression as well as the change of mechanical threshold. Several

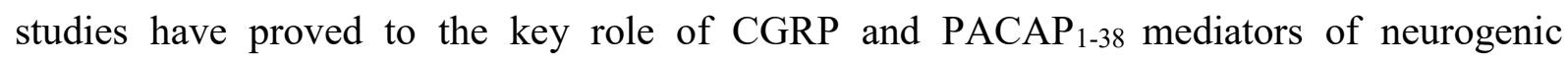
inflammation and modulators of pain inputs $(32,35,90)$. Release of these neuropeptides in the central nervous system can facilitate the nociceptive signalling and contribute to the 
vasodilation of meningeal vessels and neurogenic inflammation in the periphery (91). Based on our results it is assumed that the CFA-induced CGRP and PACAP 1-38 $_{\text {increases play crucial role }}$ in the triggering of central sensitization, thereby regulation of these peptides may influence the rate of mechanical hyperalgesia (82).

\section{$\underline{\text { Clinical studies confirming our observations }}$}

Numerous clinical studies reflect the role of neuropeptides in primary headache disorders. In migraineurs, the peripheral plasma level of CGRP increased during migraine attack as compared to the attack free period $(30,31,92)$. A very similar observation has recently been made for PACAP ${ }_{1-38}$ as well, suggesting a potential biomarker function of PACAP $_{1-38}$ in the disease (31). In addition, similarly to CGRP (32), i.v. administration of PACAP PAs $_{1-38}$ induced headache and vasodilation, both in healthy subjects and patients suffering from migraine, whereas it caused delayed migraine-like attacks only in migraineurs $(33,93)$. Magnetic resonance imaging angiography examinations proved that $\mathrm{PACAP}_{1-38}$ induced headache is associated with prolonged vasodilation of the MMA, but not the middle cerebral artery (MCA). Sumatriptan was able to alleviate the headache, which mirrored the contraction of the MMA,

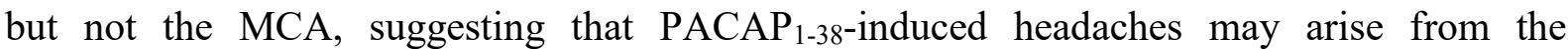
extracerebral arteries (94). Moreover, correlation was showed between the interictal plasma PACAP $_{1-38}$ IR and the microstructural integrity of the white matter in migraineurs (95).

Therapeutic solutions targeting our neuropeptides and molecules

Nowadays the therapies based on monoclonal antibodies of CGRP and PACAP $\mathrm{P}_{1-38}$ seem to be promising in the prevention of migraine (96). Recently, a phase 3 clinical trial showed that 12 months of treatment with galcanezumab, which is a fully humanized CGRP monoclonal antibody, was safe and associated with a reduction in the number of monthly migraine headache days (97). Besides galcanezumab, erenumab, eptinezumab and fremanezumab were able to reduce the frequency of attacks in patients with episodic and chronic migraine (23). Considering the similar behaviours of CGRP and PACAP ${ }_{1-38}$, the therapies aimed at PACAP ${ }_{1-38}$ may also be useful for those who have an inadequate response to therapeutics directed at CGRP or its receptors. A phase 2a, randomized, double blind, placebo-controlled study is underway to appraise the efficacy and safety of a PAC1 receptor antibody (AMG 301) in subjects with chronic or episodic migraine (98). Preclinical studies are also evaluating a monoclonal antibody

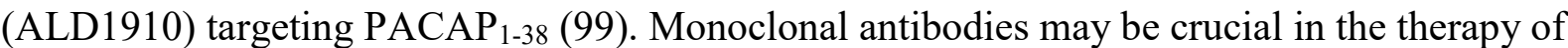
migraine, however it needs further examinations to certify their relevance. 
Several lines of evidence reflect that modulation of glutamate neurotransmission could interfere with migraine pathogenesis, thereby KYNA or its derivatives might offer a novel approach to migraine therapy (100). Indeed, numerous studies have demonstrated that the NMDA receptor inhibitor KYNA and its analogues have antinociceptive effects at the levels of both first and second order sensory neurons $(52,55,101)$. In the animal model of CFA-induced TS activation, both the KYNA and one of its derivatives decreased the levels of several inflammatory mediators in the TRG (83). Recently, the effects of two KYNA analogues have been tested in the orofacial formalin model, revealing that they were able to inhibit the formalin-induced behavioral and morphological changes, nevertheless these molecules increased the concentration of KYNA in the TNC of rat (102). Notably, systemic administration of NTG decreased the expression of kynurenine aminotransferase II (KAT II) - an enzyme catalyzing the transformation of L-kynurenine to KYNA - in the TS of rats (103). In line with this, in another model of TS activation, decreased KAT immunreactivity was observed in mast cells, Schwann cells and dural macrophages (104).

Besides animal experimental data, clinical results have also provided evidences for the connection between kynurenine system and primary headache disorders. Indeed, in patients suffering from cluster headache or chronic migraine, alterations of the kynurenine pathway were observed, which among others manifested in the reduction of KYNA concentration in the serum $(105,106)$. In our study, which is under publication we observed significant discrease in the neuroprotective pathway of kynurenine metabolism in migraineurs population compared to healthy subjects. Futhermore, correlation was detected between clinical parameters of patients (e.g. age, attack frequency, disease duration) and kynurenine metabolites.

\section{$\underline{\text { Potential mechanisms in the background of kynurenine and PACAP pathways }}$}

Our study is the first, which investigated the relationship between the kynurenine and PACAP systems in the pathogenesis of migraine. All proposed antagonists of the NMDA receptor that we applied (KYNA, SZR72 and MK-801, as reference compound) decreased the expression of PACAP, both at the levels of proteome and transcriptome, which is consistent with our hypothesis that KYNA and SZR72 may decrease the ES-TRIG-induced PACAP overexpression. Innovative result of our study that the SZR72 can downregulate both protein and gene expression of preproPACAP and PACAP ${ }_{1-38}$, suggesting that SZR72 may be a potential new drug in the PACAP-targeted migraine therapy in the future. However, the excessive reduction of PACAP expression level should be considered. It is crucial, but hard to find the optimal concentration of this peptide, because shifting in the systemic PACAP balance 
can lead to several symptoms (protective vs. harmful effects) due to its pleiotropic nature. To reveal the long-term effects of PACAP in the pathomechanism of migraine needs further investigations. Our results are consistent with previous studies, which reported that the main mediator of PACAP gene expression is the intracellular $\mathrm{Ca}^{2+}$ homeostasis (50). Indeed, besides the action of voltage-dependent $\mathrm{Ca}^{2+}$ channels, the main inducer of PACAP gene expression is the $\mathrm{Ca}^{2+}$ influx through the NMDA receptors. Drugs used in our experiments presumably blocked the NMDA receptor, thereby moderating the amount of $\mathrm{Ca}^{2+}$ coming into the cell, which may result in decreased PACAP gene expression. The proposed mechanism for the regulation of PACAP gene expression is presented in Figure 16.

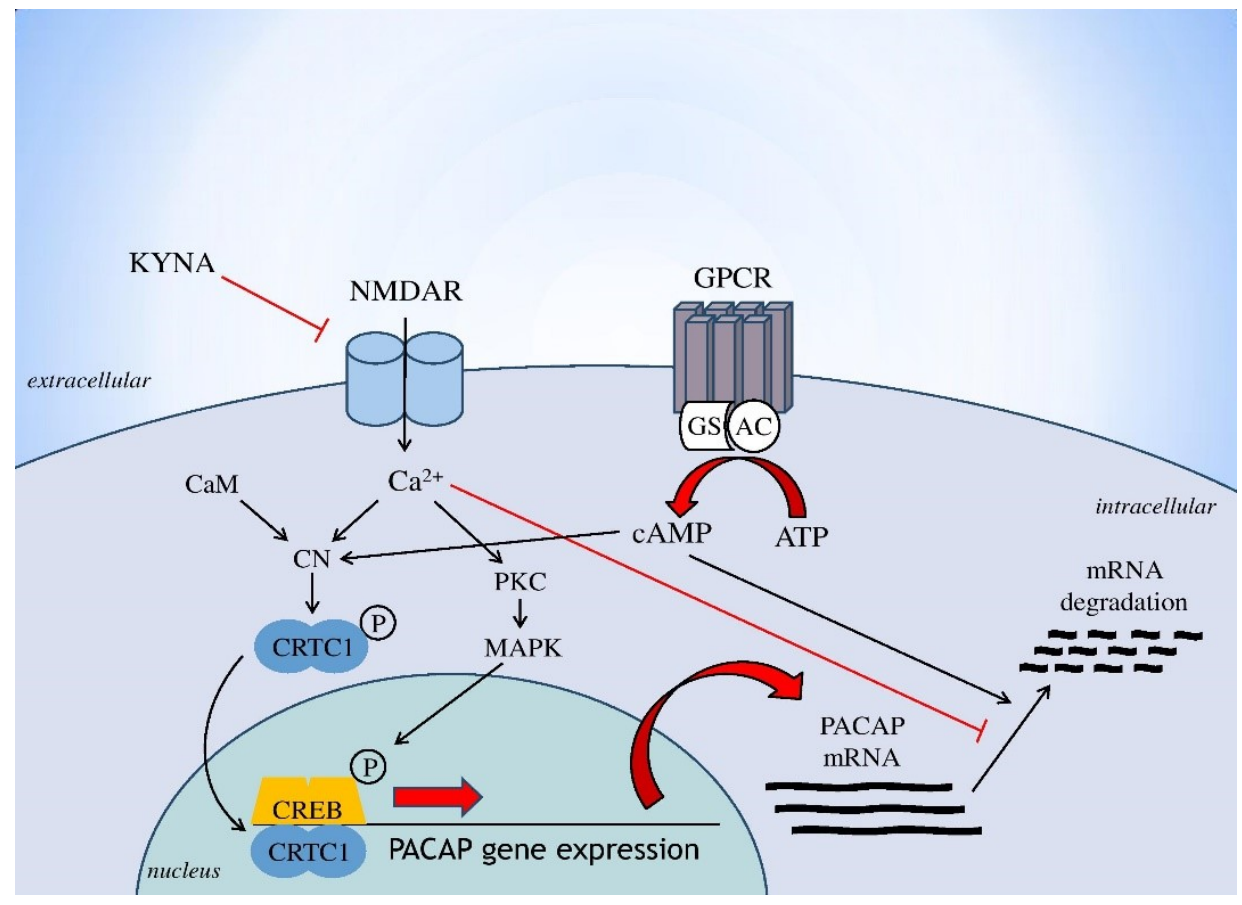

Figure 16. Regulation of PACAP gene expression (Based on Fukuchi et al., 2016., Genes to cells). AC: adenylate cylase ATP: adenosine monophosphate CaM: calmodulin cAMP: cyclic adenosine monophosphate CN: calcineurin CREB: cAMP response element binding protein CRTC1: CN/Cre binding protein GPCR: G proteincoupled receptor Gs: stimulatory G protein KYNA: kynurenic acid MAPK: mitogen activated protein kinase NMDAR: NMDA receptor PKC: protein kinase $\mathrm{C}$

Other interesting observation of the present study that the expression levels of preproPACAP were significantly different between the MK-801-, and the SZR72-treated groups, which results showing consistency with our hypothesis that the treatments may have different degrees of influence on the preproPACAP expression. It raises the possibility of the involvement of 
additional KYNA targets besides NMDA. Our opinion is that the differences between the variant drug treated groups are based on the receptor specificity of the molecules. There are evidences that KYNA has also effect on the AMPA-, kainate-, aryl hydrocarbon- (AHR), G protein-coupled 35- and opiate receptors (107-110). Regarding the SZR72, investigations are in process, but the exact targets and mechanisms of this analogue have not yet been identified. Presumably, the SZR72 has similar targets to the base compound. Our findings raise the role of these receptors in migraine and draw attention to the importance of further examinations.

Other studies have also been revealed associations between these systems. Immunohistochemical data suggest a possible interaction between glutamatergic, PACAP, and CGRP systems, based on the expression pattern of PACAP and glutamate in the TRG (81). In addition, a study reported that PACAP participated in the consolidation and extinction via NMDA receptors during contextual fear conditioning experiments in rats (111).

Our results provided the first direct evidence that NMDA receptor inhibition can prevent the overexpression of PACAP in an experimental model of migraine, as well as our investigations support that the modulation of glutamatergic neurotransmission, including the use of KYNA derivatives, may have therapeutic value in migraine. 


\section{CONCLUSION}

Our results provide the first direct evidence that the expression levels of CGRP and preproPACAP simultaneously increase after CFA induced trigeminal activation in the central region of the TS. Correlations, which were found between the alterations of CGRP, preproPACAP expression and mechanical threshold prove the influence of neuropeptides in the mechanism of hyperalgesia.

The present study also demonstrated that the NMDA receptor inhibition can prevent the overexpression of preproPACAP in the ES-TRIG model of migraine, emphasizing the importance of glutamatergic, especially the kynurenine pathway during the therapeutic improvements in the future. Different results were observed in the PACAP-modulating effects of KYNA, SZR72 and MK-801 in this TS activation model, which draw attention to a wide scale of receptors (NMDA, AMPA, kainite, GPR35, AHR, opiate, etc.) regarding their involvement in the pathomechanism of migraine.

These data confirm our knowledge about the role of these neuropeptides in migraine and contribute to the development of new and more efficient therapeutic approaches. 


\section{ORIGINAL STATEMENTS OF THE THESIS}

1.) Orofacial CFA treatment caused simultaneous CGRP and preproPACAP elevation in the $\mathrm{TNC}$ of rat.

2.) Mechanical allodynia was increased in the animals treated with CFA.

3.) Correlation was observed between the alterations of neuropeptides and mechanonociceptive threshold.

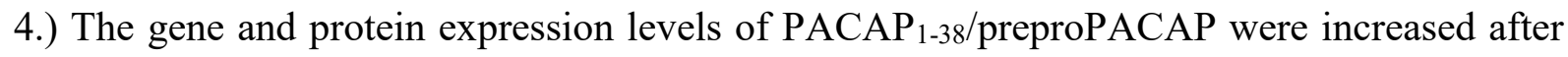
electrical stimulation of TS in the rat TNC.

5.) KYNA, SZR72 and MK-801 pretreatments prevented this ES-TRIG-evoked elevation.

6.) Significant difference was detected between the MK-801-, and the SZR72-treated groups in the level of preproPACAP. 


\section{ACKNOWLEDGEMENT}

I would like to thank my supervisor, János Tajti M.D., Ph.D. D.Sc, for the continuous help through the years we were working together. During the years he was leading these researches; he readily provided me with advice and encouraged me to work hard. I would also like to extend my thanks to László Vécsei M.D., Ph.D. D.Sc, Head of the MTA-SZTE Neuroscience Research Group, for his excellent scientific guidance and continuous support of my research activity. Furthermore, I would like to express my special thanks to my colleague Bernadett Tuka Ph.D., who has taught me much about neuroscience and the scientific way of thinking.

Furthermore, I thank all my friends and colleagues in the Neuroscience Research Groups in the Department of Neurology for their assistance.

Last but not least, I wish to thank my family and fiancé for their kind support, help and love during my studies and in my private life. 


\section{REFERENCES}

1. GBD 2016 Headache Collaborators. Global, regional, and national burden of migraine and tension-type headache, 1990-2016: a systematic analysis for the Global Burden of Disease Study 2016. Lancet Neurol. 2018;17(11):954-76.

2. Lipton RB, Stewart WF, Scher AI. Epidemiology and economic impact of migraine. Curr Med Res Opin. 2001;17 Suppl 1:s4-12.

3. Rasmussen BK, Jensen R, Schroll M, Olesen J. Epidemiology of headache in a general population--a prevalence study. J Clin Epidemiol. 1991;44(11):1147-57.

4. Smitherman TA, Burch R, Sheikh H, Loder E. The prevalence, impact, and treatment of migraine and severe headaches in the United States: a review of statistics from national surveillance studies. Headache. 2013 Mar;53(3):427-36.

5. Tfelt-Hansen PC, Hougaard A. Migraine: Differential effects of placebos in migraine clinical trials. Nat Rev Neurol. 2014 0;10(1):10-1.

6. Steiner TJ, Stovner LJ, Katsarava Z, Lainez JM, Lampl C, Lantéri-Minet M, et al. The impact of headache in Europe: principal results of the Eurolight project. J Headache Pain. 2014 May 21;15:31.

7. Tajti J, Szok D, Majláth Z, Tuka B, Csáti A, Vécsei L. Migraine and neuropeptides. Neuropeptides. 2015 0;52:19-30.

8. Tajti J, Párdutz A, Vámos E, Tuka B, Kuris A, Bohár Z, et al. Migraine is a neuronal disease. J Neural Transm (Vienna). 2011 Apr;118(4):511-24.

9. Pietrobon D, Moskowitz MA. Pathophysiology of migraine. Annu Rev Physiol. 2013;75:365-91.

10. Lauritzen M. Pathophysiology of the migraine aura. The spreading depression theory. Brain. 1994 Feb;117 ( Pt 1):199-210.

11. Anttila V, Wessman M, Kallela M, Palotie A. Genetics of migraine. Handb Clin Neurol. 2018;148:493-503. 
12. Mulder EJ, Van Baal C, Gaist D, Kallela M, Kaprio J, Svensson DA, et al. Genetic and environmental influences on migraine: a twin study across six countries. Twin Res. 2003 Oct;6(5):422-31.

13. Svensson DA, Larsson B, Waldenlind E, Pedersen NL. Shared rearing environment in migraine: results from twins reared apart and twins reared together. Headache. 2003 Mar;43(3):235-44.

14. Gormley P, Anttila V, Winsvold BS, Palta P, Esko T, Pers TH, et al. Corrigendum: Metaanalysis of 375,000 individuals identifies 38 susceptibility loci for migraine. Nat Genet. $201628 ; 48(10): 1296$

15. Rainero I, Limone P, Ferrero M, Valfrè W, Pelissetto C, Rubino E, et al. Insulin sensitivity is impaired in patients with migraine. Cephalalgia. 2005 0;25(8):593-7.

16. McCarthy LC, Hosford DA, Riley JH, Bird MI, White NJ, Hewett DR, et al. Singlenucleotide polymorphism alleles in the insulin receptor gene are associated with typical migraine. Genomics. 2001 0;78(3):135-49.

17. Fox AW, Davis RL. Migraine chronobiology. Headache. 1998 Jun;38(6):436-41.

18. Alstadhaug K, Salvesen R, Bekkelund S. 24-hour distribution of migraine attacks. Headache. 2008 0;48(1):95-100.

19. Moskowitz MA. Defining a pathway to discovery from bench to bedside: the trigeminovascular system and sensitization. Headache. 2008 May;48(5):688-90.

20. Pietrobon D, Striessnig J. Neurobiology of migraine. Nat Rev Neurosci. 2003 May;4(5):386-98.

21. Tuka B, Helyes Z, Markovics A, Bagoly T, Németh J, Márk L, et al. Peripheral and central alterations of pituitary adenylate cyclase activating polypeptide-like immunoreactivity in the rat in response to activation of the trigeminovascular system. Peptides. 2012 Feb;33(2):307-16.

22. McCulloch J, Uddman R, Kingman TA, Edvinsson L. Calcitonin gene-related peptide: functional role in cerebrovascular regulation. Proc Natl Acad Sci USA. 1986 0;83(15):5731-5. 
23. Edvinsson L. Headache advances in 2017: a new horizon in migraine therapy. Lancet Neurol. 2018;17(1):5-6.

24. Miyata A, Arimura A, Dahl RR, Minamino N, Uehara A, Jiang L, et al. Isolation of a novel 38 residue-hypothalamic polypeptide which stimulates adenylate cyclase in pituitary cells. Biochem Biophys Res Commun. 1989 Oct 16;164(1):567-74.

25. Arimura A. PACAP: the road to discovery. Peptides. 2007 Sep;28(9):1617-9.

26. Vaudry D, Falluel-Morel A, Bourgault S, Basille M, Burel D, Wurtz O, et al. Pituitary adenylate cyclase-activating polypeptide and its receptors: 20 years after the discovery. Pharmacol Rev. 2009 Sep;61(3):283-357.

27. Laburthe M, Couvineau A, Tan V. Class II G protein-coupled receptors for VIP and PACAP: structure, models of activation and pharmacology. Peptides. 2007 Sep;28(9):1631-9.

28. Schytz HW, Olesen J, Ashina M. The PACAP receptor: a novel target for migraine treatment. Neurotherapeutics. 2010 Apr;7(2):191-6.

29. Tajti J, Uddman R, Möller S, Sundler F, Edvinsson L. Messenger molecules and receptor mRNA in the human trigeminal ganglion. J Auton Nerv Syst. 1999 May 28;76(2-3):17683.

30. Goadsby PJ, Edvinsson L, Ekman R. Release of vasoactive peptides in the extracerebral circulation of humans and the cat during activation of the trigeminovascular system. Ann Neurol. 1988 Feb;23(2):193-6.

31. Tuka B, Helyes Z, Markovics A, Bagoly T, Szolcsányi J, Szabó N, et al. Alterations in PACAP-38-like immunoreactivity in the plasma during ictal and interictal periods of migraine patients. Cephalalgia. 2013 Oct;33(13):1085-95.

32. Lassen LH, Haderslev PA, Jacobsen VB, Iversen HK, Sperling B, Olesen J. CGRP may play a causative role in migraine. Cephalalgia. $2002 \mathrm{Feb}$;22(1):54-61.

33. Schytz HW, Birk S, Wienecke T, Kruuse C, Olesen J, Ashina M. PACAP38 induces migraine-like attacks in patients with migraine without aura. Brain. 2009 0;132(Pt 1):1625 . 
34. Vécsei L, Tuka B, Tajti J. Role of PACAP in migraine headaches. Brain. 2014 Mar;137(Pt 3):650-1.

35. Markovics A, Kormos V, Gaszner B, Lashgarara A, Szoke E, Sandor K, et al. Pituitary adenylate cyclase-activating polypeptide plays a key role in nitroglycerol-induced trigeminovascular activation in mice. Neurobiol Dis. 2012 0;45(1):633-44.

36. Aczél T, Kun J, Szőke É, Rauch T, Junttila S, Gyenesei A, et al. Transcriptional Alterations in the Trigeminal Ganglia, Nucleus and Peripheral Blood Mononuclear Cells in a Rat Orofacial Pain Model. Front Mol Neurosci. 2018;11:219.

37. Zhang Q, Han X, Wu H, Zhang M, Hu G, Dong Z, et al. Dynamic changes in CGRP, PACAP, and PACAP receptors in the trigeminovascular system of a novel repetitive electrical stimulation rat model: Relevant to migraine. Mol Pain. 2019 Dec;15:1744806918820452.

38. Mitsikostas DD, Sanchez del Rio M, Waeber C, Huang Z, Cutrer FM, Moskowitz MA. Non-NMDA glutamate receptors modulate capsaicin induced c-fos expression within trigeminal nucleus caudalis. Br J Pharmacol. 1999 Jun;127(3):623-30.

39. Storer RJ, Goadsby PJ. Trigeminovascular nociceptive transmission involves N-methylD-aspartate and non-N-methyl-D-aspartate glutamate receptors. Neuroscience. 1999;90(4):1371-6.

40. Rajda C, Tajti J, Komoróczy R, Seres E, Klivényi P, Vécsei L. Amino acids in the saliva of patients with migraine. Headache. 1999 Oct;39(9):644-9.

41. Goadsby PJ, Charbit AR, Andreou AP, Akerman S, Holland PR. Neurobiology of migraine. Neuroscience. 2009 Jun 30;161(2):327-41.

42. Tallaksen-Greene SJ, Young AB, Penney JB, Beitz AJ. Excitatory amino acid binding sites in the trigeminal principal sensory and spinal trigeminal nuclei of the rat. Neurosci Lett. 1992 Jul 6;141(1):79-83.

43. Vikelis M, Mitsikostas DD. The role of glutamate and its receptors in migraine. CNS Neurol Disord Drug Targets. 2007 0;6(4):251-7. 
44. Goadsby PJ, Classey JD. Glutamatergic transmission in the trigeminal nucleus assessed with local blood flow. Brain Res. 2000 Sep 1;875(1-2):119-24.

45. Ferrari MD, Odink J, Bos KD, Malessy MJ, Bruyn GW. Neuroexcitatory plasma amino acids are elevated in migraine. Neurology. 1990 Oct;40(10):1582-6.

46. Cananzi AR, D'Andrea G, Perini F, Zamberlan F, Welch KM. Platelet and plasma levels of glutamate and glutamine in migraine with and without aura. Cephalalgia. 1995 Apr;15(2):132-5.

47. Martínez F, Castillo J, Rodríguez JR, Leira R, Noya M. Neuroexcitatory amino acid levels in plasma and cerebrospinal fluid during migraine attacks. Cephalalgia. 1993 Apr;13(2):89-93.

48. Kaneko Y, Tuazon JP, Ji X, Borlongan CV. Pituitary Adenylate Cyclase Activating Polypeptide Elicits Neuroprotection Against Acute Ischemic Neuronal Cell Death Associated with NMDA Receptors. Cell Physiol Biochem. 2018;51(4):1982-95.

49. Mabuchi T, Shintani N, Matsumura S, Okuda-Ashitaka E, Hashimoto H, Muratani T, et al. Pituitary adenylate cyclase-activating polypeptide is required for the development of spinal sensitization and induction of neuropathic pain. J Neurosci. 2004 0;24(33):728391.

50. Fukuchi M, Kuwana Y, Tabuchi A, Tsuda M. Balance between cAMP and $\mathrm{Ca}(2+)$ signals regulates expression levels of pituitary adenylate cyclase-activating polypeptide gene in neurons. Genes Cells. 2016 0;21(8):921-9.

51. Vécsei L, Szalárdy L, Fülöp F, Toldi J. Kynurenines in the CNS: recent advances and new questions. Nat Rev Drug Discov. 2013 0;12(1):64-82.

52. Fejes-Szabó A, Bohár Z, Vámos E, Nagy-Grócz G, Tar L, Veres G, et al. Pre-treatment with new kynurenic acid amide dose-dependently prevents the nitroglycerine-induced neuronal activation and sensitization in cervical part of trigemino-cervical complex. $\mathbf{J}$ Neural Transm (Vienna). 2014 Jul;121(7):725-38.

53. Knyihar-Csillik E, Mihaly A, Krisztin-Peva B, Robotka H, Szatmari I, Fulop F, et al. The kynurenate analog SZR-72 prevents the nitroglycerol-induced increase of c-fos 
immunoreactivity in the rat caudal trigeminal nucleus: comparative studies of the effects of SZR-72 and kynurenic acid. Neurosci Res. 2008 0;61(4):429-32.

54. Vámos E, Fejes A, Koch J, Tajti J, Fülöp F, Toldi J, et al. Kynurenate derivative attenuates the nitroglycerin-induced CamKII $\alpha$ and CGRP expression changes. Headache. 2010 May;50(5):834-43.

55. Lukács M, Warfvinge K, Kruse LS, Tajti J, Fülöp F, Toldi J, et al. KYNA analogue SZR72 modifies CFA-induced dural inflammation- regarding expression of pERK1/2 and IL-1 $\beta$ in the rat trigeminal ganglion. J Headache Pain. 2016 0;17(1):64.

56. Lukács M, Haanes KA, Majláth Z, Tajti J, Vécsei L, Warfvinge K, et al. Dural administration of inflammatory soup or Complete Freund's Adjuvant induces activation and inflammatory response in the rat trigeminal ganglion. J Headache Pain. 2015;16:564.

57. Morgan JR, Gebhart GF. Characterization of a model of chronic orofacial hyperalgesia in the rat: contribution of NA(V) 1.8. J Pain. 2008 Jun;9(6):522-31.

58. Okumura M, Iwata K, Yasuda K, Inoue K, Shinoda M, Honda K, et al. Alternation of gene expression in trigeminal ganglion neurons following complete Freund's adjuvant or capsaicin injection into the rat face. J Mol Neurosci. 2010 Oct;42(2):200-9.

59. Krzyzanowska A, Avendaño C. Behavioral testing in rodent models of orofacial neuropathic and inflammatory pain. Brain Behav. 2012 Sep;2(5):678-97.

60. Ren K, Dubner R. Inflammatory Models of Pain and Hyperalgesia. ILAR J. 1999 Jun;40(3):111-8.

61. Malick A, Burstein R. Peripheral and central sensitization during migraine. Funct Neurol. 2000;15 Suppl 3:28-35.

62. Kolhekar R, Murphy S, Gebhart GF. Thalamic NMDA receptors modulate inflammation-produced hyperalgesia in the rat. Pain. 1997 May;71(1):31-40.

63. Ab Aziz CB, Ahmad AH. The role of the thalamus in modulating pain. Malays J Med Sci. 2006 Jul;13(2):11-8. 
64. Buzzi MG, Moskowitz MA. The trigemino-vascular system and migraine. Pathol Biol. 1992 Apr;40(4):313-7.

65. Noseda R, Burstein R. Migraine pathophysiology: anatomy of the trigeminovascular pathway and associated neurological symptoms, CSD, sensitization and modulation of pain. Pain. 2013 0;154 Suppl 1.

66. Krzyzanowska A, Pittolo S, Cabrerizo M, Sánchez-López J, Krishnasamy S, Venero C, et al. Assessing nociceptive sensitivity in mouse models of inflammatory and neuropathic trigeminal pain. J Neurosci Methods. 2011 Sep 30;201(1):46-54.

67. Romero-Reyes M, Akerman S, Nguyen E, Vijjeswarapu A, Hom B, Dong H-W, et al. Spontaneous behavioral responses in the orofacial region: a model of trigeminal pain in mouse. Headache. 2013 0;53(1):137-51.

68. Romero-Reyes M, Uyanik JM. Orofacial pain management: current perspectives. J Pain Res. 2014;7:99-115.

69. Abe T, Ohshita N, Sugiyo S, Moritani M, Kobayashi M, Takemura M. Elimination of neurokinin-1 receptor neurons in caudal nucleus reverses the effects of systemic bicuculline on c-Fos expression in rat trigeminal sensory nucleus: I. High intensity electrical stimulation of the trigeminal ganglion. Neuroscience. 2005;133(3):739-47.

70. Limmroth V, Katsarava Z, Liedert B, Guehring H, Schmitz K, Diener HC, et al. An in vivo rat model to study calcitonin gene related peptide release following activation of the trigeminal vascular system. Pain. 2001 May;92(1-2):101-6.

71. Markowitz S, Saito K, Moskowitz MA. Neurogenically mediated leakage of plasma protein occurs from blood vessels in dura mater but not brain. J Neurosci. 1987 0;7(12):4129-36.

72. Samsam M, Coveñas R, Ahangari R, Yajeya J, Narváez JA, Tramu G. Simultaneous depletion of neurokinin $\mathrm{A}$, substance $\mathrm{P}$ and calcitonin gene-related peptide from the caudal trigeminal nucleus of the rat during electrical stimulation of the trigeminal ganglion. Pain. 2000 Feb;84(2-3):389-95. 
73. Samsam M, Coveñas R, Csillik B, Ahangari R, Yajeya J, Riquelme R, et al. Depletion of substance $\mathrm{P}$, neurokinin A and calcitonin gene-related peptide from the contralateral and ipsilateral caudal trigeminal nucleus following unilateral electrical stimulation of the trigeminal ganglion; a possible neurophysiological and neuroanatomical link to generalized head pain. J Chem Neuroanat. 2001 Mar;21(2):161-9.

74. Takemura M, Shimada T, Shigenaga Y. GABA B receptor-mediated effects on expression of c-Fos in rat trigeminal nucleus following high- and low-intensity afferent stimulation. Neuroscience. 2001;103(4):1051-8.

75. Zagami AS, Goadsby PJ, Edvinsson L. Stimulation of the superior sagittal sinus in the cat causes release of vasoactive peptides. Neuropeptides. 1990 Jun;16(2):69-75.

76. Robert C, Bourgeais L, Arreto C-D, Condes-Lara M, Noseda R, Jay T, et al. Paraventricular hypothalamic regulation of trigeminovascular mechanisms involved in headaches. J Neurosci. 2013 May 15;33(20):8827-40.

77. Raval P, Bingham S, Aiyar N, Elliott JD, Hunter AJ, Ohlstein EH, et al. Trigeminal nerve ganglion stimulation-induced neurovascular reflexes in the anaesthetized cat: role of endothelin(B) receptors in carotid vasodilatation. Br J Pharmacol. 1999 0;126(2):48593.

78. Willoch F, Gamringer U, Medele R, Steude U, Tölle TR, PET activation study. Analgesia by electrostimulation of the trigeminal ganglion in patients with trigeminopathic pain: a PET activation study. Pain. 2003 May;103(1-2):119-30.

79. Knyihar-Csillik E, Tajti J, Mohtasham S, Sari G, Vecsei L. Electrical stimulation of the Gasserian ganglion induces structural alterations of calcitonin gene-related peptideimmunoreactive perivascular sensory nerve terminals in the rat cerebral dura mater: a possible model of migraine headache. Neurosci Lett. 1995 0;184(3):189-92.

80. Jansen-Olesen I, Baun M, Amrutkar DV, Ramachandran R, Christophersen DV, Olesen J. PACAP-38 but not VIP induces release of CGRP from trigeminal nucleus caudalis via a receptor distinct from the PAC1 receptor. Neuropeptides. 2014 Apr;48(2):53-64. 
81. Eftekhari S, Salvatore CA, Johansson S, Chen T-B, Zeng Z, Edvinsson L. Localization of CGRP, CGRP receptor, PACAP and glutamate in trigeminal ganglion. Relation to the blood-brain barrier. Brain Res. 2015 Mar 10;1600:93-109.

82. Mahmoudi J, Mohaddes G, Erfani M, Sadigh-Eteghad S, Karimi P, Rajabi M, et al. Cerebrolysin attenuates hyperalgesia, photophobia, and neuroinflammation in a nitroglycerin-induced migraine model in rats. Brain Res Bull. 2018;140:197-204.

83. Csáti A, Edvinsson L, Vécsei L, Toldi J, Fülöp F, Tajti J, et al. Kynurenic acid modulates experimentally induced inflammation in the trigeminal ganglion. J Headache Pain. 2015;16:99.

84. Villa G, Ceruti S, Zanardelli M, Magni G, Jasmin L, Ohara PT, et al. Temporomandibular joint inflammation activates glial and immune cells in both the trigeminal ganglia and in the spinal trigeminal nucleus. Mol Pain. 2010 0;6:89.

85. Biggs JE, Lu VB, Stebbing MJ, Balasubramanyan S, Smith PA. Is BDNF sufficient for information transfer between microglia and dorsal horn neurons during the onset of central sensitization? Mol Pain. 2010 Jul 23;6:44.

86. Liu C, Zhang Y, Liu Q, Jiang L, Li M, Wang S, et al. P2X4-receptor participates in EAAT3 regulation via BDNF-TrkB signaling in a model of trigeminal allodynia. Mol Pain. 2018 Dec;14:1744806918795930.

87. Anand P, Shenoy R, Palmer JE, Baines AJ, Lai RYK, Robertson J, et al. Clinical trial of the p38 MAP kinase inhibitor dilmapimod in neuropathic pain following nerve injury. Eur J Pain. 2011 0;15(10):1040-8.

88. Long T, He W, Pan Q, Zhang S, Zhang Y, Liu C, et al. Microglia P2X4 receptor contributes to central sensitization following recurrent nitroglycerin stimulation. $\mathrm{J}$ Neuroinflammation. 2018 0;15(1):245.

89. Liverman CS, Brown JW, Sandhir R, Klein RM, McCarson K, Berman NEJ. Oestrogen increases nociception through ERK activation in the trigeminal ganglion: evidence for a peripheral mechanism of allodynia. Cephalalgia. 2009 May;29(5):520-31. 
90. Ramón C, Cernuda-Morollón E, Pascual J. Calcitonin gene-related peptide in peripheral blood as a biomarker for migraine. Curr Opin Neurol. 2017;30(3):281-6.

91. Messlinger K, Fischer MJM, Lennerz JK. Neuropeptide effects in the trigeminal system: pathophysiology and clinical relevance in migraine. Keio J Med. 2011;60(3):82-9.

92. Cernuda-Morollón E, Larrosa D, Ramón C, Vega J, Martínez-Camblor P, Pascual J. Interictal increase of CGRP levels in peripheral blood as a biomarker for chronic migraine. Neurology. 2013 Oct 1;81(14):1191-6.

93. Guo S, Vollesen ALH, Hansen RD, Esserlind A-L, Amin FM, Christensen AF, et al. Part I: Pituitary adenylate cyclase-activating polypeptide-38 induced migraine-like attacks in patients with and without familial aggregation of migraine. Cephalalgia. 2017 Feb;37(2):125-35.

94. Amin FM, Asghar MS, Guo S, Hougaard A, Hansen AE, Schytz HW, et al. Headache and prolonged dilatation of the middle meningeal artery by PACAP38 in healthy volunteers. Cephalalgia. 2012 0;32(2):140-9.

95. Veréb D, Szabó N, Tuka B, Tajti J, Király A, Faragó P, et al. Correlation of neurochemical and imaging markers in migraine: PACAP38 and DTI measures. Neurology. 2018 18;91(12):e1166-74.

96. Levin M, Silberstein SD, Gilbert R, Lucas S, Munsie L, Garrelts A, et al. Basic Considerations for the Use of Monoclonal Antibodies in Migraine. Headache. 2018;58(10):1689-96.

97. Camporeale A, Kudrow D, Sides R, Wang S, Van Dycke A, Selzler KJ, et al. A phase 3, long-term, open-label safety study of Galcanezumab in patients with migraine. BMC Neurol. 2018 0;18(1):188.

98. Rubio-Beltrán E, Correnti E, Deen M, Kamm K, Kelderman T, Papetti L, et al. PACAP38 and PAC1 receptor blockade: a new target for headache? J Headache Pain. 2018 0;19(1):64.

99. Moldovan Loomis C, Dutzar B, Ojala EW, Hendrix L, Karasek C, Scalley-Kim M, et al. Pharmacologic Characterization of ALD1910, a Potent Humanized Monoclonal 
Antibody against the Pituitary Adenylate Cyclase-Activating Peptide. J Pharmacol Exp Ther. 2019;369(1):26-36.

100. Lovelace MD, Varney B, Sundaram G, Lennon MJ, Lim CK, Jacobs K, et al. Recent evidence for an expanded role of the kynurenine pathway of tryptophan metabolism in neurological diseases. Neuropharmacology. 2017 0;112(Pt B):373-88.

101. Párdutz A, Fejes A, Bohár Z, Tar L, Toldi J, Vécsei L. Kynurenines and headache. J Neural Transm (Vienna). 2012 Feb;119(2):285-96.

102. Veres G, Fejes-Szabó A, Zádori D, Nagy-Grócz G, László AM, Bajtai A, et al. A comparative assessment of two kynurenic acid analogs in the formalin model of trigeminal activation: a behavioral, immunohistochemical and pharmacokinetic study. $\mathrm{J}$ Neural Transm (Vienna). 2017;124(1):99-112.

103. Nagy-Grócz G, Tar L, Bohár Z, Fejes-Szabó A, Laborc KF, Spekker E, et al. The modulatory effect of anandamide on nitroglycerin-induced sensitization in the trigeminal system of the rat. Cephalalgia. 2016 0;36(9):849-61.

104. Knyihár-Csillik E, Chadaide Z, Okuno E, Krisztin-Péva B, Toldi J, Varga C, et al. Kynurenine aminotransferase in the supratentorial dura mater of the rat: effect of stimulation of the trigeminal ganglion. Exp Neurol. 2004 Apr;186(2):242-7.

105. Curto M, Lionetto L, Negro A, Capi M, Fazio F, Giamberardino MA, et al. Altered kynurenine pathway metabolites in serum of chronic migraine patients. J Headache Pain. $2015 ; 17: 47$.

106. Curto M, Lionetto L, Negro A, Capi M, Perugino F, Fazio F, et al. Altered serum levels of kynurenine metabolites in patients affected by cluster headache. J Headache Pain. $2015 ; 17: 27$.

107. Prescott C, Weeks AM, Staley KJ, Partin KM. Kynurenic acid has a dual action on AMPA receptor responses. Neurosci Lett. 2006 Jul 10;402(1-2):108-12.

108. Rózsa E, Robotka H, Vécsei L, Toldi J. The Janus-face kynurenic acid. J Neural Transm (Vienna). 2008 0;115(8):1087-91. 
109. Hilmas C, Pereira EF, Alkondon M, Rassoulpour A, Schwarcz R, Albuquerque EX. The brain metabolite kynurenic acid inhibits alpha7 nicotinic receptor activity and increases non-alpha7 nicotinic receptor expression: physiopathological implications. J Neurosci. 2001 Oct 1;21(19):7463-73.

110. Mezrich JD, Fechner JH, Zhang X, Johnson BP, Burlingham WJ, Bradfield CA. An interaction between kynurenine and the aryl hydrocarbon receptor can generate regulatory T cells. J Immunol. 2010 Sep 15;185(6):3190-8.

111. Schmidt SD, Myskiw JC, Furini CRG, Schmidt BE, Cavalcante LE, Izquierdo I. PACAP modulates the consolidation and extinction of the contextual fear conditioning through NMDA receptors. Neurobiol Learn Mem. 2015 Feb;118:120-4. 
APPENDIX 
I. 
OPEN ACCESS

Edited by: Milena De Felice,

University of Sheffield, United Kingdom

Reviewed by: Marco Carotenuto, Università degli Studi della Campania

Luigi Vanvitelli Caserta, Italy Marcelo M. Valença,

Universidade Federal de

Pernambuco, Brazi

*Correspondence: László Vécsei

vecsei.laszlo@med.u-szeged.hu

Specialty section:

This article was submitted to Headache Medicine and Facial Pain, a section of the journal

Frontiers in Neurology

Received: 30 October 2017 Accepted: 26 December 2017 Published: 16 January 2018

Citation:

Körtési T, Tuka B, Tajti J, Bagoly T,

Fülöp F, Helyes Zs and Vécsei L

(2018) Kynurenic Acid Inhibits the

Electrical Stimulation Induced

Elevated Pituitary Adenylate

Cyclase-Activating Polypeptide

Expression in the TNC.

Front. Neurol. 8:745.

doi: 10.3389/fneur.2017.00745

\section{Kynurenic Acid Inhibits the Electrical Stimulation Induced Elevated Pituitary Adenylate Cyclase-Activating Polypeptide Expression in the TNC}

\author{
Tamás Körtési', Bernadett Tuka², János Tajti', Teréz Bagoly³, Ferenc Fülöp $p^{4,5}$, \\ Zsuzsanna Helyes ${ }^{3,6,7}$ and László Vécsei ${ }^{1,2 *}$
}

'Faculty of Medicine, Department of Neurology, Albert Szent-Györgyi Clinical Center, University of Szeged, Szeged, Hungary, ${ }^{2}$ MTA-SZTE Neuroscience Research Group, University of Szeged, Szeged, Hungary, ${ }^{3}$ Faculty of Medicine, Department of Pharmacology and Pharmacotherapy, University of Pécs, Pécs, Hungary, ${ }^{4}$ Faculty of Pharmacy, Institute of Pharmaceutical Chemistry, University of Szeged, Szeged, Hungary, ${ }^{5}$ MTA-SZTE Stereochemistry Research Group, Hungarian Academy of Sciences, Szeged, Hungary, ${ }^{6}$ János Szentágothai Research Center, University of Pécs, Pécs, Hungary, ${ }^{7}$ MTA-PTE NAP B Chronic Pain Research Group, University of Pécs, Pécs, Hungary

Background: Migraine is a primary headache of imprecisely known mechanism, but activation of the trigeminovascular system (TS) appears to be essential during the attack. Intensive research has recently focused on pituitary adenylate cyclase-activating polypeptide (PACAP) and the kynurenine systems as potential pathogenic factors.

Aim: We investigated the link between these important mediators and the effects of kynurenic acid (KYNA) and its synthetic analog (KYNA-a) on PACAP expression in the rat trigeminal nucleus caudalis (TNC) in a TS stimulation model related to migraine mechanisms.

Methods: Adult male Sprague-Dawley rats were pretreated with KYNA, KYNA-a, the NMDA receptor antagonist MK-801, or saline (vehicle). Next, the trigeminal ganglion (TRG) was electrically stimulated, the animals were transcardially perfused following $180 \mathrm{~min}$, and the TNC was removed. In the TNC samples, 38 amino acid form of PACAP

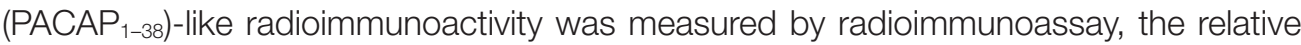
optical density of preproPACAP was assessed by Western blot analysis, and PACAP ${ }_{1-38}$ mRNA was detected by real-time PCR.

Results and conclusion: Electrical TRG stimulation resulted in significant increases of PACAP $_{1-38}-\mathrm{LI}$, preproPACAP, and PACAP ${ }_{1-38}$ mRNA in the TNC. These increases were prevented by the pretreatments with KYNA, KYNA-a, and MK-801. This is the first study to provide evidence for a direct link between PACAP and the kynurenine system during TS activation.

Keywords: migraine, trigeminovascular system, pituitary adenylate cyclase-activating polypeptide, kynurenic acid, MK-801 


\section{INTRODUCTION}

Migraine is a neurovascular primary headache disorder with a complex genetic background $(1,2)$, the pathomechanism of which is still not fully understood. One of the proposed mechanisms of the disease is the activation and sensitization of the trigeminovascular system (TS). However, central sensitization and hyperexcitability due to excessive glutamate release are also suspected to be involved in the development and persistence of pain.

Calcitonin gene-related peptide (CGRP) is one of the main regulators of the TS, and the recently identified pituitary adenylate cyclase-activating polypeptide (PACAP) also plays key roles (3-6). In migraineurs, the level of CGRP in the peripheral blood is increased during a migraine attack compared with the interictal period (4). A very similar observation has recently been made for PACAP as well, suggesting a potential biomarker function of PACAP in migraine (7). In addition, similarly to CGRP (8), intravenous administration of the 38 amino acid form of PACAP $\left(\mathrm{PACAP}_{1-38}\right)$ provoked headache and vasodilatation, both in healthy participants and migraine sufferers, whereas it delayed migraine-like attacks only in migraineurs (9-11).

In experimental conditions, intraperitoneal administration of PACAP $_{1-38}$ evoked marked photophobia, meningeal vasodilatation and increased the number of c-fos-positive activated neurons in the spinal trigeminal nucleus caudalis (TNC) in wild type, but not in PACAP ${ }_{1-38}$-deficient mice (12). In line with this, an increased concentration of PACAP ${ }_{1-38}$ was detected in the TNC after the activation of the TS in different animal models (13).

Interesting and promising endogenous regulators of glutamatergic neurotransmission include certain metabolites of the kynurenine pathway formed during the catabolism of tryptophan. Some of these metabolites are neuroactive and play essential roles in the modulation of $\mathrm{N}$-methyl-D-aspartate glutamate receptor (NMDAR) function. Since glutamate-induced overexcitation plays a significant role in a number of neuronal diseases, the kynurenine system has recently become the subject of intense neurobiological research (14).

Kynurenic acid (KYNA), an endogenous NMDAR antagonist, is one of the end products of this pathway, which can dosedependently inhibit the activation and sensitization of TS (15). However, the penetration of KYNA across the blood-brain barrier is very limited, necessitating the development of synthetic analogs with potentially better pharmacokinetic properties to exploit its

\footnotetext{
Abbreviations: BSA, bovine serum albumin; CFA, complete Freund's adjuvant; CGRP, calcitonin gene-related peptide; EDTA, ethylenediaminetetraacetic acid; ES, electrical stimulation; ES-TRG, electrical stimulation of the TRG; IQRs, interquartile ranges; KAT II, kynurenine aminotransferase II; KYNA, kynurenic acid; KYNA-a, kynurenic acid synthetic analog; MAPK, mitogen-activated protein kinase; MCA, middle cerebral artery; MMA, middle meningeal artery; NMDAR, $\mathrm{N}$-methyl-D-aspartate glutamate receptor; nNOS, neuronal nitrogen-monoxide synthase; NTG, nitroglycerin; PACAP, pituitary adenylate cyclase-activating polypeptide; PACAP $_{1-38}, 38$ amino acid form of PACAP; PBS, phosphate-buffered saline; RIA, radioimmunoassay; RT-PCR, real-time polymerase chain reaction; SDS, sodium dodecyl sulfate; TBST, Tris-buffered saline containing Tween 20; TNC, trigeminal nucleus caudalis; TRG, trigeminal ganglion; TS, trigeminovascular system; TSH, thyroid-stimulating hormone; VIP, vasoactive intestinal polypeptide.
}

therapeutic potential. In a chemically induced animal model of migraine, a derivative of KYNA was able to inhibit nitroglycerin (NTG)-induced increase of c-fos (16) and CGRP (17) expression in rat TNC. Furthermore, the same KYNA analog promoted an anti-inflammatory response in the trigeminal ganglion (TRG) in a complete Freund's adjuvant (CFA)-induced model of dural neuroinflammation (18).

To date, only a few studies have provided evidence for an association between PACAP and the NMDAR. Calcium influx through the NMDAR is an important mediator of PACAP expression, inducing gene transcription via the mitogen-activated protein kinase signaling cascade (19). PACAP has been demonstrated to enhance the functional coupling of neuronal nitrogen-monoxide synthase and the NMDAR in models of both inflammatory and neuropathic pain (20).

Based on all these recent findings, the aim of this study was to investigate a potential association between the KYNA system and PACAP expression, with particular regard to NMDAR activation and a possible novel therapeutic function for the stable KYNA analog in terms of its ability to influence migraine-related elevation of PACAP levels.

\section{MATERIALS AND METHODS}

\section{Animals}

The study used 76 young adult (10-12 weeks old) male SpragueDawley rats for the experiments; 18 intact non-stimulated animals in the control group and a total of 58 animals in the groups undergoing electrical stimulation of the TRG (ES-TRG) to model TS activation in migraine. The animals were bred and maintained under standard laboratory conditions on a 12- to 12-h light cycle at $24 \pm 11^{\circ} \mathrm{C}$ and approximately $50 \%$ relative humidity in the Laboratory Animal House of the Department of Neurology. The rats had free access to standard rat chow and water.

\section{Ethics}

All experimental procedures performed in this study complied fully with the guidelines of Act 1998/XXVIII of the Hungarian Parliament on Animal Experiments (243/1988) and with the recommendations of the International Association for the Study of Pain and European Communities Council (86/609/ECC). The studies were in harmony with the Ethical Codex of Animal Experiments and were approved by the Ethics Committee of the Faculty of Medicine, University of Szeged, XXIV./352/2012.

\section{Drugs}

MK-801 and KYNA were obtained from Sigma-Aldrich Corporation (St. Louis, MO, USA). The analog of KYNA (KYNA-a) was synthesized by Prof. Fülöp Ferenc and his research team in the Department of Pharmaceutical Chemistry, University of Szeged. KYNA was administered at $189.17 \mathrm{mg} / \mathrm{kg}$ body weight, MK-801 at $4 \mathrm{mg} / \mathrm{kg}$ body weight, and KYNA-a at $295.76 \mathrm{mg} / \mathrm{kg}$ body weight dose. The substances were dissolved in $1.5 \mathrm{ml}$ of physiological saline solution, and $\mathrm{pH}$ was adjusted with sodium hydroxide and hydrogen chloride. 


\section{Experimental Protocol}

Five animal groups were created: one non-stimulated control group and four ES-TRG groups with different pretreatments. The group pretreated with vehicle (physiological saline i.v.) was used as the negative control, whereas that pretreated with MK-801 (a known selective NMDAR antagonist) served as the positive ES-TRG control. Two additional groups were pretreated with KYNA and KYNA-a, respectively. The structural formulae of KYNA and KYNA-a are presented in Figure 1. All drugs were dissolved in $1.5 \mathrm{ml}$ physiological saline. After optimization of $\mathrm{pH}$, the solution was supplemented with physiological saline to a total volume of $2 \mathrm{ml}$.

First, the rats were anesthetized with intraperitoneal $4 \%$ chloral hydrate solution ( $10 \mathrm{ml} / \mathrm{kg}$ bw dose), and the anesthesia was maintained throughout the experiment. After intravenous administration of the pretreatments, the animals were placed in a stereotaxic setup. The head was fixed and the right TRG was localized. A stimulating electrode (FHC concentric bipolar electrode, OP: $200 \mu \mathrm{m}$ SS; IP: $50 \mu \mathrm{m}$ Pt/lr) was introduced into the TRG, and electrical stimulation (ES) was performed according to the following parameters: duration: $30 \mathrm{~min}$; stimulation rate: $10 \mathrm{~Hz}$;

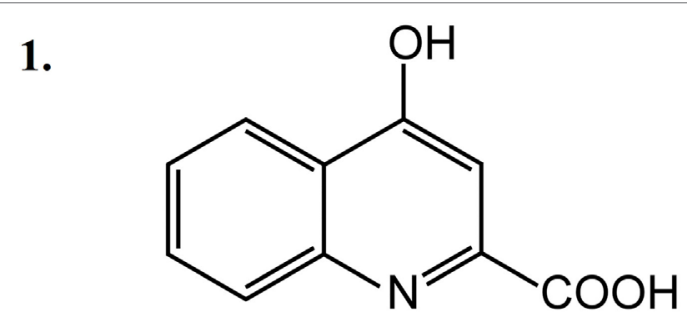

2.

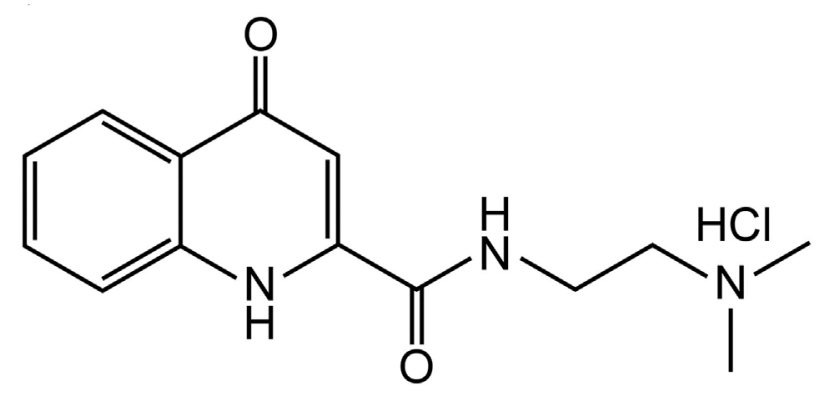

FIGURE 1 | Structural formulae of kynurenic acid (1) and kynurenic acid synthetic analog (2). current: $1 \mathrm{~mA}$; stimulation mode: continuous. Results of our previous studies suggested that the concentration of PACAP ${ }_{1-38}$ in the central nervous system is highest $3 \mathrm{~h}$ after the ES-TRG; therefore, transcardial perfusion of the animals with $200 \mathrm{ml}$ phosphatebuffered saline was initiated $180 \mathrm{~min}$ after stimulation, followed by the dissection of the TNC (13). In the non-stimulated group, perfusion and dissection were carried out following anesthesia. After preparation, the samples were stored at $-80^{\circ} \mathrm{C}$ until further use. The concentration of $\mathrm{PACAP}_{1-38}$ was measured by radioimmunoassay (RIA), the relative optical density of preproPACAP was analyzed by Western blot, and the relative gene expression of PACAP ${ }_{1-38}$ was determined by real-time polymerase chain reaction (RT-PCR). The analytical methods and their respective subject numbers are presented in Table $\mathbf{1}$.

\section{Radioimmunoassay}

The frozen samples were weighed and homogenized in $1 \mathrm{ml}$ icecold double-distilled water with a manual Potter homogenizer. The homogenates were centrifuged at 10,000 rpm for $10 \mathrm{~min}$ and then at 12,000 rpm for an additional $10 \mathrm{~min}$, and $25 \mu \mathrm{l}$ samples of the supernatants were used for RIA measurements. The tracer was mono- ${ }^{125} \mathrm{I}_{\text {-labeled }} \mathrm{PACAP}_{1-38}$ prepared in our laboratory. The synthetic peptide was used as the RIA standard in concentrations ranging from 0 to $2,000 \mathrm{fmol} / \mathrm{ml}$. The assay buffer was composed of $0.05 \mathrm{M}$ ( $\mathrm{pH} 7.4)$ phosphate buffer containing $0.1 \mathrm{M}$ sodium chloride, $0.25 \%(\mathrm{w} / \mathrm{v})$ bovine serum albumin (BSA), and $0.05 \%$ $(\mathrm{w} / \mathrm{v})$ sodium azide. The anti-PACAP ${ }_{1-38}$ (Abcam, ab35342; Lot. No.: GR48676-4; $100 \mu \mathrm{l}, 1: 10,000$ dilution), the RIA tracer $(100 \mu \mathrm{l}$, $3,000 \mathrm{cpm} /$ tube), and the standards or samples of unknown concentration $(100 \mu \mathrm{l})$ were injected into polypropylene tubes containing $700 \mu \mathrm{l}$ assay buffer ( $1 \mathrm{ml}$ total volume). After incubation for $48-72 \mathrm{~h}$ at $4^{\circ} \mathrm{C}$, the antibody-bound peptide was separated from the free peptide by the addition of $100 \mu \mathrm{l}$ separating solution $(10 \mathrm{~g}$ charcoal, $1 \mathrm{~g}$ dextran, and $0.5 \mathrm{~g}$ commercial nonfat milk powder dissolved in $100 \mathrm{ml}$ distilled water). Following centrifugation at $3,000 \mathrm{rpm}$ at $4^{\circ} \mathrm{C}$ for $20 \mathrm{~min}$, the contents of the tubes were gently decanted, and the radioactivity of the precipitates was measured in a gamma counter (gamma, type: NZ310). PACAP ${ }_{1-38}$-like immunoreactivities of the samples were calculated from the calibration curve and expressed as fentomoles per milligram wet tissue $(7,13)$.

\section{Western Blot Analysis}

The samples were sonicated in ice-cold buffer containing $50 \mathrm{mM}$ Tris- $\mathrm{HCl}, 150 \mathrm{mM} \mathrm{NaCl}, 0.1 \%$ Igepal, $0.1 \%$ cholic acid, $2 \mathrm{mg} / \mathrm{ml}$

TABLE 1 | The applied analytical methods and their respective subject number

\begin{tabular}{|c|c|c|c|c|c|c|c|c|}
\hline \multicolumn{3}{|c|}{ Radioimmunoassay } & \multicolumn{3}{|c|}{ Western blot analysis } & \multicolumn{3}{|c|}{ Real-time PCR } \\
\hline Treatment & Electrical stimulation of the TRG (ES-TRG) & $n$ & Treatment & ES-TRG & $n$ & Treatment & ES-TRG & $n$ \\
\hline- & - & 7 & - & - & 6 & - & - & 5 \\
\hline $0.9 \% \mathrm{NaCl}$ & + & 7 & $0.9 \% \mathrm{NaCl}$ & + & 6 & $0.9 \% \mathrm{NaCl}$ & + & 5 \\
\hline Kynurenic acid synthetic analog & + & 7 & Kynurenic acid (KYNA) & + & 6 & KYNA & + & 5 \\
\hline- & & & KYNA-a & + & 6 & KYNA-a & + & 5 \\
\hline- & & & MK-801 & + & 6 & MK-801 & + & 5 \\
\hline
\end{tabular}


leupeptin, $2 \mathrm{mM}$ phenylmethylsulphonyl fluoride, $1 \mathrm{mg} / \mathrm{ml}$ pepstatin, $2 \mathrm{mM}$ ethylenediaminetetraacetic acid, and $0.1 \%$ sodium dodecyl sulfate (SDS). After homogenization, the samples were centrifuged at $12,000 \mathrm{rpm}$ for $10 \mathrm{~min}$ at $4^{\circ} \mathrm{C}$, and supernatants were aliquoted and stored at $20^{\circ} \mathrm{C}$ until use. The protein concentration was determined by the BCA Protein Assay Kit using BSA as the standard. Before protein separation, each sample was mixed with the sample buffer and denatured by boiling for $5 \mathrm{~min}$. Equal amounts of protein samples (20 mg/lane) were separated by standard SDS polyacrylamide gel electrophoresis on 10\% Tris-Glycine gel and electrotransferred onto an AmershamHybond-ECL nitrocellulose membrane (0.45-mm pore size). We used the Page Ruler Prestained Protein Ladder $(10-170 \mathrm{kDa})$ to define approximate molecular weights. Following blotting, the membranes were blocked for $1 \mathrm{~h}$ at room temperature in Tris-buffered saline containing Tween 20 (TBST) and 5\% nonfat dry milk powder. Subsequently, the membranes were incubated in TBST containing $1 \%$ nonfat dry milk and anti-PACAP antibody (against the C terminal; ab174982, dilution: 1:500, incubation parameters: overnight, $4^{\circ} \mathrm{C}$ ), antiglyceraldehyde 3-phosphate dehydrogenase (GAPDH) antibody (D16H11, dilution: 1:1,000, incubation parameters: overnight, room temperature). The following day, the membranes were incubated in TBST containing $1 \%$ nonfat dry milk powder and horseradish peroxidase-conjugated goat anti-rabbit secondary antibody (sc-2030, Santa Cruz Biotechnology) for $2 \mathrm{~h}$ at room temperature. The protein bands were revealed with SuperSignal West Pico Chemiluminescent Substrate using Carestream Kodak BioMax Light film.

\section{Real-time PCR}

For RT-PCR analysis, total RNA was isolated from the TNC with Trizol, according to the manufacturer's protocol. RNA concentrations were determined using a MaestroNano spectrophotometer, and the verification of RNA integrity was performed by gel electrophoresis, using $1 \%$ agarose gel. cDNA was synthesized from $1 \mu \mathrm{g}$ total RNA with random hexamer primers by RevertAid First Strand cDNA Synthesis Kit (Thermo Scientific, USA). The produced cDNA was stored at $-20^{\circ} \mathrm{C}$ until further use. The RT-PCR was performed on a CFX 96 Real-Time System (Bio-Rad, USA) to detect changes in mRNA expression, using forward (5'-CCTACCGCAAAGTCTTGGAC-3') and reverse (5'-TTGACAGCCATTTGTTTTCG-3') primers designed for $\mathrm{PACAP}_{1-38}$. Thermal cycling conditions were $95^{\circ} \mathrm{C}$ for $2 \mathrm{~min}$ followed by 40 cycles of $95^{\circ} \mathrm{C}$ for $10 \mathrm{~s}$ and $60^{\circ} \mathrm{C} 30 \mathrm{~s}$. The relative mRNA level was calculated by the $2^{-\Delta \Delta C t}$ method. A pre-optimized primer and probe assay for $18 \mathrm{~S}$ rRNA was used as an endogenous control (Applied Biosystems, USA).

\section{Statistical Analysis}

The Shapiro-Wilk test was used to determine the distribution of data. It shows that our data do not follow the normal distribution so after the Kruskal-Wallis test we used the Tukey post hoc test to analyze the results. A probability level of $p<0.05$ was considered significant. Median \pm interquartile ranges were represented in the box-plot figures.

\section{RESULTS}

\section{Electrical TRG-Stimulation-Induced PACAP $_{1-38}$-LI Increase in the TNC Is Prevented by KYNA-a Pretreatment}

Electrical stimulation of the TRG resulted in a significant increase of $\mathrm{PACAP}_{1-38}$ - $\mathrm{LI}$ in the TNC of the vehicle-treated group $(27.49 \mathrm{fmol} / \mathrm{mg})$ compared with the intact non-stimulated control group $(19.31 \mathrm{fmol} / \mathrm{mg} ; p<0.05)$. KYNA-a-pretreatment prevented this ES-TRG-evoked elevation $(14.68 \mathrm{fmol} / \mathrm{mg})$ when compared with the stimulated, vehicle-treated animals $(p<0.01)$ (Figure 2).

\section{Electrical TRG-Stimulation-Induced preproPACAP Increase in the TNC Is Prevented by KYNA-a, KYNA, and MK-801 Pretreatment}

A significant increase in the relative optical density of preproPACAP protein was observed in the vehicle-treated ES-TRG group (1.78) as compared with the non-stimulated control group $(0.81 ; p<0.001)$. The relative optical density values of preproPACAP in the ES-TRG groups pretreated with KYNA (0.74), KYNA-a (0.51), or MK-801 (1.04) were significantly reduced compared with the vehicle-treated ES-TRG group $(p<0.001)$.

\begin{tabular}{|c|c|c|c|c|c|c|c|c|}
\hline \multicolumn{2}{|c|}{ Radioimunoassay } & \multicolumn{3}{|c|}{ Western blot analysis } & \multicolumn{3}{|c|}{ Real-Time PCR } \\
\hline treatment & $\begin{array}{c}\text { ES- } \\
\text { TRG }\end{array}$ & $\mathrm{n}$ & treatment & $\begin{array}{c}\text { ES- } \\
\text { TRG }\end{array}$ & $\mathrm{n}$ & treatment & $\begin{array}{c}\text { ES- } \\
\text { TRG }\end{array}$ & $\mathrm{n}$ \\
\hline- & - & 7 & - & - & 6 & - & - & 5 \\
\hline $\begin{array}{c}0.9 \% \\
\mathrm{NaCl}\end{array}$ & + & 7 & $\begin{array}{c}0.9 \% \\
\mathrm{NaCl}\end{array}$ & + & 6 & $\begin{array}{c}0.9 \% \\
\text { NaCl }\end{array}$ & + & 5 \\
\hline KYNA-a & + & 7 & KYNA & + & 6 & KYNA & + & 5 \\
\hline & - & & KYNA-a & + & 6 & KYNA-a & + & 5 \\
\hline & & MK-801 & + & 6 & MK-801 & + & 5 \\
\hline
\end{tabular}

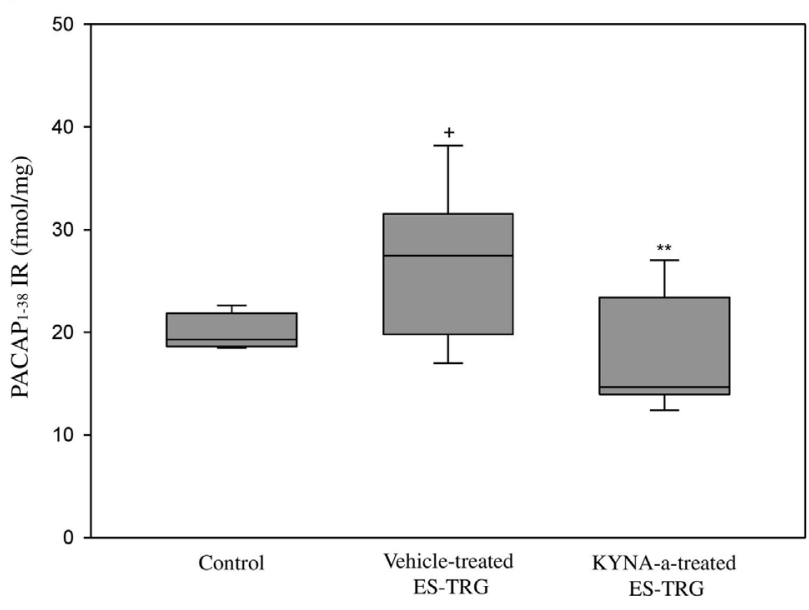

FIGURE 2 | Immunoreactivity of 38 amino acid form of PACAP (PACAP ${ }_{1-38}$ ) in the TNC following electrical stimulation of the trigeminal ganglion. ${ }^{+} p<0.001$ vs. Control group, ${ }^{* *} p<0.005$ vs. Vehicle-treated electrical stimulation of the TRG (ES-TRG) group. Black lines demonstrate medians.

Median \pm interquartile range $(n=7)$. 
The difference of relative optical density between the MK-801and the KYNA-a-treated groups was significant $(p<0.01)$. No significant differences were observed between the KYNA- and KYNA-a-treated groups. No differences were found with either the KYNA or MK-801-treated groups (Figures 3A,B).

\section{Electrical TRG-Stimulation-Induced Increased PACAP ${ }_{1-38}$ mRNA Expression in the TNC Is Prevented by KYNA-a, KYNA, and MK-801 Pretreatment}

A significant increase in the relative mRNA expression of PACAP $_{1-38}$ was observed in the vehicle-treated ES-TRG group (1.162) when compared with the non-stimulated control group (0.987; $p<0.05)$. The relative mRNA expression of PACAP P $_{1-38}$ in the ES-TRG groups pretreated with KYNA (0.804), KYNA-a (0.655; $p<0.01)$, or MK-801 (0.715) were significantly reduced compared with the vehicle-treated ES-TRG group $(p<0.001)$. Comparison of the different pharmacology-treated groups did not reveal any significant difference (Figure 4).

\section{DISCUSSION}

In recent years, a number of clinical studies investigated the possible relevance of PACAP in migraine. In patients suffering from migraines without aura, the development of PACAP ${ }_{1-38}$-evoked

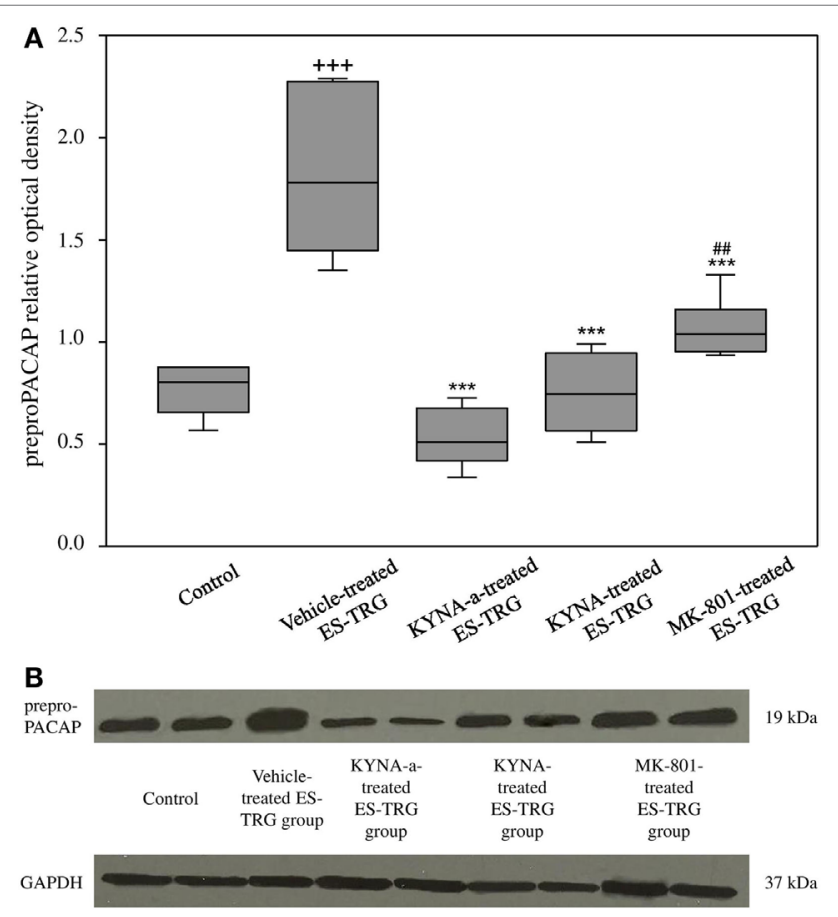

FIGURE 3 | (A) Relative optical density of the preproPACAP protein in the TNC following electrical stimulation of the trigeminal ganglion. ${ }^{+++} p<0.001$ vs. Control group. ${ }^{\star \star \star} p<0.001$ vs. Vehicle-treated electrical stimulation of the TRG (ES-TRG) group. \# $p<0.01$ vs. kynurenic acid synthetic analog (KYNA-a)-treated ES-TRG group. Black lines demonstrate medians. Median \pm interquartile range $(n=6)$. (B) Western blot of preproPACAP and glyceraldehyde 3-phosphate dehydrogenase (GAPDH) expression in the TNC. migraine-like attack was independent of the severity of family load (21). In the same study, 90 min after the injection, the levels of numerous markers relevant in the disease (such as vasoactive intestinal polypeptide, prolactin, $\mathrm{S} 100 \mathrm{~B}$, and thyroid-stimulating hormone) were increased in the plasma (22). In addition, magnetic resonance imaging angiography examinations revealed that PACAP $_{1-38}$-induced headache was associated with prolonged vasodilatation of the middle meningeal artery (MMA), but not the middle cerebral artery (MCA) (23). The serotonin 5-HT1B/D receptor agonist, sumatriptan, was able to alleviate the headache, which mirrored the contraction of the MMA, but not the MCA, suggesting that $\mathrm{PACAP}_{1-38}$-induced headaches may arise from the extracerebral arteries (23). These human and experimental data suggest that PACAP may be a key molecule in the pathomechanism of migraine.

Several lines of evidence reflect that abnormality of the kynurenine pathway plays roles in several diseases (24). Results of animal experiments suggest a link between the kynurenine pathway and migraine. Indeed, several studies have demonstrated that the NMDAR inhibitor KYNA and its analogs have antinociceptive effects at the levels of both first- and second -order sensory neurons (25). In the animal model of CFAinduced TS activation, KYNA and one of its derivatives both decreased the levels of several inflammatory mediators in the TRG (26). Recently, the effects of two KYNA analogs have been tested in the orofacial formalin model, revealing that the two analogs were able to inhibit the formalin-induced behavioral and morphological changes, and increased the concentration of KYNA in the rat TNC (27). Notably, systemic administration of NTG decreased the expression of kynurenine aminotransferase II in the TS of rats, an enzyme catalyzing the transformation of L-kynurenine to KYNA (28). In line with this, in another

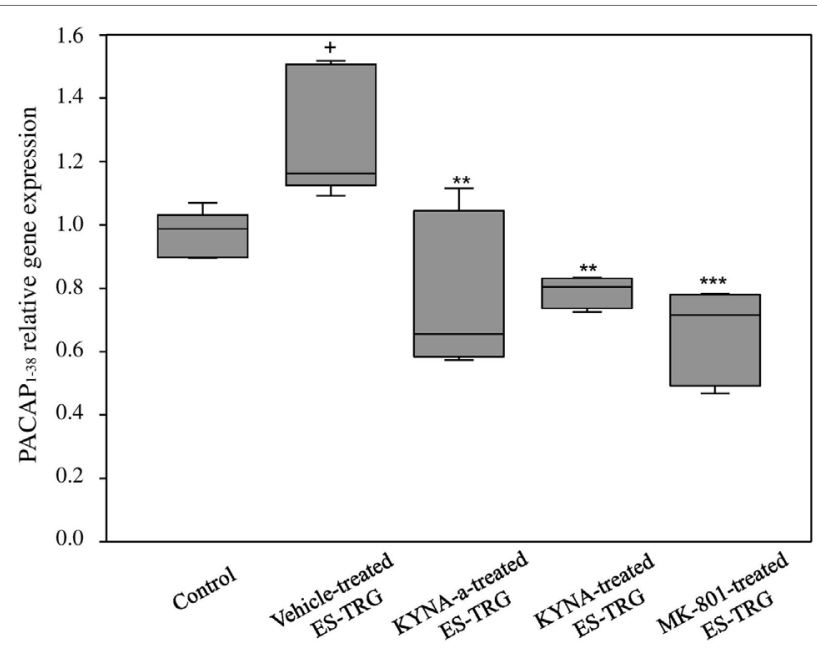

FIGURE 4 | Relative mRNA expression of 38 amino acid form of PACAP $\left(\mathrm{PACAP}_{1-38}\right)$ in the TNC following electrical stimulation of the trigeminal ganglion. ${ }^{+} p<0.05$ vs. Control group. ${ }^{* *} p<0.01$ vs. Vehicle-treated electrical stimulation of the TRG (ES-TRG) group. ${ }^{* \star *} p<0.001$ vs. Vehicle-treated ES-TRG group. Black lines demonstrate medians. Median \pm interquartile range $(n=5)$. 
model of TS activation, decreased KAT immunoreactivity was observed in mast cells, Schwann cells, and dural macrophages (29). Besides animal experimental data, clinical results have also provided evidence for the connection between the kynurenine system and various headache disorders, including migraine. Indeed, in patients suffering from cluster headache or chronic migraine, alterations of the kynurenine pathway were observed, which among others manifested in the reduction of KYNA concentration in the serum (30).

Based on the consistent data linking glutamatergic transmission (especially through NMDARs), the kynurenine pathway and PACAP to the pathogenesis of migraine, this is the first study that investigated the relationship between these systems. Findings that all proposed antagonists of the NMDAR were used here (KYNA, KYNA-a and the reference compound MK-801) decreased the expression of PACAP, both at the levels of proteome and transcriptome. One of innovation of this study, that KYNA-a can downregulate both protein and gene expression of preproPACAP and PACAP ${ }_{1-38}$, suggesting that KYNA-a is a potential new drug in the PACAP-targeted migraine therapy in the future. However, the excessive reduction of PACAP expression level should be considered. It is crucial and hard to find the optimal concentration of this peptide, because shifting in the PACAP balance can lead to several symptoms (protective vs. harmful effects) due to the pleiotropic nature of this peptide. To reveal the long-term effects of PACAP in the migraine is needs further investigations. Our results are consistent with previous studies, which reported that the main mediator of PACAP gene expression is intracellular calcium homeostasis (19). Indeed, besides the action of voltagedependent calcium channels, the main inducer of PACAP gene expression is calcium influx through the NMDARs. The drugs used in our experiment block the NMDAR, thereby moderating the amount of calcium coming into the cell, which may result in decreased PACAP gene expression. The proposed mechanism for the regulation of PACAP gene expression is presented in Figure 5. The other interesting observation of this study that the expression levels of preproPACAP are significantly different between the MK-801- and the KYNA-a-treated groups, raises the possibility of the involvement of additional KYNA targets besides NMDA. Our opinion is that the differences between the variant drug-treated groups are based on the receptor specificity of the molecules. There is evidence that besides NMDAR, KYNA has an effect on the AMPA, kainate, aryl hydrocarbon, G protein-coupled receptor 35, and opiate receptor (31). Regarding KYNA-a, investigations are in process, but the exact targets and mechanisms of this analog have not yet been identified. Presumably, KYNA-a has similar targets to the base compound. Our findings raise the role of these receptors in migraine and draw attention to the importance of further examinations (Figure 5).

In other studies, associations between these systems have also been revealed. Immunohistochemical data suggest a possible interaction between glutamatergic, PACAP, and CGRP systems, based on the expression pattern of PACAP and glutamate in the TRG (32). In addition, a study investigating contextual fear

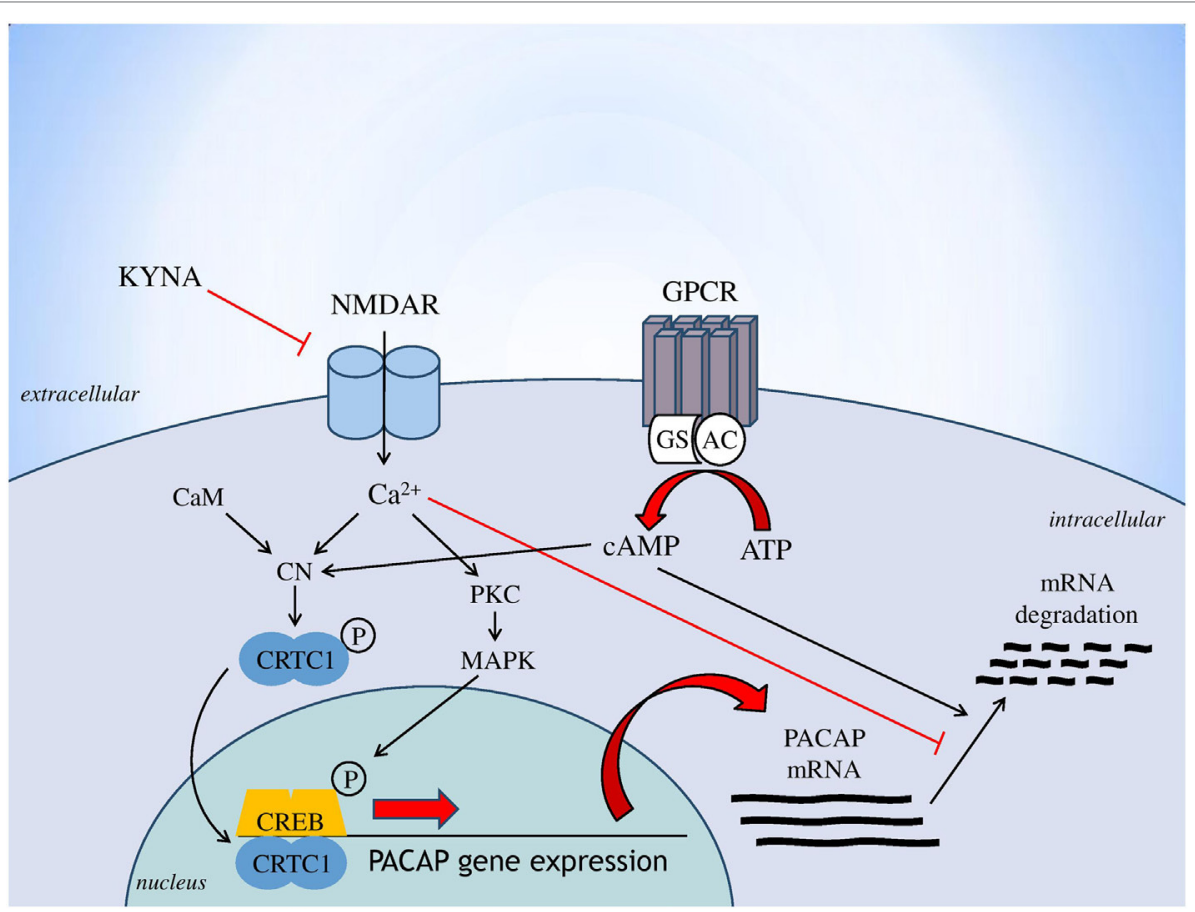

FIGURE 5 | Regulation of PACAP gene expression [based on Fukuchi et al. (19), genes to cells]. Abbreviations: AC, adenylate cylase; ATP, adenosine monophosphate; CaM, calmodulin; cAMP, cyclic adenosine monophosphate; CN, calcineurin; CREB, cAMP response element binding protein; CRTC1, CN/Cre binding protein; GPCR, G protein-coupled receptor; Gs, stimulatory G protein; KYNA, kynurenic acid; MAPK, mitogen-activated protein kinase; NMDAR, N-methylD-aspartate glutamate receptor; PKC, protein kinase C; PACAP, pituitary adenylate cyclase-activating polypeptide. 
conditioning in rats reported that PACAP participated in the consolidation and extinction via NMDARs (33).

Our results provided the direct evidence that NMDAR inhibition can prevent the overexpression of PACAP in an experimental model of migraine and support the idea that therapies aimed at the modulation of glutamatergic transmission, including the use of KYNA derivatives, may be of therapeutic value in migraine. These data contribute to the better understanding of migraine pathogenesis and thereby to the development of more efficient therapeutic approaches.

\section{ETHICS STATEMENT}

All experimental procedures performed in this study complied fully with the guidelines of Act 1998/XXVIII of the Hungarian Parliament on Animal Experiments (243/1988) and with the recommendations of the International Association for the Study of Pain and European Communities Council (86/609/ECC). The studies were in harmony with the Ethical Codex of Animal Experiments and were approved by the Ethics Committee of the Faculty of Medicine, University of Szeged, XXIV./352/2012.

\section{AUTHOR CONTRIBUTIONS}

TK: participated in the design and implementation of experiments, and statistical analysis, interpreted data and wrote the manuscript; BT: participated in the implementation of the experiments and statistical analysis; JT: participated in the conception and design of the experiments, the interpretation of the data, and writing; all the authors: critical revision of the manuscript; TB: participated in RIA measurements; FF: synthesized KYNA-a; ZH: participated in coordinating RIA measurements, in the final approval of the version to be published; LV: participated in the design of the experiments and in the final approval of the version to be published.

\section{ACKNOWLEDGMENTS}

This work was supported by the projects EUROHEADPAINFP7Health 2013-Innovation; Grant No. 602633; GINOP-2.3.2-152016-00034, KTIA_NAP_13-2014-0022, and GINOP-2.3.2-152016-00048. The authors are grateful to Jennifer Tusz for his valuable contribution in proofreading the manuscript.

\section{REFERENCES}

1. Ashina M, Hansen JM, Olesen J. Pearls and pitfalls in human pharmacological models of migraine: 30 years' experience. Cephalalgia (2013) 33(8):540-53. doi:10.1177/0333102412475234

2. Gormley P, Anttila V, Winsvold BS, Palta P, Esko T, Pers TH, et al. Metaanalysis of 375,000 individuals identifies 38 susceptibility loci for migraine. Nat Genet (2016) 48(8):856-66. doi:10.1038/ng.3598

3. Palkovits M, Somogyvari-Vigh A, Arimura A. Concentrations of pituitary adenylate cyclase activating polypeptide (PACAP) in human brain nuclei. Brain Res (1995) 699(1):116-20. doi:10.1016/0006-8993(95)00869-R

4. Pietrobon D, Moskowitz MA. Pathophysiology of migraine. Annu Rev Physiol (2013) 75:365-91. doi:10.1146/annurev-physiol-030212-183717

5. Tajti J, Uddman R, Edvinsson L. Neuropeptide localization in the "migraine generator" region of the human brainstem. Cephalalgia (2001) 21(2):96-101. doi:10.1046/j.1468-2982.2001.00140.x

6. Tajti J, Uddman R, Moller S, Sundler F, Edvinsson L. Messenger molecules and receptor mRNA in the human trigeminal ganglion. J Auton Nerv Syst (1999) 76(2-3):176-83. doi:10.1016/S0165-1838(99)00024-7

7. Tuka B, Helyes Z, Markovics A, Bagoly T, Szolcsanyi J, Szabo N, et al. Alterations in PACAP-38-like immunoreactivity in the plasma during ictal and interictal periods of migraine patients. Cephalalgia (2013) 33(13):1085-95. doi:10.1177/0333102413483931

8. Lassen LH, Haderslev PA, Jacobsen VB, Iversen HK, Sperling B, Olesen J. CGRP may play a causative role in migraine. Cephalalgia (2002) 22(1):54-61. doi:10.1046/j.1468-2982.2002.00310.x

9. Schytz HW, Birk S, Wienecke T, Kruuse C, Olesen J, Ashina M. PACAP38 induces migraine-like attacks in patients with migraine without aura. Brain (2009) 132(Pt 1):16-25. doi:10.1093/brain/awn307

10. Schytz HW, Olesen J, Ashina M. The PACAP receptor: a novel target for migraine treatment. Neurotherapeutics (2010) 7(2):191-6. doi:10.1016/j. nurt.2010.02.003

11. Vecsei L, Tuka B, Tajti J. Role of PACAP in migraine headaches. Brain (2014) 137(Pt 3):650-1. doi:10.1093/brain/awu014

12. Markovics A, Kormos V, Gaszner B, Lashgarara A, Szoke E, Sandor K, et al. Pituitary adenylate cyclase-activating polypeptide plays a key role in nitroglycerol-induced trigeminovascular activation in mice. Neurobiol Dis (2012) 45(1):633-44. doi:10.1016/j.nbd.2011.10.010

13. Tuka B, Helyes Z, Markovics A, Bagoly T, Nemeth J, Mark L, et al. Peripheral and central alterations of pituitary adenylate cyclase activating polypeptide-like

immunoreactivity in the rat in response to activation of the trigeminovascular system. Peptides (2012) 33(2):307-16. doi:10.1016/j.peptides.2011.12.019

14. Vecsei L, Szalardy L, Fulop F, Toldi J. Kynurenines in the CNS: recent advances and new questions. Nat Rev Drug Discov (2013) 12(1):64-82. doi:10.1038/ $\operatorname{nrd} 3793$

15. Fejes-Szabo A, Bohar Z, Vamos E, Nagy-Grocz G, Tar L, Veres G, et al. Pre-treatment with new kynurenic acid amide dose-dependently prevents the nitroglycerine-induced neuronal activation and sensitization in cervical part of trigemino-cervical complex. J Neural Transm (Vienna) (2014) 121(7):725-38. doi:10.1007/s00702-013-1146-2

16. Knyihar-Csillik E, Mihaly A, Krisztin-Peva B, Robotka H, Szatmari I, Fulop F, et al. The kynurenate analog SZR-72 prevents the nitroglycerol-induced increase of c-fos immunoreactivity in the rat caudal trigeminal nucleus: comparative studies of the effects of SZR-72 and kynurenic acid. Neurosci Res (2008) 61(4):429-32. doi:10.1016/j.neures.2008.04.009

17. VamosE, Fejes A, Koch J, TajtiJ, Fulop F, Toldi J, etal.Kynurenatederivative attenuates the nitroglycerin-induced CamKIIalpha and CGRP expression changes. Headache (2010) 50(5):834-43. doi:10.1111/j.1526-4610.2009.01574.x

18. Lukacs M, Warfvinge K, Kruse LS, Tajti J, Fulop F, Toldi J, et al. KYNA analogue SZR72 modifies CFA-induced dural inflammation-regarding expression of pERK1/2 and IL-1beta in the rat trigeminal ganglion. J Headache Pain (2016) 17(1):64. doi:10.1186/s10194-016-0654-5

19. Fukuchi M, Kuwana Y, Tabuchi A, Tsuda M. Balance between cAMP and $\mathrm{Ca}(2+)$ signals regulates expression levels of pituitary adenylate cyclase-activating polypeptide gene in neurons. Genes Cells (2016) 21(8):921-9. doi:10.1111/gtc. 12393

20. Mabuchi T, Shintani N, Matsumura S, Okuda-Ashitaka E, Hashimoto H, Muratani T, et al. Pituitary adenylate cyclase-activating polypeptide is required for the development of spinal sensitization and induction of neuropathic pain. J Neurosci (2004) 24(33):7283-91. doi:10.1523/JNEUROSCI.0983-04.2004

21. Guo S, Vollesen AL, Hansen RD, Esserlind AL, Amin FM, Christensen AF, et al. Part I: pituitary adenylate cyclase-activating polypeptide- 38 induced migraine-like attacks in patients with and without familial aggregation of migraine. Cephalalgia (2017) 37(2):125-35. doi:10.1177/0333102416639516

22. Guo S, Vollesen AL, Hansen YB, Frandsen E, Andersen MR, Amin FM, et al. Part II: biochemical changes after pituitary adenylate cyclase-activating polypeptide-38 infusion in migraine patients. Cephalalgia (2017) 37(2):136-47. doi:10.1177/0333102416639517

23. Amin FM, Asghar MS, Guo S, Hougaard A, Hansen AE, Schytz HW, et al. Headache and prolonged dilatation of the middle meningeal artery 
by PACAP38 in healthy volunteers. Cephalalgia (2012) 32(2):140-9. doi:10.1177/0333102411431333

24. Lovelace MD, Varney B, Sundaram G, Lennon MJ, Lim CK, Jacobs K, et al. Recent evidence for an expanded role of the kynurenine pathway of tryptophan metabolism in neurological diseases. Neuropharmacology (2017) 112(Pt B):373-88. doi:10.1016/j.neuropharm.2016.03.024

25. Pardutz A, Fejes A, Bohar Z, Tar L, Toldi J, Vecsei L. Kynurenines and headache. J Neural Transm (Vienna) (2012) 119(2):285-96. doi:10.1007/ s00702-011-0665-y

26. Csati A, Edvinsson L, Vecsei L, Toldi J, Fulop F, Tajti J, et al. Kynurenic acid modulates experimentally induced inflammation in the trigeminal ganglion. J Headache Pain (2015) 16:99. doi:10.1186/s10194-015-0581-x

27. Veres G, Fejes-Szabo A, Zadori D, Nagy-Grocz G, Laszlo AM, Bajtai A, et al. A comparative assessment of two kynurenic acid analogs in the formalin model of trigeminal activation: a behavioral, immunohistochemical and pharmacokinetic study. J Neural Transm (Vienna) (2017) 124(1):99-112. doi:10.1007/ s00702-016-1615-5

28. Nagy-Grocz G, Tar L, Bohar Z, Fejes-Szabo A, Laborc KF, Spekker E, et al. The modulatory effect of anandamide on nitroglycerin-induced sensitization in the trigeminal system of the rat. Cephalalgia (2016) 36(9):849-61. doi:10.1177/0333102415613766

29. Knyihar-Csillik E, Chadaide Z, Okuno E, Krisztin-Peva B, Toldi J, Varga C, et al. Kynurenine aminotransferase in the supratentorial dura mater of the rat: effect of stimulation of the trigeminal ganglion. Exp Neurol (2004) 186(2):242-7. doi:10.1016/j.expneurol.2003.12.001
30. Curto M, Lionetto L, Negro A, Capi M, Fazio F, Giamberardino MA, et al. Altered kynurenine pathway metabolites in serum of chronic migraine patients. J Headache Pain (2015) 17:47. doi:10.1186/s10194-016-0638-5

31. Dezsi L, Tuka B, Martos D, Vecsei L. Alzheimer's disease, astrocytes and kynurenines. Curr Alzheimer Res (2015) 12(5):462-80. doi:10.2174/1567205 01205150526114000

32. Eftekhari S, Salvatore CA, Johansson S, Chen TB, Zeng Z, Edvinsson L. Localization of CGRP, CGRP receptor, PACAP and glutamate in trigeminal ganglion. Relation to the blood-brain barrier. Brain Res (2015) 1600:93-109. doi:10.1016/j.brainres.2014.11.031

33. Schmidt SD, Myskiw JC, Furini CR, Schmidt BE, Cavalcante LE, Izquierdo I. PACAP modulates the consolidation and extinction of the contextual fear conditioning through NMDA receptors. Neurobiol Learn Mem (2015) 118:120-4. doi:10.1016/j.nlm.2014.11.014

Conflict of Interest Statement: The authors declare that the research was conducted in the absence of any commercial or financial relationships that could be construed as a potential conflict of interest.

Copyright (c) 2018 Körtési, Tuka, Tajti, Bagoly, Fülöp, Helyes and Vécsei. This is an open-access article distributed under the terms of the Creative Commons Attribution License (CC BY). The use, distribution or reproduction in other forums is permitted, provided the original author(s) or licensor are credited and that the original publication in this journal is cited, in accordance with accepted academic practice. No use, distribution or reproduction is permitted which does not comply with these terms. 
II.

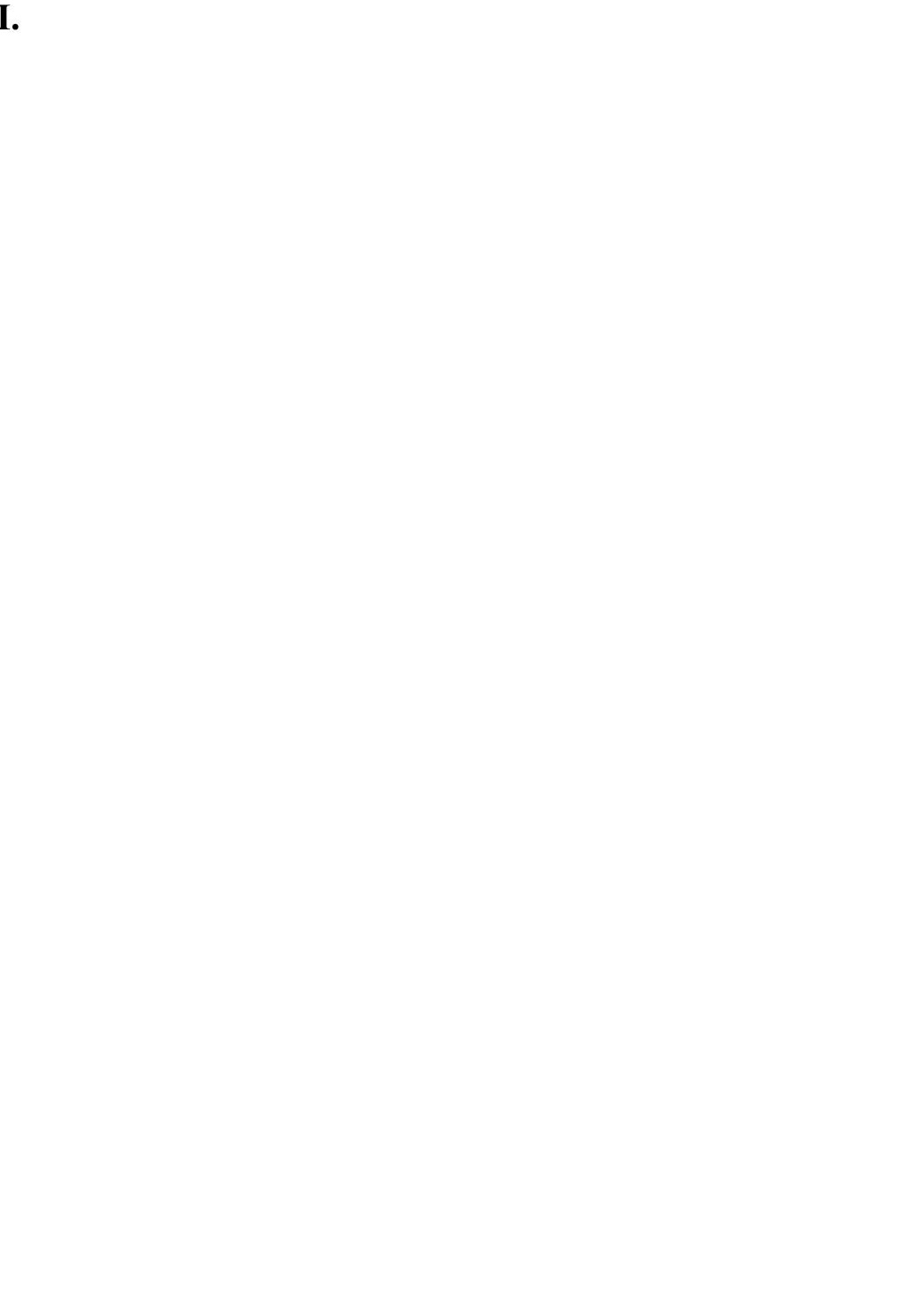




\title{
The effect of orofacial complete Freund's adjuvant treatment on the expression of migraine-related molecules
}

\author{
Tamás Körtési ${ }^{1}$, Bernadett Tuka², Aliz Nyári, László Vécsei²,3 and János Tajti
}

\begin{abstract}
Background: Migraine is a neurovascular primary headache disorder, which causes significant socioeconomic problems worldwide. The pathomechanism of disease is enigmatic, but activation of the trigeminovascular system (TS) appears to be essential during the attack. Migraine research of recent years has focused on neuropeptides, such as calcitonin generelated peptide (CGRP) and pituitary adenylate cyclase-activating polypeptide 1-38 (PACAP1-38) as potential pathogenic factors and possible therapeutic offensives. The goal of present study was to investigate the simultaneous expression of CGRP and precursor of PACAP1-38 (preproPACAP) in the central region of the TS in a time-dependent manner following TS activation in rats.
\end{abstract}

Methods: The right whisker pad of rats was injected with $50 \mu$ l Complete Freund's Adjuvant (CFA) or saline. A mechanical allodynia test was performed with von Frey filaments before and after treatment. Transcardial perfusion of the animals was initiated 24, 48, 72 and $120 \mathrm{~h}$ after injection, followed by the dissection of the nucleus trigeminus caudalis (TNC). After preparation, the samples were stored at $-80^{\circ} \mathrm{C}$ until further use. The relative optical density of CGRP and preproPACAP was analyzed by Western blot. One-way ANOVA and Kruskal-Wallis followed by Tukey post hoc test were used to evaluate the data. Regression analysis was applied to explore the correlation between neuropeptides expression and hyperalgesia.

Results: Orofacial CFA injection resulted in significant CGRP and preproPACAP release in the TNC 24, 48, 72 and $120 \mathrm{~h}$ after the treatment. The level of neuropeptides reached its maximum at $72 \mathrm{~h}$ after CFA injection, corresponding to the peak of facial allodynia. Negative, linear correlation was detected between the expression level of neuropeptides and value of mechanonociceptive threshold.

Conclusion: This is the first study which suggests that the expression of CGRP and preproPACAP simultaneously increases in the central region of activated TS and it influences the formation of mechanical hyperalgesia. Our results contribute to a better understanding of migraine pathogenesis and thereby to the development of more effective therapeutic approaches.

Keywords: Migraine, Trigeminovascular system, CFA, CGRP, preproPACAP

\footnotetext{
* Correspondence: tajti.janos@med.u-szeged.hu

'Department of Neurology, Faculty of Medicine, Albert Szent-Györgyi Clinical

Center University of Szeged, Semmelweis u. 6, Szeged H-6725, Hungary

Full list of author information is available at the end of the article
}

(c) The Author(s). 2019 Open Access This article is distributed under the terms of the Creative Commons Attribution 4.0 International License (http://creativecommons.org/licenses/by/4.0/), which permits unrestricted use, distribution, and reproduction in any medium, provided you give appropriate credit to the original author(s) and the source, provide a link to the Creative Commons license, and indicate if changes were made. 


\section{Background}

Recently, two peptides of key molecules have been highlighted for their involvement in the pathomechanism of primary headache disorders: calcitonin gene-related peptide (CGRP), as an "old warrior" and pituitary adenylate cyclase-activating polypeptide 1-38 (PACAP1-38), which is a newer, potential target for headache therapies. These peptides are very similar in features and functions: e.g. they are potent vasodilators, they are present in both the peripheral and central nervous system and they can function in the transmission of nociception and neurogenic inflammation. Subsequently, they have gained ground in the therapeutic developments in migraine. In 2004, the first CGRP receptor antagonists (gepants) effectively terminated migraine in humans, but nowadays several other anti-CGRP treatments are in clinical trials or are under development (anti-CGRP and anti-CGRP receptor monoclonal antibodies) for the prevention of migraine [1]. PACAP1-38 also has pivotal role in migraine, as indicated by several preclinical [2-4] and clinical [5-9] examinations, but there are fewer confirmed results targeted on the PACAP1-38 antibody therapies [10]. The analogous behaviour of these peptides presents the possibility that anti-PACAP1-38 treatments could provide a therapeutic advantage for migraineurs who do not respond the anti-CGRP therapies.

Thus it is interesting to investigate the simultaneous release of CGRP and precursor of PACAP1-38 (preproPACAP) in a migraine-related environment. In our case, the orofacial Complete Freund's Adjuvant (CFA) rat model was selected to determine these alterations. CFA has been used for animal modelling of autoimmune and inflammatory illnesses for nearly 50 years and it is an accepted model of orofacial inflammatory hyperalgesia [11-16].

The precise mode of action of CFA is not known, but it primarily triggers an inflammatory reaction through the activation of the cellular immune response [11]. The CFA-induced chemical stimulation of the orofacial area can activate the extra- and intracranial trigeminal primary afferents, which provide the sensory innervation of the face and oral cavity, as well as the vasculature-associated meningeal nociceptive afferents. The cell bodies of these peripheral fibres are located in the trigeminal ganglion (TRG), while the central projections of these neurons terminate in the trigeminal nucleus caudalis (TNC). Sensitisation of the peripheral fibres and the second order nociceptive neurons in the TNC can contribute to the phenomenon of facial allodynia developing in primary headache disorders [17]. Perception of pain can be connected to the thalamic third order neurons [18-22].

This commonly used peripheral inflammation model can integrate those mechanisms which are involved in migraine, because several primary headache diseases associated with inflammation of extracranial structures, such as the temporomandibular joint (TMJ) or the sinuses, can be evoked by similar mechanisms to those mentioned above [16, 23, 24]. Comorbidity was also observed between migraine and TMJ disorders [25], therefore orofacial inflammation induced by CFA might be suitable to generate hyperalgesia/allodynia on the face by the activation/sensitization of the trigeminovascular system (TS), namely to mimic the features of migraine [12].

In the course of our research we aimed to model allodynia-associated activated TS using CFA in rats. We used von Frey filaments to assess nociceptive sensitization and measure the temporal changes in facial mechano-nociceptive threshold after periods of $24,48,72$, and $120 \mathrm{~h}$ following CFA injection. In order to estimate the release of neuropeptides in the TNC in the assessed time periods following CFA injection, Western blot assay was used with specific preproPACAP and CGRP antibodies.

This the first study which evaluated the presence of preproPACAP and CGRP together in the TNC and correlated the behavioural changes following facial inflammation. These investigations might provide better insight into the background of trigeminal pain disorders.

\section{Materials and methods \\ Animals}

Thirty young adult (10-12 weeks old) male Sprague-Dawley rats were used for the experiments. The animals were bred and maintained under standard laboratory conditions with a 12-12-h light/dark cycle at $24 \pm 1{ }^{\circ} \mathrm{C}$ and approx. $50 \%$ relative humidity in the Laboratory Animal House of the Department of Neurology. The rats had free access to standard rat chow and water.

\section{Ethics}

All experimental procedures performed in this study complied fully with the guidelines of Act 1998/XXVIII of the Hungarian Parliament on Animal Experiments (243/1988) and with the recommendations of the International Association for the Study of Pain and European Communities Council (86/609/ECC). The studies were in harmony with the Ethical Codex of Animal Experiments and were approved by the Ethics Committee of the Faculty of Medicine, University of Szeged, XI./1102/2018.

\section{Drugs}

Complete Freund's Adjuvant (killed mycobacteria suspended in paraffin oil; $1 \mathrm{mg} / \mathrm{ml}$ ) was obtained from Sigma-Aldrich Corporation (St. Louis, MO, USA), and $50 \mu \mathrm{l}$ was administered per animal.

\section{Orofacial pain sensitivity tested with von Frey filaments}

In this experiment mechanical pain thresholds of the orofacial region were determined with von Frey filaments. Tests were performed before (0) and at 24, 48, 
72, $120 \mathrm{~h}$ after CFA/saline injection. Animals were lightly restrained using a soft cotton glove in order to allow an easier habituation, then a set of calibrated nylon monofilaments (SENSElab - AESTHESIOMETER, SOMEDIC Sales AB, Box 194, 24231 Hörby) was used with increasing strengths (0.39-8.3 g) to measure facial mechanosensitivity. Filaments were applied in ascending order, starting from the $3.3 \mathrm{~g}$ filament during control measurements and the $0.39 \mathrm{~g}$ filament after CFA treatment. The mechanonociceptive threshold was defined as the lowest force evoking at least two withdrawal responses (face stroking with the forepaw or head shaking) out of five stimulations [12].

\section{Experimental protocol}

In our experiment five animal groups were created: 1 control group and 4 groups with CFA treatment. The groups and treatments are presented in Table 1.

First, the rats were anesthetized with intraperitoneal $4 \%$ chloral hydrate solution $(10 \mathrm{ml} / \mathrm{kg}$ bw dose $)$ and the anesthesia was maintained throughout the experiment. Next, $50 \mu \mathrm{l}$ of CFA was injected into the right whisker pad. Control rats were injected with an equal volume of saline. The von Frey allodynia test was performed before and after treatment, as described above. Transcardial perfusion of the animals with $200 \mathrm{ml}$ phosphate-buffered saline (PBS) was initiated 24, 48, 72 and $120 \mathrm{~h}$ after injection. The medullary segment containing TNC (between rostral $1 \mathrm{~mm}$ and caudal $5 \mathrm{~mm}$ from the obex) was removed. After preparation, the samples were stored at $-80^{\circ} \mathrm{C}$ until further use. The relative optical density of CGRP and preproPACAP was analyzed by Western blot.

\section{Protein quantification by Western blot analysis}

The samples were sonicated in ice-cold buffer containing $50 \mathrm{mM}$ Tris- $\mathrm{HCl}, 150 \mathrm{mM} \mathrm{NaCl}, 0.1 \%$ Igepal. $0.1 \%$ cholic acid, $2 \mathrm{mg} / \mathrm{ml}$ leupeptin, $2 \mathrm{mM}$ phenylmethylsulphonyl fluoride, $1 \mathrm{mg} / \mathrm{ml}$ pepstatin, $2 \mathrm{mM}$ ethylenediaminetetraacetic acid (EDTA), and $0.1 \%$ sodium dodecyl sulfate (SDS). After homogenization, the samples were centrifuged at $12.000 \mathrm{rpm}$ for $10 \mathrm{~min}$ at $4{ }^{\circ} \mathrm{C}$, and supernatants were aliquoted and stored at $20^{\circ} \mathrm{C}$ until use. The protein concentration was determined by the BCA Protein Assay Kit using BSA as the standard. Prior to protein separation, each sample was mixed with the sample buffer, and denatured by boiling for $5 \mathrm{~min}$. Equal amounts of protein samples $(20$ $\mathrm{mg} / \mathrm{lane}$ ) were separated by standard SDS polyacrylamide gel electrophoresis on 10\% Tris-Glycine gel and electrotransferred onto an AmershamHybond-ECL nitrocellulose membrane $(0.45-\mathrm{mm}$ pore size). We used the Page Ruler Prestained Protein Ladder $(10-170 \mathrm{kDa})$ to define approximate molecular weights. Following blotting, the membranes were blocked for $1 \mathrm{~h}$ at room temperature in Tris-buffered saline containing Tween 20 (TBST) and 5\% nonfat dry milk powder. Subsequently, the membranes were incubated in TBST containing $1 \%$ nonfat dry milk and anti-PACAP antibody (against the $\mathrm{C}$ terminal; ab174982, dilution: 1:500, incubation parameters: overnight, $4{ }^{\circ} \mathrm{C}$ ) or anti-CGRP antibody (Sigma-Aldrich-c8198, dilution: 1:2000, incubation parameters: overnight, room temperature), anti-glyceraldehyde 3-phosphate dehydrogenase (GAPDH) antibody (D16H11, dilution: 1:1000, incubation parameters: overnight, room temperature). The following day, the membranes were incubated in TBST containing $1 \%$ nonfat dry milk powder and horseradish peroxidase-conjugated goat anti-rabbit secondary antibody (sc-2030, Santa Cruz Biotechnology) for $2 \mathrm{~h}$ at room temperature. The protein bands were revealed with Syngene PXi 6 Access Touch Gel Documentation System.

\section{Statistical analysis}

The Shapiro-Wilk test was used to determine the distribution of data. Data of the Western blot analysis followed a normal distribution, so after the One-way ANOVA test we used the Tukey's post hoc test to analyze the results. The data from the von Frey allodynia test did not show a normal distribution, therefore we used the Kruskal-Wallis test with Tukey's post hoc test. A probability level of $p<0.05$ was considered significant. Mean \pm SD are represented in the diagrams. Regression analyses were performed between the levels of neuropeptides and the value of hyperalgesia with SPSS 20.0 Software.

\section{Results \\ Orofacial CFA treatment resulted in significant preproPACAP increase in the TNC}

A significant increase in the relative optical density of preproPACAP was observed 24 (0.58), 48 (0.69), 72 (1.01) and $120(0.85)$ hours after CFA treatment compared to the control group (0.49). The highest preproPACAP concentration was measured $72 \mathrm{~h}$ after the CFA treatment. The difference between the $72 \mathrm{~h}$ and $120 \mathrm{~h}$ groups was significant, therefore we did not feel it necessary to include other group investigations (Figs. 1 and 2).

Table 1 Experimental groups

\begin{tabular}{|c|c|c|c|c|c|}
\hline Group & $\begin{array}{l}\text { Control } \\
(n=6)\end{array}$ & $\begin{array}{l}\text { CFA } 1 \\
(n=6)\end{array}$ & $\begin{array}{l}\text { CFA } 2 \\
(n=6)\end{array}$ & $\begin{array}{l}\text { CFA } 3 \\
(n=6)\end{array}$ & $\begin{array}{l}\text { CFA } 4 \\
(n=6)\end{array}$ \\
\hline Orofacial treatment & $50 \mu$ l saline & $50 \mu \mathrm{l} \mathrm{CFA}$ & $50 \mu \mathrm{l} C F A$ & $50 \mu \mathrm{lCFA}$ & $50 \mu \mathrm{l} \mathrm{CFA}$ \\
\hline Perfusion and dissection & $24 \mathrm{~h}$ after treatment & $24 \mathrm{~h}$ after treatment & $48 \mathrm{~h}$ after treatment & $72 \mathrm{~h}$ after treatment & $120 \mathrm{~h}$ after treatment \\
\hline
\end{tabular}




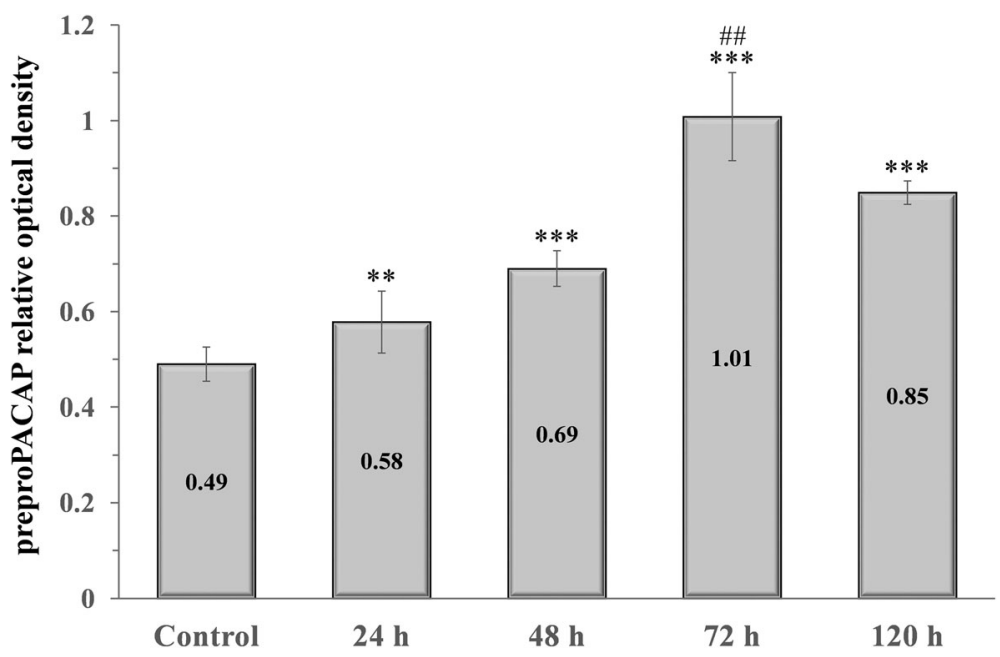

Fig. 1 Relative optical density of the preproPACAP protein in the TNC following orofacial CFA treatment. ${ }^{* *} p<0.001$ vs. Control group, ${ }^{* *} p<0.01$ vs. Control group, \#\# $p<0.01$ vs. 120 h group, Mean $\pm S D, n=6$

Orofacial CFA treatment significantly elevated CGRP relative optical density in the TNC

CGRP expression in the TNC was elevated 24 (0.99), 48 (1.26), 72 (2.36) and 120 (2.1) hours after CFA injection compared to the control group (0.73). The highest CGRP concentration was detected $72 \mathrm{~h}$ after CFA treatment. The difference was significant between the $72-\mathrm{h}$ and 120-h groups, therefore we did not feel it was necessary to include other group investigations (Figs. 3 and 4).

\section{Orofacial CFA injection decreased the mechanonociceptive threshold}

The facial mechanonociceptive threshold decreased significantly compared to the contralateral side 48, 72 and $120 \mathrm{~h}$ after CFA treatment. Compared to the control measurement (7.77), the threshold was reduced significantly 24 (6.64), 48 (4.1), 72 (2.1) and 120 (2.77) hours after CFA treatment. Allodynia reached its maximum at $72 \mathrm{~h}$, as the threshold change was lower by $120 \mathrm{~h}$. We did not find significant differences in the threshold of the contralateral whisker pad area (Fig. 5).

\section{Correlation between neuropeptides expression and mechanical hyperalgesia}

Reverse relationship was observed between the concentrations of neuropeptides and the value of the evoked mechanical threshold (CFA treated whisker pad) depending on the time. All data of the saline treated control group and the CFA treated groups were involved in the statistical probe. Regression analyses have revealed that negative, linear correlation is found between the expression levels of preproPACAP or CGRP and the levels of hyperalgesia. Then data were mixed with bootstrap analyses $(1000 \mathrm{x})$, which resulted in the following values: $n=30, \mathrm{p}_{\text {CGRP }}<0.001, \mathrm{R}_{\mathrm{CGRP}}=-0.846 ; n=30, \mathrm{p}_{\text {preproPA }}$ CAP $<0.001, R_{\text {preproPACAP }}=-0.792$ (Fig. 6).

\section{Discussion}

Migraine research in recent years has focused on neuropeptides as potential pathogenic factors and possible therapeutic alternatives. Neuropeptides such as hemokinin A, neurotensin, substance P (SP), CGRP and PACAP1-38 can activate mast cells, leading to the secretion of

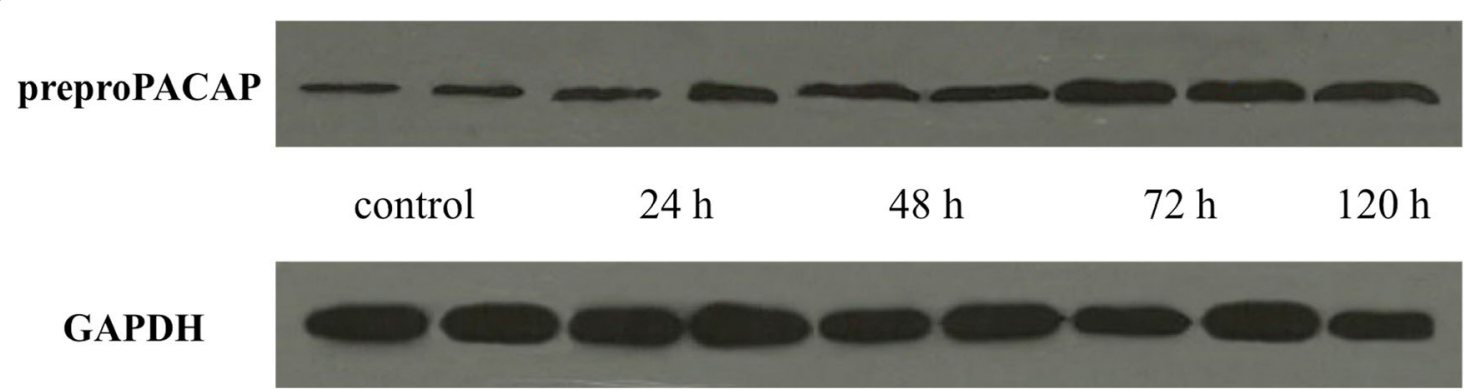

$19 \mathrm{kDa}$

Fig. 2 Western blot of preproPACAP and GAPDH expression in the TNC 


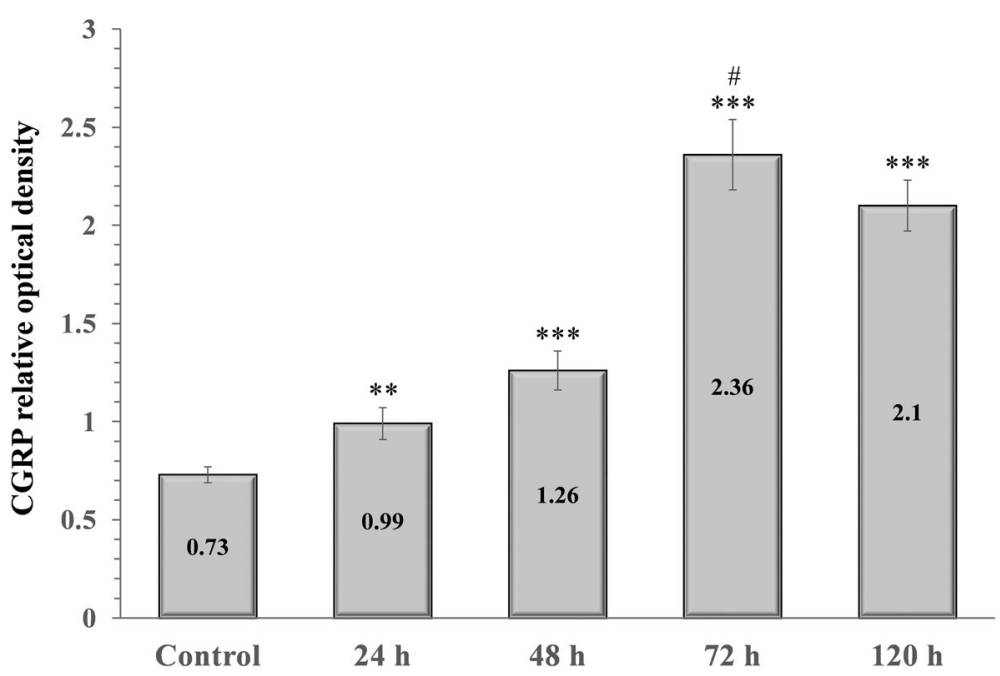

Fig. 3 Relative optical density of the CGRP protein in the TNC following orofacial CFA treatment. ${ }^{* *} p<0.001$ vs. Control group, ${ }^{* *} p<0.01$ vs. Control group, \# $p<0.05$ vs. $120 \mathrm{~h}$ group, Mean \pm SD, $n=6$

vasoactive, proinflammatory and neuro-sensitizing mediators, thereby contributing to the activation of TS [26, 27].

The aim of the present study was to investigate the simultaneous expression of CGRP and preproPACAP in the central region of the TS in a time-dependent manner following orofacial CFA treatment. Orofacial CFA injection evokes significant CGRP and preproPACAP increase in the TNC $24 \mathrm{~h}$ after treatment. The neuropeptide levels reach a maximum at $72 \mathrm{~h}$ after CFA injection, corresponding to the peak of facial allodynia.

Our opinion is that the CFA-induced inflammation can evoke continuous and long-term neuropeptide release in the TNC, which is accompanied by manifestation of mechanical hyperalgesia. It is assumed that the CFA can maintain this effect until $72 \mathrm{~h}$, then both the preproPACAP and CGRP level start to decrease in the absence of stimulus, which causes the relief of allodynia. Our presumption is supported by a recent study, where the repetitive electrical stimulation of dura mater induced elevation in the expression level of CGRP and
PACAP in the TRG and TNC in rat depending on the stimulation periods (1, 3 and 7 days). It suggests that the number of stimulations can influence the release and effects of neuropeptides [28]. Our results are consistent with a previous study, where the orofacial CFA injection provoked increased CGRP expression in the TNC, which elevation reached its maximum 3 days after CFA treatment [12]. In another study, activated microglial cells were detected in the ipsilateral TNC and in the cervical dorsal horn $72 \mathrm{~h}$ after orofacial CFA treatment of rats [29]. In this context, the activated microglial cells might also be involved to the mechanism of central sensitization and nociception [30-32]. It is proved that an antagonist of P2X4 microglia receptor blocked the NTG-induced c-Fos and CGRP release in the TNC, subsequently the hyperalgesia [33]. Results of our functional test showed that orofacial CFA injection can already cause a significant increase in mechanical allodynia $24 \mathrm{~h}$ after treatment. Allodynia reached its maximum on day 3 , as the threshold change was lower by day 5 . These

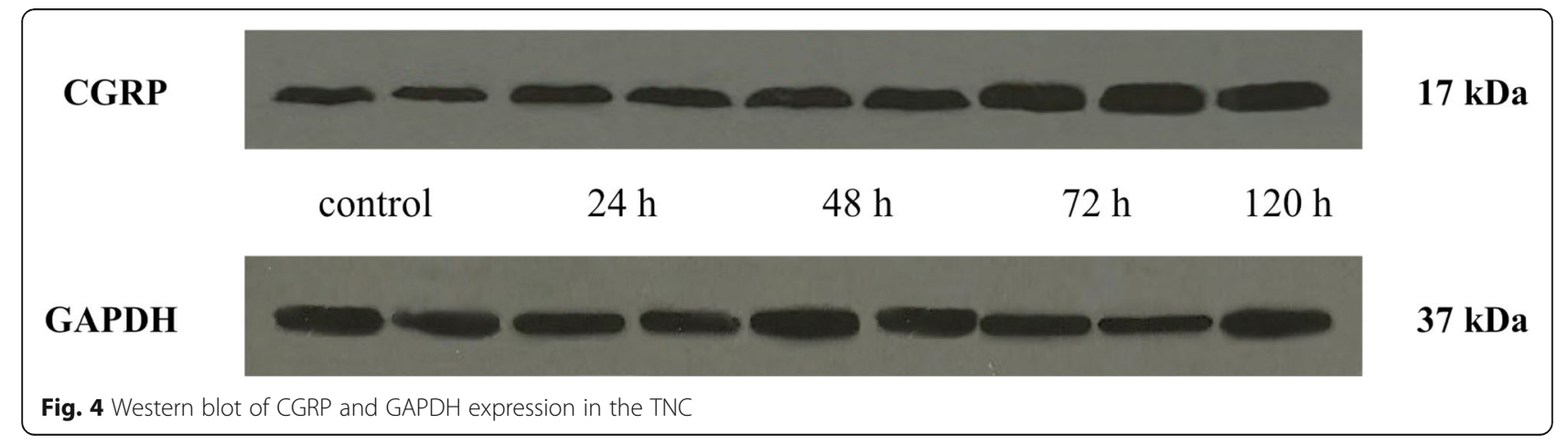




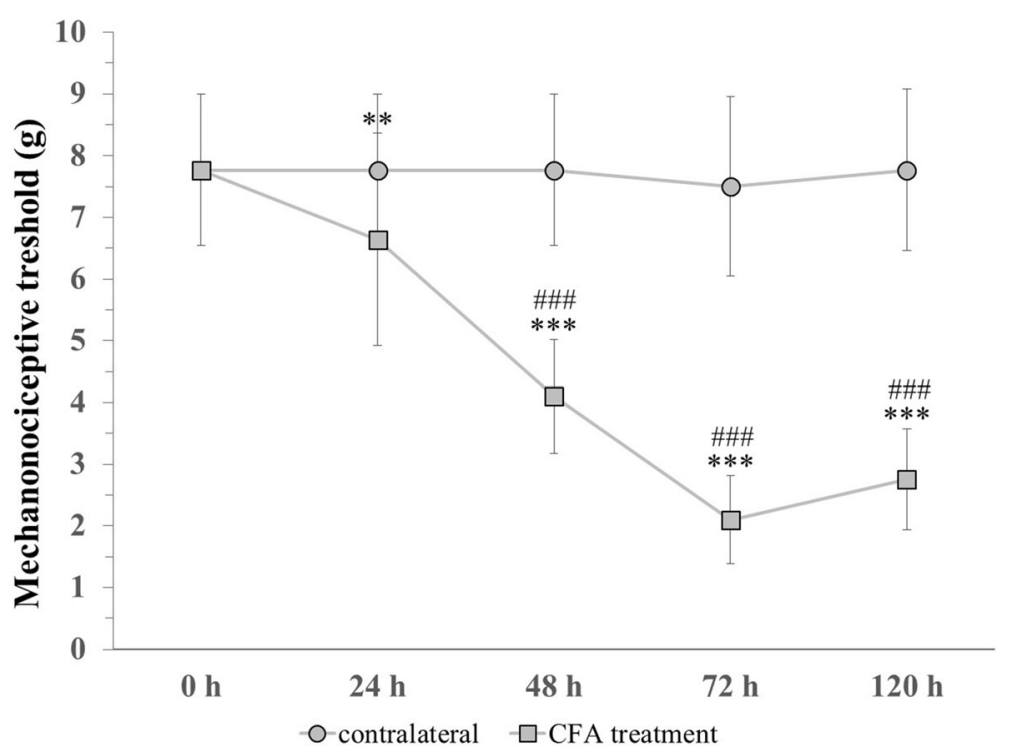

Fig. 5 Changes in mechanical theshold before (0) and 24, 48, 72, $120 \mathrm{~h}$ after CFA treatment. ${ }^{* * *} p<0.001$ vs. Control measurement (0 h) in CFA treatment group, ${ }^{* *} p<0.01$ vs. Control measurement ( 0 h) in CFA treatment group, \#\#\# $p<0.001$ vs. contralateral side. Mean $\pm S D, n=6-24$

results are consistent with observations from animal investigations where the CFA induced chronic pain-like behaviour 3 days after treatment [12, 14, 34]. Additionally, it was also demonstrated that chronic stimulation of dura mater can elicit facial cutaneous allodynia during the migraine chronification, via CGRP and PACAP elevation. One of the potential mechanisms, which can mediate the effect of PACAP is that its autoreceptor (PAC1) can influence the G-protein-coupled downstream effects via regulating the pre- and postsynaptic events [28]. Nevertheless, the moderating functional alterations might also be explained by the desensitization of receptors, but further investigations are needed to answer this hypothesis.
Another important result of present study is that the alterations of CGRP and preproPACAP expression show correlation with change of mechanical threshold. Several studies have proved to the key role of CGRP and PACAP1-38 mediators of neurogenic inflammation and modulators of pain inputs $[2,35,36]$. The release of these neuropeptides in the central nervous system facilitate nociceptive signalling and in the periphery contribute to vasodilatation of meningeal vessels and neurogenic inflammation [37]. Based on our results probable that the CFA-induced CGRP and PACAP1-38 increase play crucial role in triggering central sensitization, thereby regulation of these peptides may influence the rate of mechanical hyperalgesia [38].
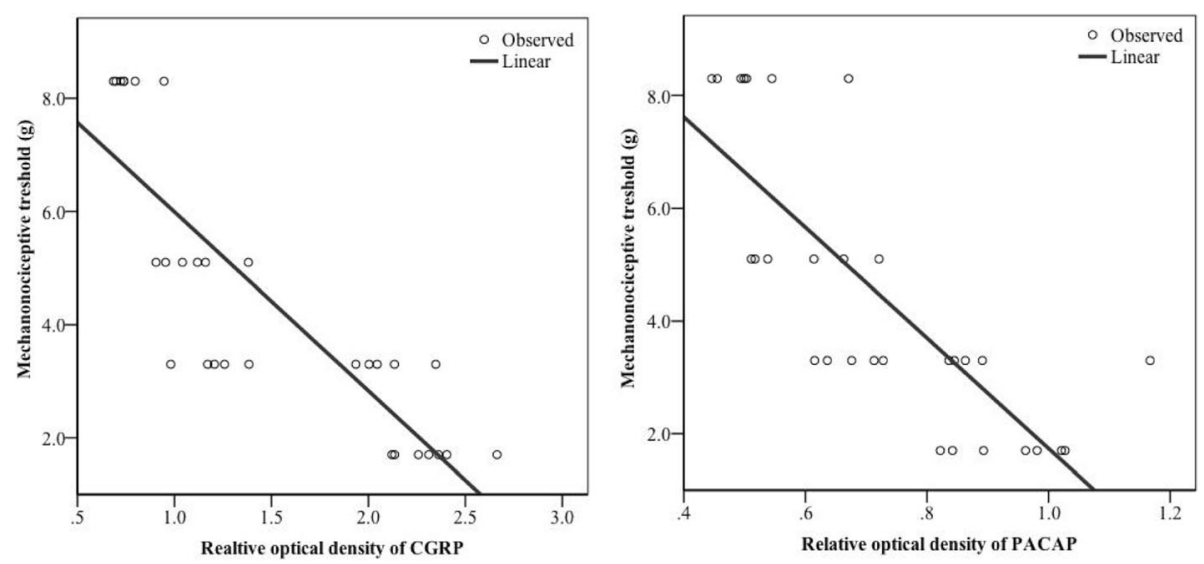

Fig. 6 Negative, linear correlation between expression levels of neuropeptides and mechanonociceptive threshold 
Role of neuropeptides in preclinical migraine models A classical study confirmed that the concentration of CGRP and SP were increased during electrical stimulation of TRG (ES-TRG) of the external jugular vein of cats [39]. A former study suggests that ES-TRG resulted in significantly elevated PACAP1-38 immunoreactivity $180 \mathrm{~min}$ after ES-TRG of the plasma and PACAP1-38 and PACAP1-27 immunoreactivity in the TNC. Besides ES-TRG, the intraperitoneal administration of nitroglycerin (NTG) also induced an increase in PACAP1-38 and PACAP1-27 expression $3 \mathrm{~h}$ after the treatment in the TNC [3]. A study showed that PACAP1-38 administration can result in increased CGRP expression in the TNC, which points to a potential connection between release of CGRP and PACAP1-38 [40]. Co-expression of CGRP and PACAP138 was investigated: $23 \%$ of the neurons expressed both CGRP and PACAP1-38 in rat TRG, and CGRP (49\%) was expressed in more neuronal somas compared to PACAP138 (29\%) [41]. In a preclinical model of migraine, the simultaneous release of CGRP and PACAP was detected: a chronic NTG treatment caused increased concentrations of these peptides in the plasma of rats, furthermore the intervention evoked mechanical and thermal hyperalgesia [38].

Nevertheless the activation of TS could be formed by different CFA treatments, which results pain associated pathological states, including migraine, neuralgias and TMJ disorders [25]. In our previous study, we investigated the effect of CFA on the expression of mitogen-activated protein kinases (MAPK), which play essential roles in pain processing. Administration of CFA in the TMJ caused significant extracellular signal-regulated kinase $1 / 2($ ERK1/2) and p38 MAPK increase in the TRG [42]. Dural administration of CFA resulted elevated ERK1/2, interleukin-1 $\beta$ and CGRP expression in the TRG [11], as well as increased c-fos and glutamate immunoreactivity in the TNC and cervical neurons [43]. Moreover, gene expression alterations (CGRP, Iba1, GFAP, etc.) were detected following orofacial CFA treatment in the TRG and TNC [12], which suggest that the CFA induced neuroinflammation can evoke increased CGRP and PACAP1-38 levels.

\section{Role of neuropeptides in clinical studies}

In migraineurs, the level of CGRP in the peripheral blood increases during a migraine attack as compared to the attack free $[8,39,44,45]$. A very similar observation has recently been made for PACAP1-38 as well, suggesting a potential biomarker function of PACAP1-38 in the disease [8]. In addition, similarly to CGRP [35], intravenous administration of PACAP1-38 induced headache and vasodilatation, both in healthy subjects and patients suffering from migraine, whereas it delayed migraine-like attacks only in migraineurs $[46,47]$. Magnetic resonance imaging angiography examinations proved that PACAP1-38 induced headache is associated with prolonged vasodilatation of the middle meningeal artery (MMA), but not the middle cerebral artery (MCA). Sumatriptan was able to alleviate the headache, which mirrored the contraction of the MMA, but not the MCA, suggesting that PACAP1-38-induced headaches may arise from the extracerebral arteries [48]. Correlation was showed between the interictal plasma PACAP1-38 immunoreactivity and the microstructural integrity of the white matter in migraineurs [5]. These data support the idea that neuropeptides could be a good candidate for the new therapeutic approaches.

Nowadays the therapies based on monoclonal antibodies of CGRP seem to be promising in the prevention of migraine [49]. Recently, a phase 3 clinical trial showed that 12 months of treatment with galcanezumab, which is a fully humanized CGRP monoclonal antibody, was safe and associated with a reduction in the number of monthly migraine headache days [50]. Besides galcanezumab, erenumab, eptinezumab and fremanezumab were able to reduce the frequency of attacks in patients with episodic migraine [51].

Considering the similar behaviours of CGRP and PACAP1-38, the therapies aimed at PACAP1-38 may also be useful for those who have an inadequate response to therapeutics directed at CGRP or its receptors. A phase 2a, randomized, double blind, placebo-controlled study is underway to appraise the efficacy and safety of a PAC1 receptor antibody (AMG 301) in subjects with chronic or episodic migraine (Study to Evaluate the Efficacy and Safety of AMG 301 in Migraine Prevention. https://clinicaltrials.gov/ct2/show/NCT03238781. Accessed 02 May 2018). Preclinical studies are also evaluating a monoclonal antibody (ALD1910) targeting PACAP1-38 (ALD1910 migraine prevention. alderbio.com. https://www.alderbio. com/pipeline/ald1910/. Accessed 19 May 2018, [10]. Monoclonal antibodies may be crucial in the therapy of migraine however it needs further examinations to certify their relevance.

\section{Conclusion}

Our results provided the first direct evidence that the expression levels of CGRP and preproPACAP simultaneously increase after CFA induced trigeminal activation in the central region of the TS. Correlations, which were found between the alterations of CGRP/preproPACAP expression and mechanical threshold prove the influence of neuropeptides in the mechanism of hyperalgesia. Data of the present study contribute to the better understanding of migraine pathogenesis and support the idea that neuropeptides may have therapeutic value in migraine treatment.

Abbreviations

BSA: Bovine serum albumin; CFA: Complete Freund's adjuvant; CGRP: Calcitonin gene-related peptide; EDTA: Ethylenediaminetetraacetic acid; ERK1/2:

Extracellular signal-regulated kinase 1/2; ES-TRG: Electrical stimulation of the 
TRG; MAPK: Mitogen-activated protein kinase; MCA: Middle cerebral artery; MMA: Middle meningeal artery; NTG: Nitroglycerin; PACAP: Pituitary adenylate cyclase-activating polypeptide; PACAP1-27: 27 amino acid form of PACAP; PACAP1-38: 38 amino acid form of PACAP; PBS: Phosphate-buffered saline; SDS: Sodium dodecyl sulfate; SP: Substance P; TBST: Tris-buffered saline containing Tween 20; TMJ: Temporomandibular joint; TNC: Trigeminal nucleus caudalis; TRG: Trigeminal ganglion; TS: Trigeminovascular system; VIP: Vasoactive intestinal polypeptide

\section{Acknowledgments}

We are grateful to Jennifer Tusz for her valuable contribution in proofreading the manuscript.

\section{Funding}

This work was supported by the project GINOP-2.3.2-15-2016-00034, the Ministry of Human Capacities, Hungary grant 20391-3/2018/FEKUSTRAT and MTA-SZTE Neuroscience Research Group.

\section{Availability of data and materials}

The datasets used and/or analysed during the current study are available from the corresponding author on reasonable request.

\section{Authors' contributions}

TK: participated in the design and implementation of experiments, statistical analysis, data interpretation and he wrote the manuscript, BT: participated in the implementation of the experiments and she wrote the manuscript ANY: participated in the implementation of experiments and she wrote the manuscript $\mathrm{LV}$ : participated in the conception and design of the experiments, the interpretation of the data and writing, all authors: critical revision of the manuscript. JT: participated in the design of the experiments and in the final approval of the version to be published.

\section{Ethics approval and consent to participate}

Not applicable.

\section{Consent for publication}

Not applicable.

\section{Competing interests}

The authors declare that they have no competing interests.

\section{Publisher's Note}

Springer Nature remains neutral with regard to jurisdictional claims in published maps and institutional affiliations.

\section{Author details}

'Department of Neurology, Faculty of Medicine, Albert Szent-Györgyi Clinical Center University of Szeged, Semmelweis u. 6, Szeged H-6725, Hungary. ${ }^{2}$ MTA-SZTE Neuroscience Research Group, University of Szeged, Semmelweis u. 6, Szeged H 6725, Hungary. ${ }^{3}$ Department of Neurology, Interdisciplinary Excellence Centre, Faculty of Medicine, Albert Szent-Györgyi Clinical Center, University of Szeged, Semmelweis u. 6, Szeged H-6725, Hungary.

\section{Received: 13 February 2019 Accepted: 16 April 2019}

\section{Published online: 29 April 2019}

\section{References}

1. Tepper SJ (2018) Anti-calcitonin gene-related peptide (CGRP) therapies: update on a previous review after the American headache society 60th scientific meeting, San Francisco, June 2018. Headache 58(Suppl 3):276-290

2. Markovics A, Kormos V, Gaszner B, Lashgarara A, Szoke E, Sandor K et al (2012) Pituitary adenylate cyclase-activating polypeptide plays a key role in nitroglycerol-induced trigeminovascular activation in mice. Neurobiol Dis 45(1):633-644

3. Tuka B, Helyes Z, Markovics A, Bagoly T, Nemeth J, Mark L et al (2012) Peripheral and central alterations of pituitary adenylate cyclase activating polypeptide-like immunoreactivity in the rat in response to activation of the trigeminovascular system. Peptides 33(2):307-316

4. Syed AU, Koide M, Braas KM, May V, Wellman GC (2012) Pituitary adenylate cyclase-activating polypeptide (PACAP) potently dilates middle meningeal arteries: implications for migraine. J Mol Neurosci 48(3):574-583
5. Vereb D, Szabo N, Tuka B, Tajti J, Kiraly A, Farago P et al (2018) Correlation of neurochemical and imaging markers in migraine: PACAP38 and DTI measures. Neurology 91(12):e1166-e1e74

6. Han X, Ran Y, Su M, Liu Y, Tang W, Dong Z et al (2017) Chronic changes in pituitary adenylate cyclase-activating polypeptide and related receptors in response to repeated chemical dural stimulation in rats. Mol Pain 13: 1744806917720361

7. Hansen JM, Fahrenkrug J, Petersen J, Wienecke T, Olsen KS, Ashina M (2013) Vasoactive intestinal peptide (VIP) and pituitary adenylate cyclase-activating polypeptide (PACAP) in the circulation after sumatriptan. Scand J Pain 4(4): 211-216

8. Tuka B, Helyes Z, Markovics A, Bagoly T, Szolcsanyi J, Szabo N et al (2013) Alterations in PACAP-38-like immunoreactivity in the plasma during ictal and interictal periods of migraine patients. Cephalalgia 33(13):1085-1095

9. Hou L, Wan D, Dong Z, Tang W, Han X, Li L et al (2016) Pituitary adenylate cyclase-activating polypeptide expression in peripheral blood mononuclear cells of migraineurs. Cell Biosci 6:40

10. Rubio-Beltran E, Correnti E, Deen M, Kamm K, Kelderman T, Papetti L et al (2018) PACAP38 and PAC1 receptor blockade: a new target for headache? J Headache Pain 19(1):64

11. Lukacs M, Haanes KA, Majlath Z, Tajti J, Vecsei L, Warfvinge K et al (2015) Dural administration of inflammatory soup or complete Freund's adjuvant induces activation and inflammatory response in the rat trigeminal ganglion. J Headache Pain 16:564

12. Aczel T, Kun J, Szoke E, Rauch T, Junttila S, Gyenesei A et al (2018) Transcriptional alterations in the trigeminal ganglia, Nucleus and Peripheral Blood Mononuclear Cells in a Rat Orofacial Pain Model. Front Mol Neurosci 11:219

13. Morgan JR, Gebhart GF (2008) Characterization of a model of chronic orofacial hyperalgesia in the rat: contribution of $N A(V)$ 1.8. J Pain 9(6): 522-531

14. Okumura M, Iwata K, Yasuda K, Inoue K, Shinoda M, Honda K et al (2010) Alternation of gene expression in trigeminal ganglion neurons following complete Freund's adjuvant or capsaicin injection into the rat face. J Mol Neurosci 42(2):200-209

15. Ren K, Dubner R (1999) Inflammatory models of pain and hyperalgesia. ILAR 40(3):111-118

16. Krzyzanowska A, Avendano C (2012) Behavioral testing in rodent models of orofacial neuropathic and inflammatory pain. Brain Behav 2(5):678-697

17. Malick A, Burstein R (2000) Peripheral and central sensitization during migraine. Funct Neurol 15(Suppl 3):28-35

18. Kolhekar R, Murphy S, Gebhart GF (1997) Thalamic NMDA receptors modulate inflammation-produced hyperalgesia in the rat. Pain 71(1):31-40

19. Ab Aziz CB, Ahmad AH (2006) The role of the thalamus in modulating pain. Malays J Med Sci 13(2):11-18

20. Buzzi MG, Moskowitz MA (1992) The trigemino-vascular system and migraine. Pathologie-biologie 40(4):313-317

21. Noseda R, Burstein R. Migraine pathophysiology: anatomy of the trigeminovascular pathway and associated neurological symptoms, CSD, sensitization and modulation of pain. Pain. 2013;154(Suppl 1). PMID: 24347803.

22. Pietrobon D, Moskowitz MA (2013) Pathophysiology of migraine. Annu Rev Physiol 75:365-391

23. Krzyzanowska A, Pittolo S, Cabrerizo M, Sanchez-Lopez J, Krishnasamy S, Venero C et al (2011) Assessing nociceptive sensitivity in mouse models of inflammatory and neuropathic trigeminal pain. J Neurosci Methods 201(1):46-54

24. Romero-Reyes M, Akerman S, Nguyen E, Vijjeswarapu A, Hom B, Dong HW et al (2013) Spontaneous behavioral responses in the orofacial region: a model of trigeminal pain in mouse. Headache 53(1):137-151

25. Romero-Reyes M, Uyanik JM (2014) Orofacial pain management: current perspectives. J Pain Res 7:99-115

26. Tajti J, Szok D, Majlath Z, Tuka B, Csati A, Vecsei L (2015) Migraine and neuropeptides. Neuropeptides 52:19-30

27. Romero-Reyes M, Pardi V Akerman S (2015) A potent and selective calcitonin gene-related peptide (CGRP) receptor antagonist, MK-8825, inhibits responses to nociceptive trigeminal activation: role of CGRP in orofacial pain. Exp Neurol 271:95-103

28. Zhang Q, Han X, Wu H, Zhang M, Hu G, Dong Z et al (2019) Dynamic changes in CGRP, PACAP, and PACAP receptors in the trigeminovascular system of a novel repetitive electrical stimulation rat model: relevant to migraine. Mol Pain 15: 1744806918820452 
29. Villa G, Ceruti S, Zanardelli M, Magni G, Jasmin L, Ohara PT et al (2010) Temporomandibular joint inflammation activates glial and immune cells in both the trigeminal ganglia and in the spinal trigeminal nucleus. Mol Pain 6:89

30. Biggs JE, Lu VB, Stebbing MJ, Balasubramanyan S, Smith PA (2010) Is BDNF sufficient for information transfer between microglia and dorsal horn neurons during the onset of central sensitization? Mol Pain 6:44

31. Liu C, Zhang Y, Liu Q, Jiang L, Li M, Wang S et al (2018) P2X4-receptor participates in EAAT3 regulation via BDNF-TrkB signaling in a model of trigeminal allodynia. Mol Pain 14:1744806918795930

32. Anand P, Shenoy R, Palmer JE, Baines AJ, Lai RY, Robertson J et al (2011) Clinical trial of the p38 MAP kinase inhibitor dilmapimod in neuropathic pain following nerve injury. Eur J Pain 15(10):1040-1048

33. Long T, He W, Pan Q, Zhang S, Zhang Y, Liu C et al (2018) Microglia P2X4 receptor contributes to central sensitization following recurrent nitroglycerin stimulation. J Neuroinflammation 15(1):245

34. Liverman CS, Brown JW, Sandhir R, Klein RM, McCarson K, Berman NE (2009) Oestrogen increases nociception through ERK activation in the trigeminal ganglion: evidence for a peripheral mechanism of allodynia. Cephalalgia 29(5):520-531

35. Lassen $L H$, Haderslev PA, Jacobsen VB, Iversen HK, Sperling B, Olesen J (2002) CGRP may play a causative role in migraine. Cephalalgia 22(1):54-61

36. Ramon C, Cernuda-Morollon E, Pascual J (2017) Calcitonin gene-related peptide in peripheral blood as a biomarker for migraine. Curr Opin Neurol 30(3):281-286

37. Messlinger K, Fischer MJ, Lennerz JK (2011) Neuropeptide effects in the trigeminal system: pathophysiology and clinical relevance in migraine. Keio J Med 60(3):82-89

38. Mahmoudi J, Mohaddes G, Erfani M, Sadigh-Eteghad S, Karimi P, Rajabi M et al (2018) Cerebrolysin attenuates hyperalgesia, photophobia, and neuroinflammation in a nitroglycerin-induced migraine model in rats. Brain Res Bull 140:197-204

39. Goadsby PJ, Edvinsson L, Ekman R (1988) Release of vasoactive peptides in the extracerebral circulation of humans and the cat during activation of the trigeminovascular system. Ann Neurol 23(2):193-196

40. Jansen-Olesen I, Baun M, Amrutkar DV, Ramachandran R, Christophersen DV, Olesen J (2014) PACAP-38 but not VIP induces release of CGRP from trigeminal nucleus caudalis via a receptor distinct from the PAC1 receptor. Neuropeptides 48(2):53-64

41. Eftekhari S, Salvatore CA, Johansson S, Chen TB, Zeng Z, Edvinsson L (2015) Localization of CGRP, CGRP receptor, PACAP and glutamate in trigeminal ganglion. Relation to the blood-brain barrier. Brain Res 1600:93-109

42. Csati A, Edvinsson L, Vecsei L, Toldi J, Fulop F, Tajti J et al (2015) Kynurenic acid modulates experimentally induced inflammation in the trigeminal ganglion. J Headache Pain 16:99

43. Lukacs M, Warfvinge K, Tajti J, Fulop F, Toldi J, Vecsei L et al (2017) Topical dura mater application of CFA induces enhanced expression of c-fos and glutamate in rat trigeminal nucleus caudalis: attenuated by KYNA derivate (SZR72). J Headache Pain 18(1):39

44. Cernuda-Morollon E, Larrosa D, Ramon C, Vega J, Martinez-Camblor P, Pascual J (2013) Interictal increase of CGRP levels in peripheral blood as a biomarker for chronic migraine. Neurology 81(14):1191-1196

45. Goadsby PJ, Edvinsson L (1993) The trigeminovascular system and migraine: studies characterizing cerebrovascular and neuropeptide changes seen in humans and cats. Ann Neurol 33(1):48-56

46. Schytz HW, Birk S, Wienecke T, Kruuse C, Olesen J, Ashina M (2009) PACAP38 induces migraine-like attacks in patients with migraine without aura. Brain 132(Pt 1):16-25

47. Guo S, Vollesen AL, Hansen RD, Esserlind AL, Amin FM, Christensen AF et al (2017) Part I: pituitary adenylate cyclase-activating polypeptide-38 induced migraine-like attacks in patients with and without familial aggregation of migraine. Cephalalgia 37(2):125-135

48. Amin FM, Asghar MS, Guo S, Hougaard A, Hansen AE, Schytz HW et al (2012) Headache and prolonged dilatation of the middle meningeal artery by PACAP38 in healthy volunteers. Cephalalgia 32(2):140-149

49. Levin M, Silberstein SD, Gilbert R, Lucas S, Munsie L, Garrelts A et al (2018 Basic considerations for the use of monoclonal antibodies in migraine. Headache 58(10):1689-1696

50. Camporeale A, Kudrow D, Sides R, Wang S, Van Dycke A, Selzler KJ et al (2018) A phase 3, long-term, open-label safety study of Galcanezumab in patients with migraine. BMC Neurol 18(1):188

51. Edvinsson L (2018) Headache advances in 2017: a new horizon in migraine therapy. Lancet Neurol 17(1):5-6

Ready to submit your research? Choose BMC and benefit from:

- fast, convenient online submission

- thorough peer review by experienced researchers in your field

- rapid publication on acceptance

- support for research data, including large and complex data types

- gold Open Access which fosters wider collaboration and increased citations

- maximum visibility for your research: over $100 \mathrm{M}$ website views per year

At BMC, research is always in progress.

Learn more biomedcentral.com/submissions 